\title{
N-Methyl-D-Aspartate Receptor Antibodies in Neuroinflammatory Diseases
}

\author{
PhD Thesis \\ by DI (FH) Melanie Ramberger
}

2015

For the obtainment of the Doctor of Philosophy degree

supervised by

Ao. Univ.-Prof. Mag. Dr. rer. nat. Markus Reindl

Clinical Department of Neurology

Medical University of Innsbruck 


\section{DECLARATION IN LIEU OF OATH}

I declare in lieu of an oath that I have written this $\mathrm{PhD}$ thesis myself and that I have not used any sources or resources other than stated for its preparation. I further declare that I have certainly indicated all direct and indirect quotations.

Figures, tables and parts of the content of this $\mathrm{PhD}$ thesis are in press at the open access publisher PLOS ONE ("Comparison of Diagnostic Accuracy of Microscopy and Flow Cytometry in Evaluating N-methyl-D-aspartate Receptor Antibodies in Serum Using a Live Cell-Based Assay", copyright holders are the authors). Other parts are in preparation for publication.

My contributions and contribution of others: I established NMDAR antibody testing in our lab and generated all data emerging from this method. Testing of MOG and AQP4 antibodies was done by my co-workers Kathrin Schanda and Simone Mader. Clinical data were provided by clinicians responsible for the patients. Selection of patients and analysis of data was done by me, responsible clinicians and my supervisor, Markus Reindl.

Date

Signature 


\section{ACKNOWLEDGMENTS}

Experimental work for this thesis was conducted in the Clinical Department of Neurology at Medical University of Innsbruck. First of all I thank Univ.-Prof. Dr. Werner Poewe who heads the department and provides all the facilities.

This work would not have been possible without my supervisor, Ao. Univ.-Prof. Dr. rer. nat. Markus Reindl, Head of the Neurological Research Laboratory, who gave me the opportunity to work on my PhD thesis in his lab. Through his supervision I gained a profound knowledge in our research field and our discussions often opened up new perspectives. He continuously supported me with new ideas and advice during good and bad times.

I learned most of the techniques in our lab from Kathrin Schanda, who always contributed to my projects through her wide knowledge. Important data also came from the project of the first student under my supervision, Patrick Peschl. I enjoyed working with them as well as with all the other members of the Neurological Research and Routine Laboratories. Without them my PhD would have been lonesome and I would not have received so many blood donations, which were crucial for my experiments.

Above all I thank the SPIN graduate program and its members, particularly my thesis steering committee, Univ.-Prof. Dr. Francesco Ferraguti and Ass.-Prof. Dr. Nicolas Singewald, for all the fruitful discussions during my PhD.

No project is done without the collaboration of many people. Priv.-Doz. Dr. Kevin Rostásy (Datteln), Ao. Univ.-Prof. Dr. Florian Deisenhammer (Innsbruck), Dr. Regina Irschick (Innsbruck), Prof. Josep Dalmau (Barcelona) and Ao. Univ.-Prof. Dr. Romana Höftberger (Vienna) contributed substantial material for my work.

I want to thank all the patients that agreed to participate in research studies and thereby contributed to a better understanding of their diseases.

Last but definitely not least I want to thank my parents, Maria and Fritz, for their constant and understanding support during all of my studying time. 


\section{ABSTRACT}

$\mathrm{N}$-methyl-D-aspartate receptor (NMDAR) encephalitis is a neurological autoimmune disease, diagnosed by a specific autoantibody against NMDAR. Among various antibody testing methods, cell-based assays (CBA) or immunohistochemistry on rat brain tissue have highest specificity and sensitivity. Nevertheless, results from antibody testing are controversially discussed. Here we compare an immunofluorescence live CBA to a flow cytometry (FACS) based assay to detect NMDAR antibodies by their binding to the surface of HEK293A cells functionally expressing NMDAR. Since a possible association of NMDAR antibodies with demyelinating diseases has been speculated, we further determined the frequency of NMDAR antibodies in cohorts of patients with various demyelinating diseases.

Both assays were first established using a discovery group of 76 individuals and then validated in a group of 32 patients in a blinded manner. In the CBA, 23 of 23 patients with NMDAR encephalitis were positive for NMDAR antibodies and 0 of 85 controls (32 healthy controls and 53 patients with other neurological diseases), resulting in a sensitivity and specificity of $100 \%$ (95\% confidence intervals (CI) $85.1-100.0$ and $95.7-100.0$ respectively). The FACS based assay detected NMDAR antibodies in 20 of 23 patients and in 0 of 85 controls. Therefore, with an equally high specificity (95\% Cl 95.7-100.0) the FACS based assay had a sensitivity of only $87 \%$ (95\% Cl 66.4-97.2), and showed a high inter-assay variation. Comparing antibody titers from CBA with delta median fluorescence intensities from FACS showed a high concordance (kappa=0.943, $p<0.0001)$ and correlation $(r=0.697$, $\mathrm{p}<0.0001)$. By using the more reliable $\mathrm{CBA}$, we encountered one patient with NMDAR encephalitis $(1 / 25 ; 4 \%)$ who experienced a relapse with concomitant clinical signs of demyelination and persisting NMDAR antibodies three years after the first manifestation of the disease. Furthermore, NMDAR antibodies were found retrospectively in one patient with multiple sclerosis $(1 / 97 ; 1 \%)$ with symptoms resembling NMDAR encephalitis.

In conclusion, the CBA yielded more reliable results for antibody detection compared to the FACS based assay. NMDAR antibodies can be associated with demyelination, albeit this is a very rare condition. By which mechanisms those antibodies contribute to demyelination needs further investigation. 


\section{ZUSAMMENFASSUNG}

Die neurologische Autoimmunerkrankung N-Methyl-D-Aspartat Rezeptor (NMDAR) Enzephalitis wird durch den Nachweis spezifischer NMDAR-Autoantikörper diagnostiziert. Zell-basierte Testmethoden oder immunhistochemische Färbungen von Rattenhirngewebe sind zuverlässige Testmethoden, allerdings sind diese Antikörpertests kontroversiell diskutiert. In dieser Studie wurde ein Immunfluoreszenz-Test basierend auf lebenden HEK293A-Zellen, die funktionelle NMDAR exprimieren (CBA), mit einer Durchflusszytometrie (FACS)-basierten Testmethode verglichen. Aufgrund einer möglichen Assoziation von NMDAR Antikörpern mit demyelinisierenden Erkrankungen wurde außerdem die Häufigkeit dieser Antikörper in einer PatientInnenkohorte mit diesen Erkrankungen untersucht.

Beide Testmethoden wurden mit einer Testgruppe, bestehend aus Serumproben von 76 ProbandInnen, etabliert, und mit 32 verblindeten ProbandInnen validiert. Mit dem CBA wurden in 23 der 23 NMDAR Enzephalitis PatientInnen spezifische Antikörper gefunden, doch in keiner der 85 Kontrollen (32 gesunde ProbandInnen und 53 PatientInnen mit anderen neurologischen Erkrankungen). Somit hatte der CBA eine Sensitivität und Spezifität von 100\% (95\% Konfidenzintervall (CI) 85.1-100.0 und 95.7-100.0). Mit dem FACS-basierten Test wurden spezifische Antikörper in 20 der 23 NMDAR Enzephalitis PatientInnen gefunden, und in keiner der 85 Kontrollen. Mit gleichbleibend hoher Spezifität (95\% Cl 95.7-100.0) hatte diese Testmethode daher eine niedrigere Sensitivität von 87\% (95\% Cl 66.4-97.2) und zeigte eine hohe Variabilität. Beide Tests hatten eine hohe Konkordanz (kappa=0.943, $p<0.0001)$ und Korrelation $(r=0.697, p<0.0001)$. Mit dem zuverlässigeren CBA wurden bei einem Patienten mit NMDAR Enzephalitis (1/25; 4\%) drei Jahre nach Erstmanifestation Hinweise auf Demyelinisierung zusammen mit Fortbestehen von NMDAR-Antikörpern gefunden. Des Weiteren wurden bei einer Patientin mit Multipler Sklerose $(1 / 97 ; 1 \%)$ und NMDAR Enzephalitis-spezifischen Symptomen retrospektiv NMDAR Antikörper gefunden.

Da die FACS-basierte Methode eine niedrigere Sensitivität, als auch eine hohe Variabilität aufweist, ist der CBA als zuverlässiger einzustufen. Zusammenfassend konnten wir zeigen, dass NMDAR Antikörper, wenngleich selten, mit demyelinisierenden Erkrankungen assoziiert sein können. Durch welche Mechanismen diese Antikörper zur Entstehung von Demyelinisierung beitragen, muss aber in weiteren Studien geklärt werden. 


\section{CONTENTS}

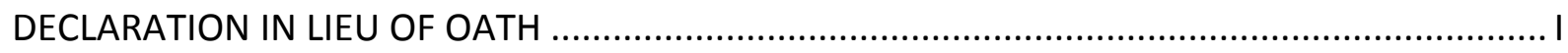

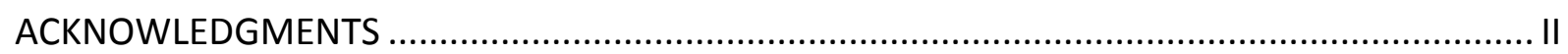

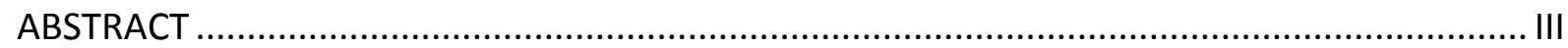

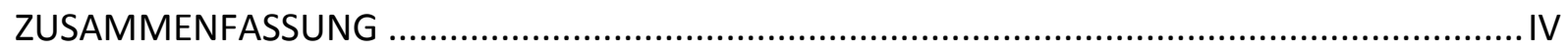

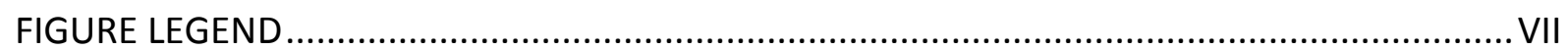

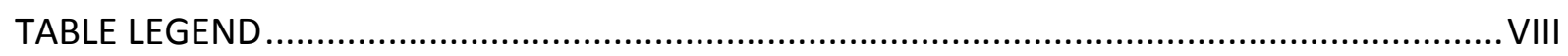

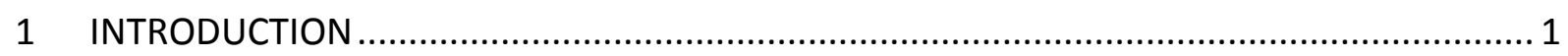

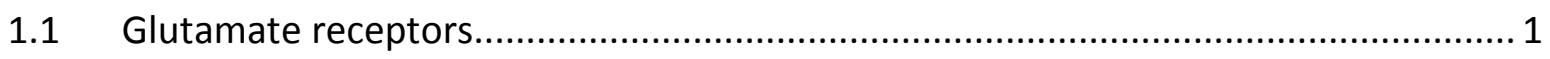

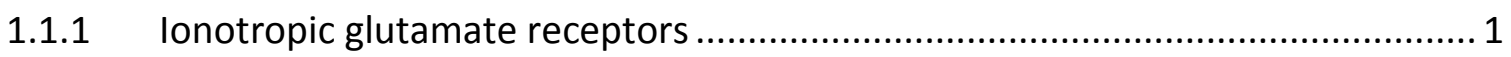

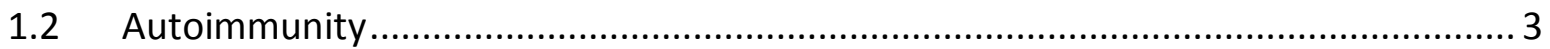

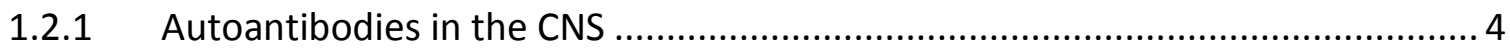

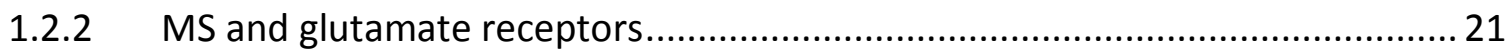

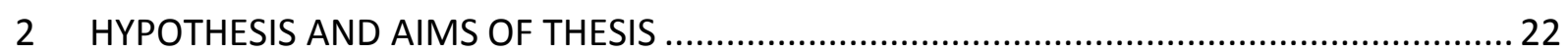

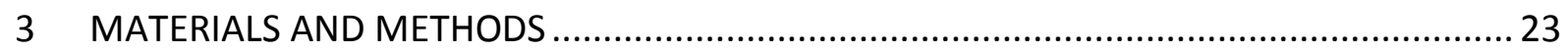

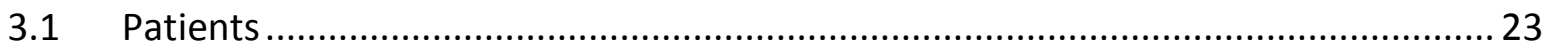

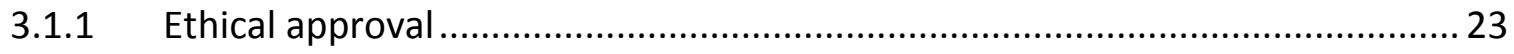

3.1.2 Patients and controls for assay validation ...................................................... 23

3.1.3 Patients screened for NMDAR antibodies.......................................................... 24

3.2 Transient expression of human NMDAR and CD2 in HEK293A cells ........................ 25

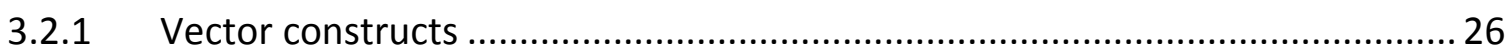

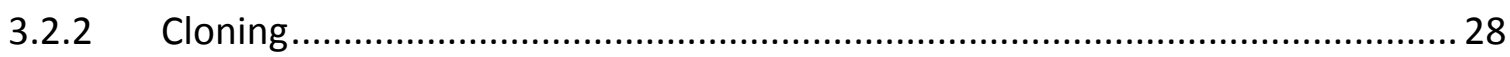

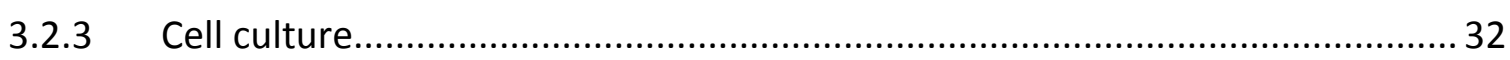

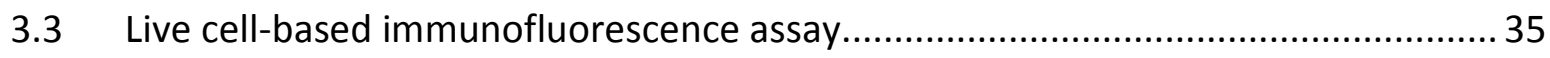

3.3.1 Absorption of patient's sera with HEK293A cells expressing NMDAR ................36

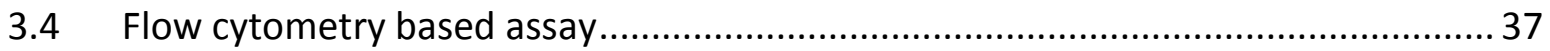

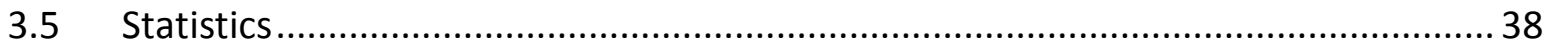

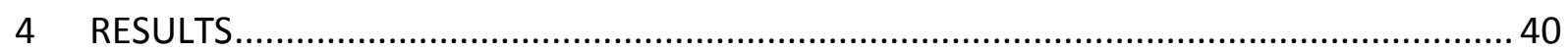

4.1 Expression of functional NMDAR in HEK293A cells............................................. 40

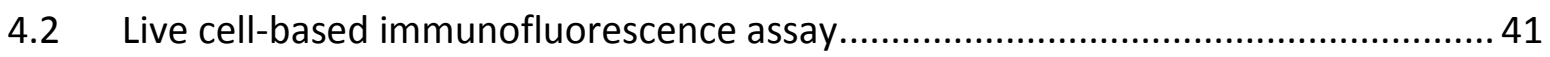

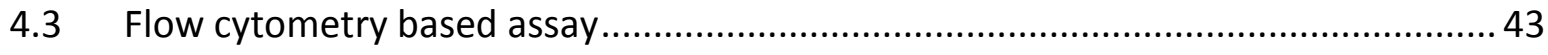

4.3.1 Assessment of strategies for analysis of data ............................................... 43

4.4 Detection of NMDAR antibodies in the discovery group ......................................... 46 
4.5 Detection of NMDAR antibodies in the validation group................................... 47

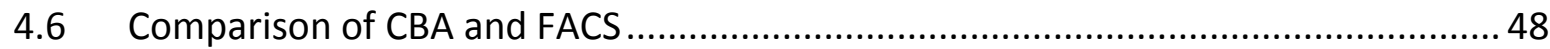

4.7 Repeat FACS analysis of a subsample using a lower serum dilution..........................52

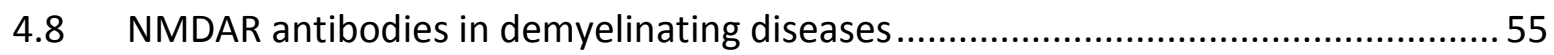

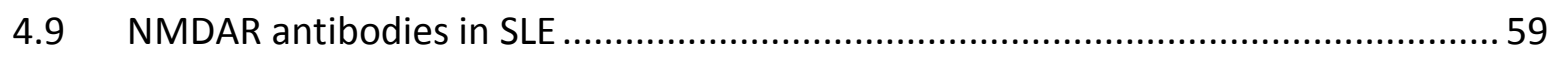

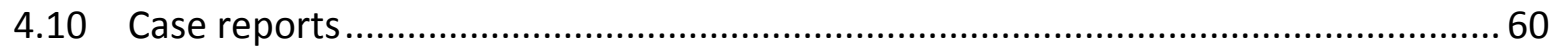

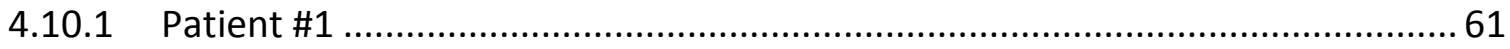

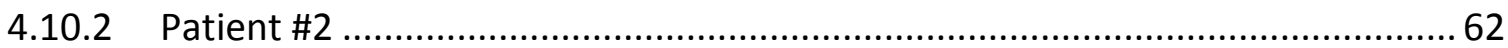

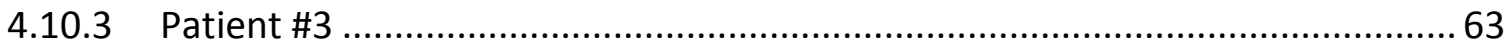

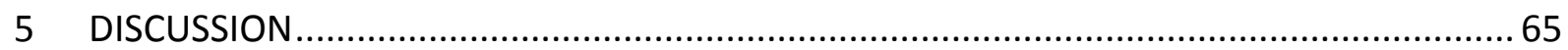

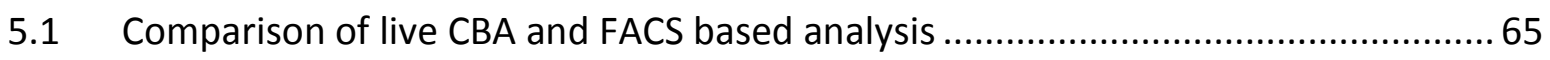

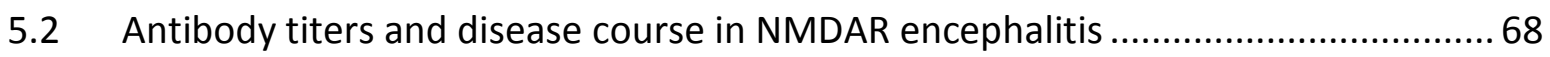

$5.3 \quad$ NMDAR autoantibodies in demyelinating diseases .............................................. 70

$5.4 \quad$ NMDAR autoantibodies in other neurological diseases........................................ 73

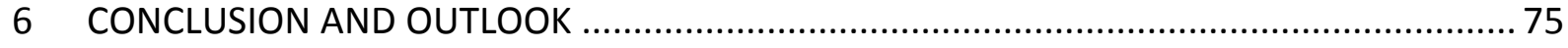

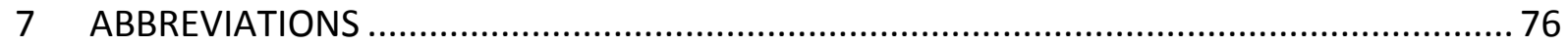

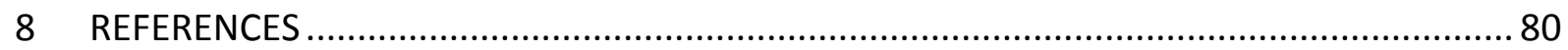

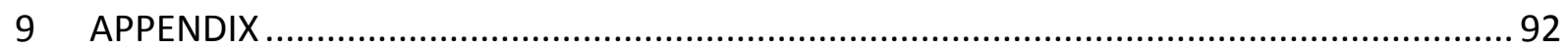

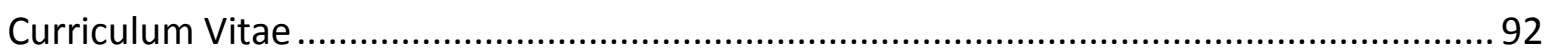




\section{FIGURE LEGEND}

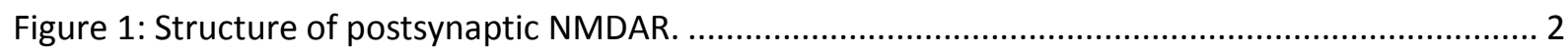

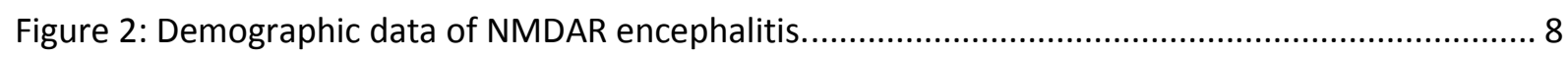

Figure 3: Immunohistochemistry and CBA for NMDAR antibody detection...................................... 10

Figure 4: Vectors used for expression of functional human NMDAR. ............................................. 27

Figure 5: Vector used for the expression of hCD2-EmGFP fusion protein.......................................... 28

Figure 6: Principle of the live cell-based immunofluorescence assay................................................. 36

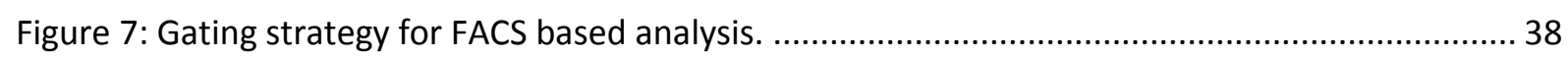

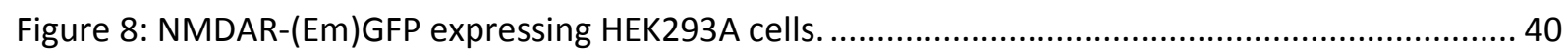

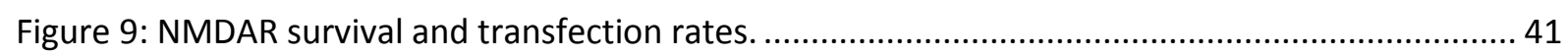

Figure 10: Immunofluorescence CBA for detection of NMDAR antibodies....................................... 42

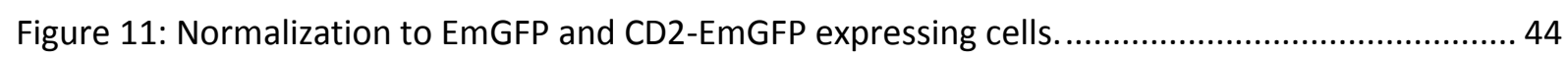

Figure 12: Further normalization strategies for the FACS assay. ...................................................... 45

Figure 13: NMDAR IgG antibody titers and $\triangle M F I$ values in the discovery group................................. 47

Figure 14: NMDAR IgG antibody titers and $\triangle M F I$ values in the validation group............................... 48

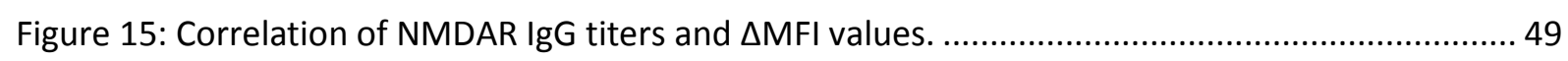

Figure 16: Comparison of $\triangle \mathrm{MFI}$ and MFI obtained by FACS analysis................................................ 50

Figure 17: Distribution of APC fluorescence according to cell size. ..................................................... 51

Figure 18: (Em)GFP and APC fluorescence in antibody positive and negative samples. ..................... 52

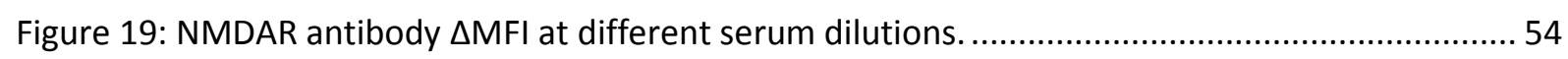

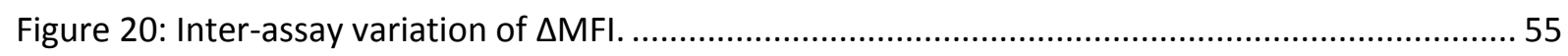

Figure 21: Serum antibody titers in demyelinating diseases, SLE, and control groups........................ 58

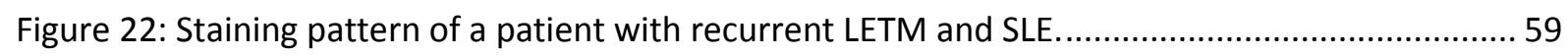

Figure 23: (Em)GFP and APC fluorescence of NMDAR-(Em)GFP and CD2-EmGFP transfected cells.... 60

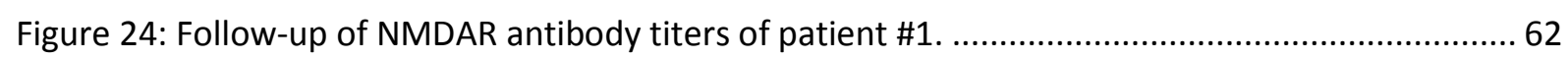

Figure 25: Follow-up of serum NMDAR, MOG and AQP4 antibody titers of patient \#2....................... 63

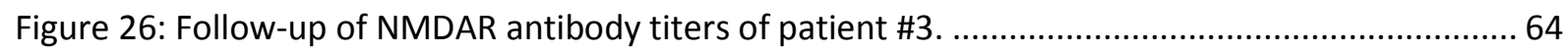




\section{TABLE LEGEND}

Table 1: Antigens associated with paraneoplastic neurological syndromes......................................... 6

Table 2: Studies reporting the presence of NMDAR antibodies in neurological diseases. ................... 14

Table 3: Cases of demyelinating diseases with the occurrence of NMDAR antibodies....................... 15

Table 4: Characteristic features of demyelinating diseases and NMDAR encephalitis........................ 20

Table 5: NMDAR subunit distribution in transfected HEK293A cells. ................................................... 41

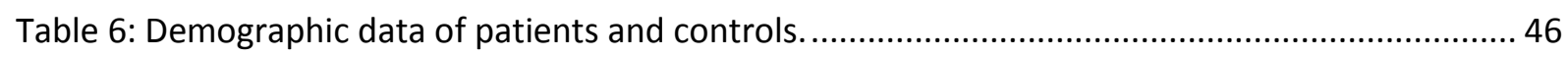

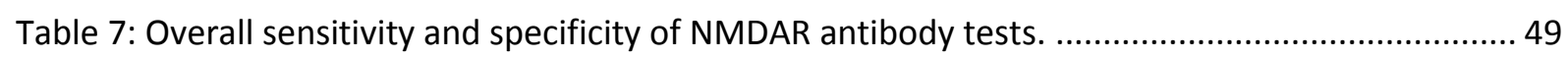

Table 8: Demographics and serum antibodies of all patients and controls........................................ 56 


\section{INTRODUCTION}

\subsection{Glutamate receptors}

The amino acid glutamate is the main excitatory neurotransmitter in the central nervous system (CNS). Its receptors are predominantly found at pre- and postsynaptic membranes, where they contribute to memory formation and learning by inducing long-term potentiation (LTP), long-term depression (LTD) and synaptic plasticity [1, 2]. Receptors that respond to glutamate are divided in two families: ionotropic and metabotropic glutamate receptors (iGluR and mGluR) that differ fundamentally in structure and effector mechanisms. While iGluR function via the opening of an ion channel pore [3], mGluR are G-proteincoupled receptors that transduce extracellular signals via intracellular second-messenger pathways [4]. In addition to their wide distribution throughout neural tissues in the brain glutamate receptors are also found in several non-neural tissues [5-7].

\subsubsection{Ionotropic glutamate receptors}

Based on pharmacology and structural homologies, the group of iGluR is divided into four types of receptors: $\alpha$-amino-3-hydroxy-5-methyl-4-isoxazolepropionic acid (AMPA), kainate, $N$-methyl-D-aspartate (NMDA) and $\delta$ receptors. As glutamate acts on all receptor types, their names derive from selective ligands, with the exception of $\delta$ receptor subunits which do not form functional receptors themselves [8]. All types are composed of four large subunits forming the central ion channel pore. Each single subunit consists of an extracellular $\mathrm{N}$ terminal domain, an extracellular ligand binding domain, the transmembrane domain with multiple membrane helices, and an intracellular C-terminal domain. Activation of iGluR leads to opening of the channel pore and subsequent influx of cations, which results in signal transduction [3]. Excess of glutamate leads to neuronal cell death via overactivation of the channel and increased influx of $\mathrm{Ca}^{2+}$ ions through iGluR. Sustained $\mathrm{Ca}^{2+}$ influx causes accumulation of $\mathrm{Ca}^{2+}$ inside mitochondria and subsequently their depolarization along with production of oxygen free radicals and release of proapoptotic factors. This process is called excitotoxicity and can affect any cell type expressing iGluR [9]. 


\subsubsection{N-methyl-D-aspartate receptor}

NMDA receptors (NMDAR) are assemblies of different subunits, GluN1, GluN2A to D, and GluN3A and $B$ (NR1, NR2A to D, and NR3A and B according to the old nomenclature, which is still widely used in literature). Functional NMDAR are heterotetramers composed of two GluN1 and two GluN2 subunits, or of GluN1 in different combinations with GluN2 and GluN3. Whereas GluN1 is ubiquitously present, distinct GluN2 and GluN3 subunits determine distribution and function of NMDAR [10]. Synaptic and extrasynaptic NMDAR are distributed throughout the brain [11], but their role in LTP and LTD in the CA1 region of the hippocampus is the best studied function $[1,2,12]$. Hippocampal NMDAR are predominantly composed of GluN1 in combination with GluN2A and/or GluN2B, with an age dependent shift from GluN2B to GluN2A [13]. Opening of the channel pore requires binding of two agonists, glutamate and glycine, as well as removal of the blocking $\mathrm{Mg}^{2+}$ ion which occurs in response to depolarization (Figure 1) [3]. Thus, activation is dependent on concomitant events at the postsynaptic membrane: binding of two ligands and voltage change of the membrane.

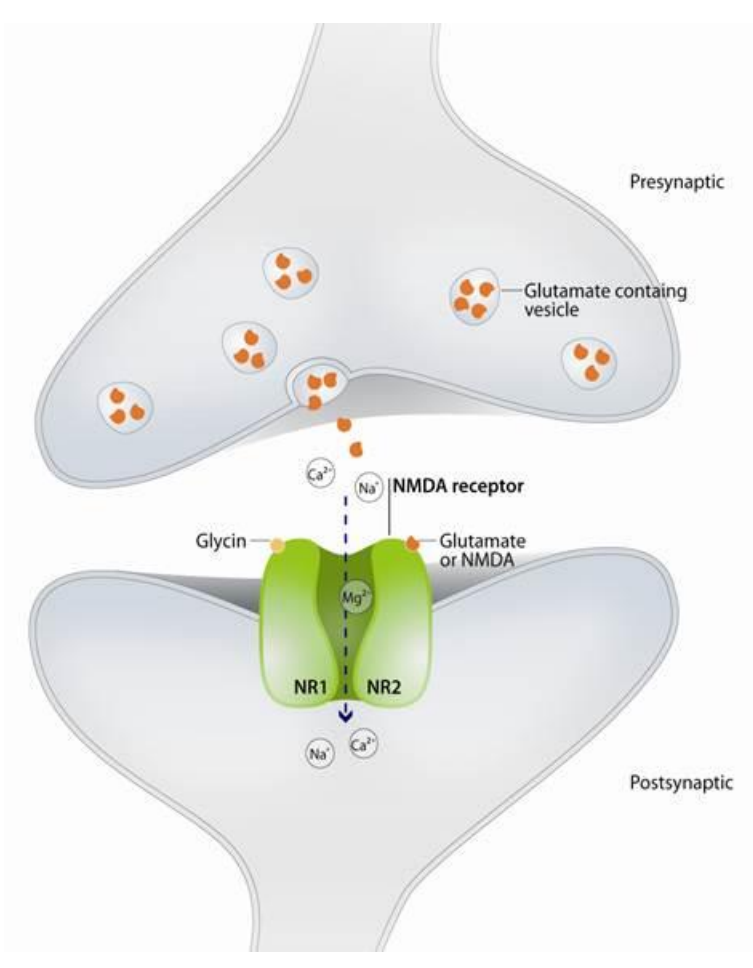

Figure 1: Structure of postsynaptic NMDAR.

Activation requires binding of glutamate (or NMDA) and glycine and removal of $\mathrm{Mg}^{2+}$ which results in opening of the channel pore and influx of $\mathrm{Ca}^{2+}$. Taken from Mader et al, InTech, 2011 [14]. $\mathrm{NMDA}=\mathrm{N}$-methyl-D-aspartate. NR=NMDA receptor subunit. 
Dizocilpine, or MK-801, is a noncompetitive NMDAR antagonist, among a plethora of NMDAR antagonists that are used in clinical and experimental applications. It binds inside the channel at the phencyclidine (PCP) binding site in a voltage-dependent manner [15]. By using MK-801 it was recently postulated that NMDAR can elicit LTD independently of $\mathrm{Ca}^{2+}$ influx, but via conformational changes, suggesting a metabotropic function of NMDAR [16] in addition to their classical ionotropic function.

Neuroimmunologists drew their attention to NMDAR after the discovery of NMDAR encephalitis. In this form of limbic encephalitis, antibodies with high reactivity against hippocampal tissue were identified, which turned out to be directed against NMDAR [17] (see 1.2.1.1).

\subsection{Autoimmunity}

The term autoimmunity describes the disability of the immune system to differentiate between foreign and self-antigens. Mislead immune attacks can originate from various compartments, including $T$ cells or $B$ cells and autoantibodies, reflecting the immune system's complexity. During development, autoreactive lymphocytes that recognize selfantigens are normally eliminated by negative selection in the central lymphoid organs, i.e. thymus and bone marrow. Defects in this central tolerance mechanism cause autoreactive clones to escape into the periphery, where they might encounter their specific self-antigen. Normally, peripheral tolerance mechanisms ensure the regulation of these autoreactive cells. However, if both tolerance mechanisms fail and tissue damage results in clinical symptoms, autoimmune diseases occur. Several mechanisms in the periphery might contribute to the development of autoimmunity: (1) invasion of a pathogen creates a local inflammatory environment which favors the generation of autoreactive T cells; (2) selfepitopes can resemble pathogenic epitopes and activate autoreactive lymphocytes, which is known as molecular mimicry; (3) genetic defects or predispositions can result in abnormal function of immune system components, including T cells, B cells, antigen-presenting cells, cytokine expression and complement system; (4) epitope spreading occurs, i.e. originally hidden epitopes become accessible for the immune system, expanding the autoimmune attack. The overall risk of developing an autoimmune disease is determined by genetic predispositions, external triggers and hormonal influences [18]. 


\subsubsection{Autoantibodies in the CNS}

When fighting against invading pathogens, B cells produce antibodies that specifically bind their antigens and execute different effector mechanisms: neutralization, complement activation, opsonization, and antibody-dependent cell-mediated cytotoxicity (ADCC). Thereby, the effector mechanism is often determined by the respective immunoglobulin (Ig) isotype. Monomeric IgG is the most abundant Ig isotype in the blood circulation, where it can, depending on the subclass (IgG1-4), activate complement, or mediate opsonization or ADCC. In contrast, IgM is secreted in a pentameric form and represents always the primary response to an antigen, since it does not undergo isotype switching. Binding affinity to antigens is relatively low, resulting in a higher probability of cross-reactivity. Prominent effector mechanisms of IgM are complement activation and neutralization. By far the highest amount of total Ig in the human body is found as IgA in external secretions, where monomers and multimers are found. Most importantly, IgA neutralizes invading pathogens before they can enter the body, or induces ADCC by binding to parasites. Monomeric IgE is involved in fighting parasites as well, and also found at high levels during allergic reactions. The exact function of monomeric IgD is lesser known, but it is thought to be important for maturation and survival of B cells [18].

In most autoimmune diseases circulating autoantibodies are present, but whether the antibodies contribute to the pathogenesis or are merely a bystander mechanism in disease progression is a matter of ongoing research and differs between various autoimmune diseases. According to the postulates defined by E. Witebsky in 1957 and modified by N. Rose in 1993 [19] three criteria must be met to prove autoimmunity caused by autoantibodies or pathogenic T cells: direct evidence from transfer of pathogenic antibody or pathogenic T cells; indirect evidence based on reproduction of the autoimmune disease in experimental animals; and circumstantial evidence from clinical clues.

Normally, structures of the CNS are not accessible for peripherally circulating antibodies or lymphocytes, attributing to the (BBB) which highly restrictively regulates the exchange of substances between the periphery and the CNS. Consequently, in order to cause damage to tissues within the CNS, antibodies need to penetrate the BBB, or intrathecal synthesis of antibodies needs to arise from penetrating B cells. Despite antibody levels in the 
cerebrospinal fluid (CSF) often correlate with disease activity, in some autoimmune diseases of the CNS antibodies are found in serum only [20].

Likewise their ability to be pathogenic, effector mechanisms of autoantibodies vary among different disease entities. While some pathologies involve destruction of target cells through activation of complement or other cell-mediated mechanisms, such as recruitment of microglia or T cells, other types of autoantibodies cause the internalization of their target structures or trigger intracellular pathways, thereby disrupting normal cell function [20].

While the exact origin of autoantibodies is unknown in most autoimmune diseases, paraneoplastic syndromes describe humoral autoimmunity that arises from an attack against an underlying tumor. The most frequent classical paraneoplastic neurological syndromes are cerebellar degeneration, sensory neuronopathy, and limbic encephalitis. Known autoantibodies target either intracellular antigens (onconeural antibodies) or surface antigens [21, 22]. Known neuronal surface antigens targeted by autoantibodies in autoimmune, often paraneoplastic, limbic encephalitis include the NMDAR [17], AMPAR [23], gamma-aminobutyric acid $(\mathrm{GABA})_{B}$ metabotropic receptor [24], voltage-gated potassium channel (VGKC), and VGKC-complex associated proteins leucine-rich glioma inactivated 1 (LGI1) and contactin associated protein 2 (CASPR2) [25]. For an overview of neuronal antigens in paraneoplastic neurological syndromes see Table 1.

Recently, antibodies to NMDAR (1.2.1.1) and VGKC $[26,27]$ have been linked to demyelinating diseases. Furthermore, autoantibodies targeting glial surface antigens in the CNS are associated with or are specific for demyelinating disease entities such as multiple sclerosis (MS), acute disseminated encephalomyelitis (ADEM) and neuromyelitis optica (NMO). These antigens include myelin oligodendrocyte glycoprotein (MOG) and aquaporin 4 (AQP4) [28]. 


\begin{tabular}{|c|c|c|}
\hline \multicolumn{3}{|c|}{ Well characterized onconeural antibodies against intracellular antigens } \\
\hline Antibody & Predominant tumors & Most common paraneoplastic neurological syndromes \\
\hline Hu (ANNA1) & $\mathrm{SCLC}$ & $\begin{array}{l}\text { Encephalomyelitis, limbic encephalitis, brainstem encephalitis, } \\
\text { paraneoplastic cerebellar degeneration, sensory neuronopathy, } \\
\text { gastrointestinal pseudoobstruction }\end{array}$ \\
\hline CV2 (CRMP5) & SCLC, thymoma & $\begin{array}{l}\text { Same as Hu, chorea, optic neuropathy, isolated myelopathy, } \\
\text { mixed neuropathies }\end{array}$ \\
\hline Amphiphysin & Breast, SCLC & $\begin{array}{l}\text { Stiff-person syndrome, myelopathy and myoclonus, } \\
\text { encephalomyelitis, sensory neuronopathy }\end{array}$ \\
\hline Ri (ANNA2) & Breast, SCLC & Brainstem encephalitis, opsoclonus myoclonus \\
\hline Yo (PCA1) & Ovary, breast & Paraneoplastic cerebellar degeneration \\
\hline Ma2 & Testicular & Limbic and brainstem encephalitis \\
\hline $\operatorname{Tr}$ & Hodgkin's & Paraneoplastic cerebellar degeneration \\
\hline Recoverin & $\mathrm{SCLC}$ & Retinopathy \\
\hline SOX-1 & & Non-syndrome-specific \\
\hline \multicolumn{3}{|c|}{ Neuronal surface antigens associated with paraneoplastic syndromes } \\
\hline Antigen & Predominant tumors & Most common paraneoplastic neurological syndromes \\
\hline NMDAR & Ovarian teratoma & (Limbic) encephalitis \\
\hline $\mathrm{GABA}_{\mathrm{B}} \mathrm{R}$ & $\mathrm{SCLC}$ & Limbic encephalitis \\
\hline VGCC & $\mathrm{SCLC}$ & Paraneoplastic cerebellar degeneration \\
\hline AMPAR & SCLC, breast, thymus & Limbic encephalitis, psychiatric syndromes \\
\hline CASPR2 & Lung, thymoma & Morvan's syndrome, encephalitis, neuromyotonia \\
\hline LGI1 & Lung, thymoma & $\begin{array}{l}\text { Limbic encephalitis, tonic or facio-brachial dystonic seizures, } \\
\text { myoclonus }\end{array}$ \\
\hline $\begin{array}{l}\text { Glycine receptor } \\
\alpha 1\end{array}$ & Rare & $\begin{array}{l}\text { Encephalomyelitis with rigidity and myoclonus, hyperekplexia, } \\
\text { stiff-person syndrome }\end{array}$ \\
\hline mGluR5 & Hodgkin's & Limbic encephalitis ( 2 cases known) \\
\hline
\end{tabular}

Table 1: Antigens associated with paraneoplastic neurological syndromes.

Alternative names are given in parentheses. Modified from [21] and [22].

AMPAR= $\alpha$-amino-3-hydroxy-5-methyl-4-isoxazolepropionic acid receptor. ANNA=anti-neuronal nuclear antibody. CASPR2=contactin associated protein 2. CRMP=collapsin response mediator protein. $\mathrm{GABA}_{\mathrm{B}} \mathrm{R}=$ gamma-aminobutyric acid receptor $\mathrm{B}$. LGI1=leucine-rich glioma-inactivated 1. mGluR5=metabotropic glutamate receptor 5 . NMDAR=N-methyl-D-aspartate receptor. $\mathrm{SCLC}=$ small-cell lung cancer. VGCC=voltagegated calcium channel. 


\subsubsection{NMDAR autoantibody-associated diseases}

Autoantibodies recognizing different epitopes of the ionotropic NMDAR were found in various neurological diseases, including paraneoplastic syndromes. Most importantly, the pathogenic role of autoantibodies in NMDAR encephalitis is well known [29], but so far their relevance in the pathogenesis of other conditions is not fully understood. Depending on the targeted epitope several antibody testing methods are used. In cell-based assays (CBA) conformational epitopes can be distinguished, whereas methods using linear peptides such as enzyme-linked immunosorbent assays (ELISA), only consider primary structures of a protein.

\section{NMDAR encephalitis}

In 2007 this new subgroup of limbic encephalitis was described as a paraneoplastic disorder, caused by antibodies against NMDAR. Initially, the association of prominent psychiatric symptoms with severe encephalitis and an underlying ovarian teratoma facilitated the discovery of this disorder $[17,30]$. Meanwhile numerous patients without tumors or tumors other than teratomas have been described. A study investigating a cohort of 577 patients with NMDAR encephalitis reported that $38 \%$ have underlying tumors, thereof $94 \%$ were teratomas [31]. A majority of patients are female and the disease often occurs in childhood or early adolescence. In adults, symptoms are initially psychiatric with insomnia and agitation, followed by dyskinesias, seizures, memory deficits, speech problems and a decreased level of consciousness often leading to autonomic instabilities [29, 31-34]. In children, the first symptom is often seizures or dyskinesias subsequently progressing to develop the other components of the syndrome [31]. An overview of demographic data resulting from this observational cohort study is shown in Figure 2. The exact frequency is unknown, but several recent studies with large series of patients [31, 34] and studies focusing on the causes of encephalitis suggest this disorder to be the second most common autoimmune encephalitis after ADEM [35], and another study found it to be more frequent than any other encephalitis of viral origin in young ( $\leq 30$ years) patients [36]. 

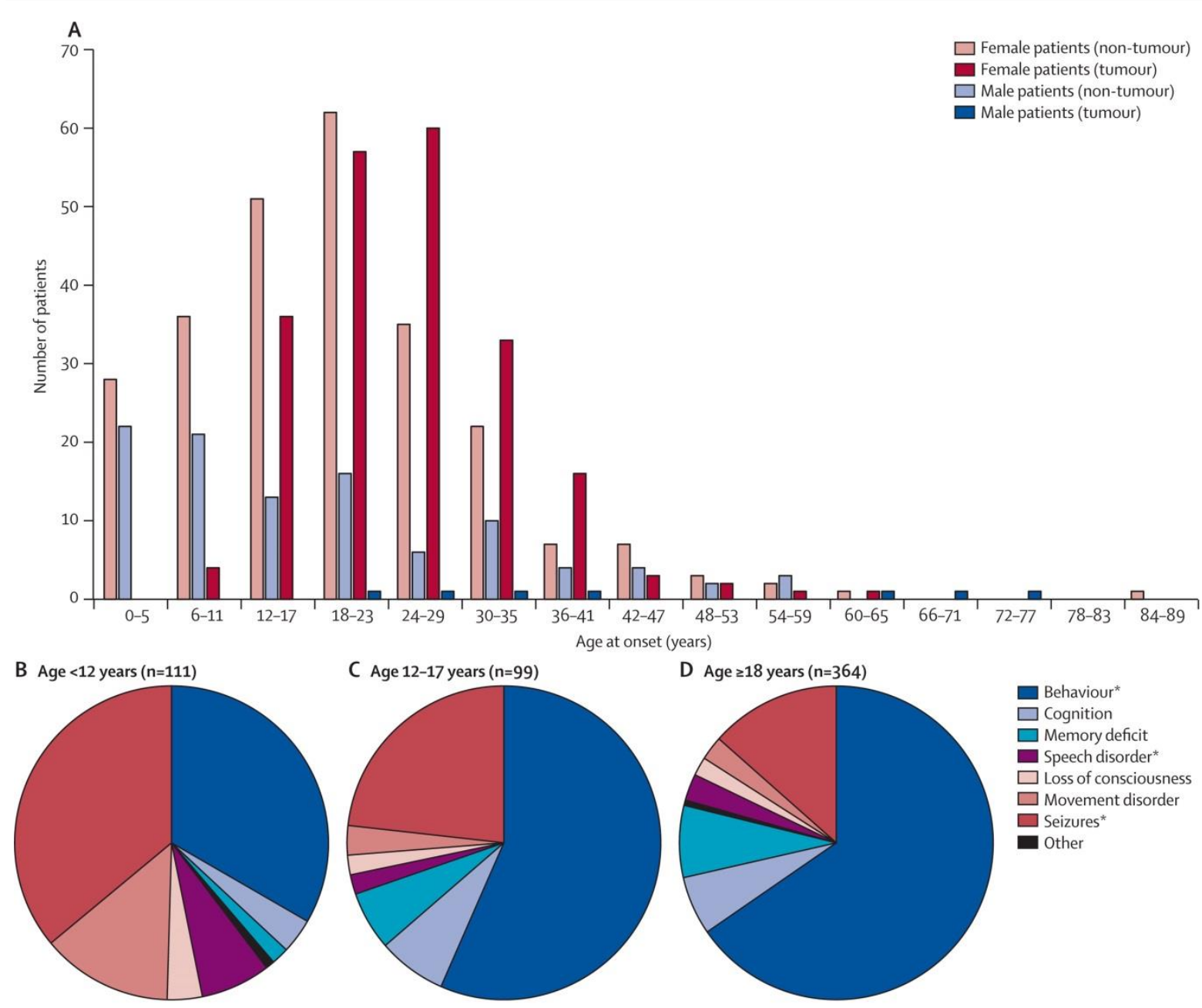

$\square$ Behaviour* $\square$ Cognition $\square$ Memory deficit - Speech disorder* $\square$ Loss of consciousness $\square$ Movement disorder $\square$ Seizures* Other

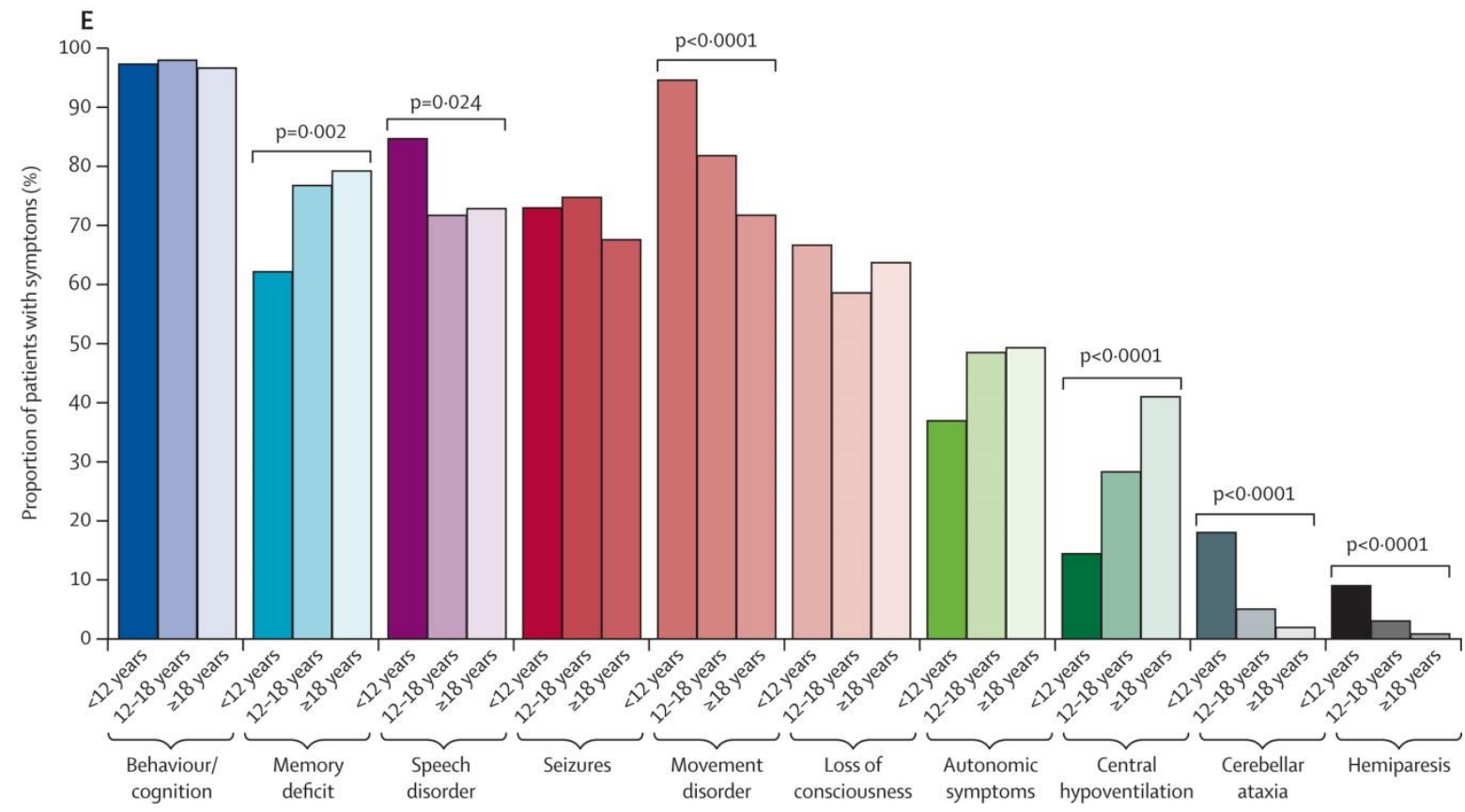

Figure 2: Demographic data of NMDAR encephalitis.

Demographic information, distribution by age of initial symptom, and cumulative symptoms during the first month of the disease. Patients' age at disease onset $(A)$ and first symptom at disease onset according to patients' age (B-D; first symptom of three patients unknown; ${ }^{*} p<0.0001$ between the three age groups). Distribution by age of cumulative symptoms during the first month of the disease (E). Taken from [31]. 
While magnetic resonance imaging (MRI) was abnormal in only $33 \%$ of the patients, $79 \%$ of patients showed abnormal CSF, and 90 \% showed abnormal electroencephalography (EEG) examinations [31]. Although most patients are known to have intrathecal synthesis of NMDAR antibodies, CSF-specific oligoclonal bands (OCB), that indicate intrathecal synthesis of IgG, were found in approximately $60 \%$ of patients [37]. In some patients EEG showed extreme delta brushes which were associated with more severe illness [38-40]. Early treatment or tumor removal when applicable is effective in most patients, limiting the frequency of relapses and lethality ( $12 \%$ and $7 \%$ risk within two years respectively). First-line immunotherapy includes administration of steroids, intravenous immunoglobulins (IVIG) or plasmapheresis which is followed by second-line therapy with rituximab or cyclophosphamide when first-line treatment fails [31]. It has been shown that NMDAR antibodies cause selective and reversible internalization of synaptic surface NMDAR, which are considered to contribute to characteristic symptoms of the disease such as memory deficits or change in behavior and cognition [41]. Indeed, the pathogenic role of NMDAR antibodies has been proven in vivo recently. Continuous ventricular infusion of patients' CSF containing NMDAR antibodies caused reversible memory deficits, and anhedonic and depressive-like behaviors in mice [42].

The gold standard for the detection of disease specific NMDAR antibodies, which is crucial for the diagnosis of NMDAR encephalitis, comprises testing the immunoreactive binding of serum and CSF samples to fixed and permeabilized NMDAR transfected cells (fixed CBA) and immunohistochemistry of frozen sections of rat brain optimized for the detection of antibodies against cell surface or synaptic proteins [29, 43] (Figure 3). Alternatively, CBA using live cells with fixation after serum (or CSF) incubation can be used to detect autoantibodies against NMDAR $[33,44]$, although the live CBA was suggested to have a lower sensitivity compared to the fixed CBA [44]. Confirmation of NMDAR subunit expression is done by either concomitant staining with recombinant antibodies against the respective NMDAR subunit [29] or by co-transfection with enhanced green fluorescent protein (EGFP) to visualize cells taking up cDNA [33]. Antibodies from NMDAR patients are of the IgG subclass and react with an N-terminal epitope on the GluN1 subunit. Binding to GluN1 depends on the conformation of the antigen using either live or fixed NMDAR expressing cells, with or without the presence of GluN2 subunits $[29,44,45]$. While most 
labs use CBA with cells expressing GluN1 in combination with GluN2B, testing methods using cells transfected with only GluN1 have been reported $[46,47]$.
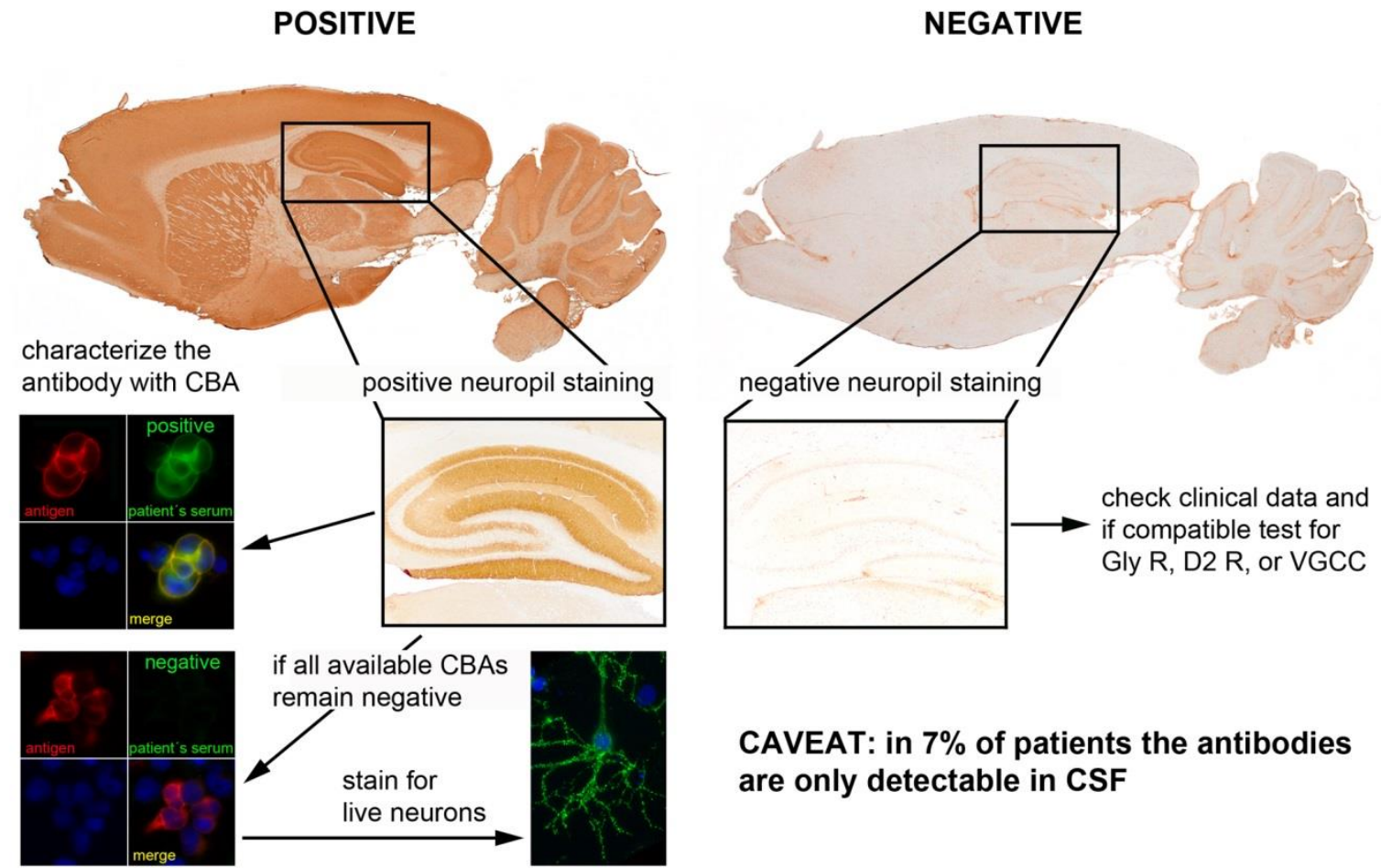

CAVEAT: in $7 \%$ of patients the antibodies are only detectable in CSF

Figure 3: Immunohistochemistry and CBA for NMDAR antibody detection.

Staining pattern of rat brain section and CBA incubated with serum positive and negative for NMDAR antibodies. Modified from [48].

$\mathrm{CBA}=$ cell-based assay. $\mathrm{CSF}=$ cerebrospinal fluid. NMDAR=N-methyl-D-aspartate receptor.

After the recognition of NMDAR antibodies, patients presenting with encephalitic and epileptic symptoms of unknown origin became more frequently diagnosed with NMDAR encephalitis, a substantial proportion of cases being pediatric [31, 32, 39, 49-54]. Although the majority of NMDAR patients do not show any signs of demyelination, two recent studies $[55,56]$ and a case study [57] describe patients that had radiological and/or clinical features of demyelination. In the largest cohort of NMDAR encephalitis patients available to date, with 691 patients in total, the authors found 23 patients that showed MRI and/or clinical features of demyelination. In approximately 50\% of these patients, NMDAR encephalitis either preceded or was followed by NMO and related disorders, or brainstem or mutifocal demyelinating syndromes. In the other $50 \%$ of these patients NMDAR encephalitis occurred simultaneously with demyelination. Most of those patients had also antibodies against MOG or AQP4 [55]. Another study defined three distinct clinicoradiologic phenotypes in a total of $22 \%$ of children positive for NMDAR antibodies: brainstem encephalitis, 
leukoencephalopathy following herpes simplex virus (HSV) encephalitis, and acquired demyelination syndromes [56].

\section{Systemic lupus erythematosus}

Systemic lupus erythematosus (SLE) is an autoimmune disease affecting various tissues, including the skin, joints, kidney, lung, heart and brain, and most patients (90\%) are female. Due to major disruptions of the immune system, patients are particularly prone to opportunistic infections, which are, beside myocardial infarction and stroke, frequent causes of death. Clinical presentations of the disease include rash, arthritis, anemia, thrombocytopenia, serositis, and nephritis, as well as neuropsychiatric manifestations such as seizures and psychosis. Pathogenic autoantibodies against double-stranded (ds)DNA are specific for SLE, found in $70 \%$ of patients, but in only $0.5 \%$ of controls. Beside antibodies against dsDNA, which are mainly associated with kidney and skin diseases, further antibodies are found in SLE patients. Non-DNA antigens that can be targeted in SLE include: nucleosomes, Ro (a ribonucleoprotein complex), La (an RNA-binding protein), C1q (a subunit of the $\mathrm{C} 1$ complement component), Sm (nuclear particles consisting of several different polypeptides), phospholipids, $\alpha$-actinin, and the NMDAR [58].

Antibodies originally targeted against dsDNA from a subgroup of patients with SLE were shown to cross-react with a well-defined motif on GluN2 subunits of NMDAR and can mediate neuronal cell death $[59,60]$. Indeed, several studies found antibodies to GluN2 in subgroups of SLE patients [61-65], frequently confirming a postulated association of the antibodies with neuropsychiatric symptoms [66-71], which was in part restricted to antibodies in CSF but not in serum $[67,69,70]$. If analyzed, an association of GluN2 antibodies with antibodies against dsDNA was only limited [61-63, 67, 68, 71]. It has to be considered that in all these studies antibody levels have been determined by measuring their binding affinity to linear epitopes with ELISA, which are known to have lower specificity compared to cell or tissue based methods, particularly in the context of measuring antibody levels of SLE patients [72]. Taken together, it is likely that NMDAR antibodies are associated with neuropsychiatric symptoms in SLE, but the heterogeneity of symptoms and multitude of further autoantibodies present in SLE patients makes a clear correlation difficult to determine. 


\section{Other diseases with suspected NMDAR antibodies}

In the meantime, antibodies against NMDAR have been related to numerous neurological disorders, including post-HSV encephalitis [26, 39, 73, 74], schizophrenia [75-78], affective disorder, Parkinson's disease [77, 78], stroke [77], dementia [79-81], narcolepsy [75], amyotrophic lateral sclerosis [77], major depression [76], borderline personality disorder [77, 82], bipolar disorder [83], and Creutzfeldt-Jakob disease [84-86]. However, some of these results must be questioned since NMDAR antibodies were partly also found in healthy controls [76-78, 80-82], suggesting low specificity of the testing methods used (for details see Table 2). In addition, NMDAR antibodies were also reported in few cases of demyelinating diseases such as optic neuritis (ON) $[26,87,88]$, NMO spectrum disorders (NMOSD) [89-91], ADEM [26, 92] or MS [91, 93-95] (see Table 3). 


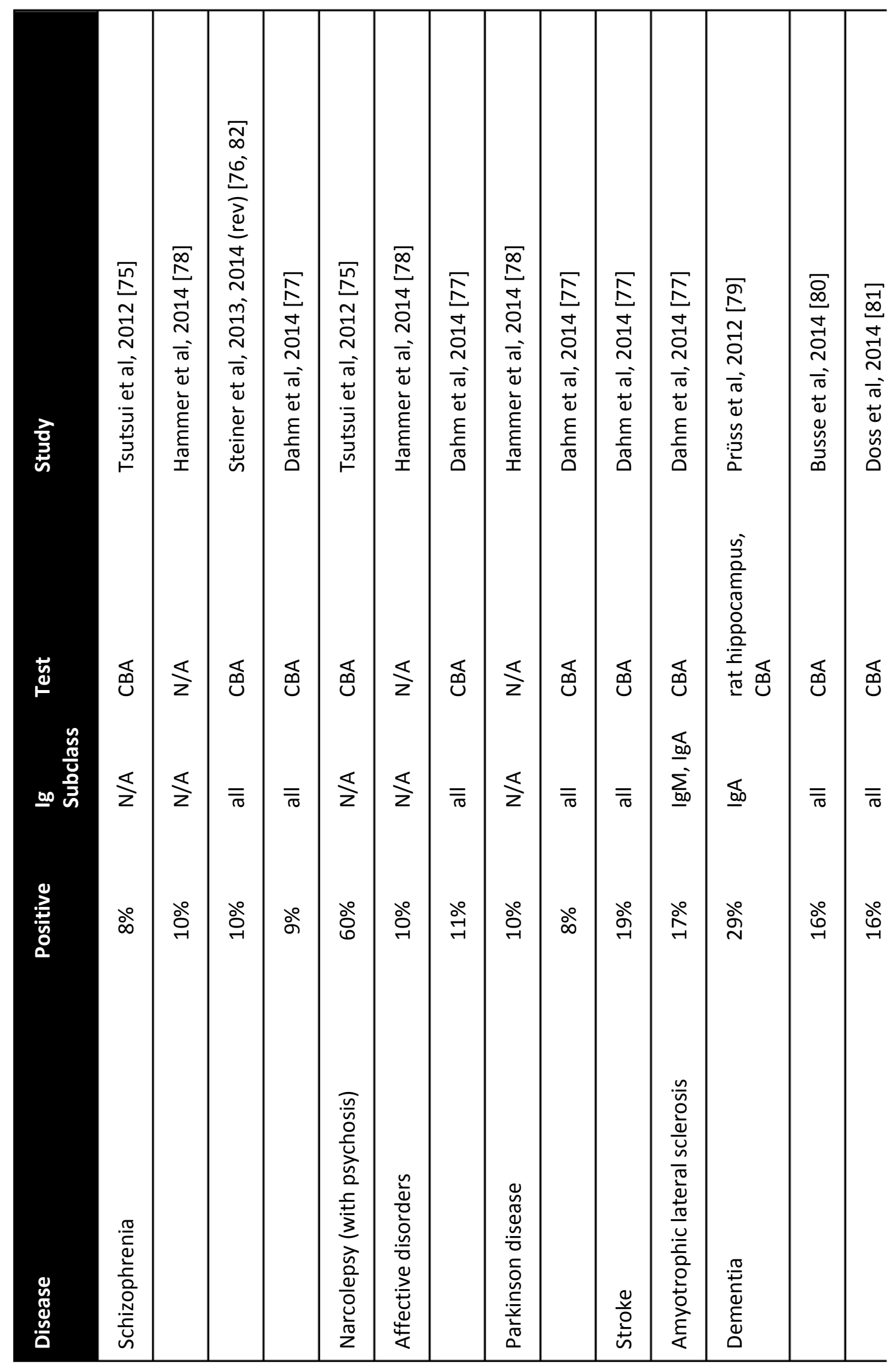

Page 13 


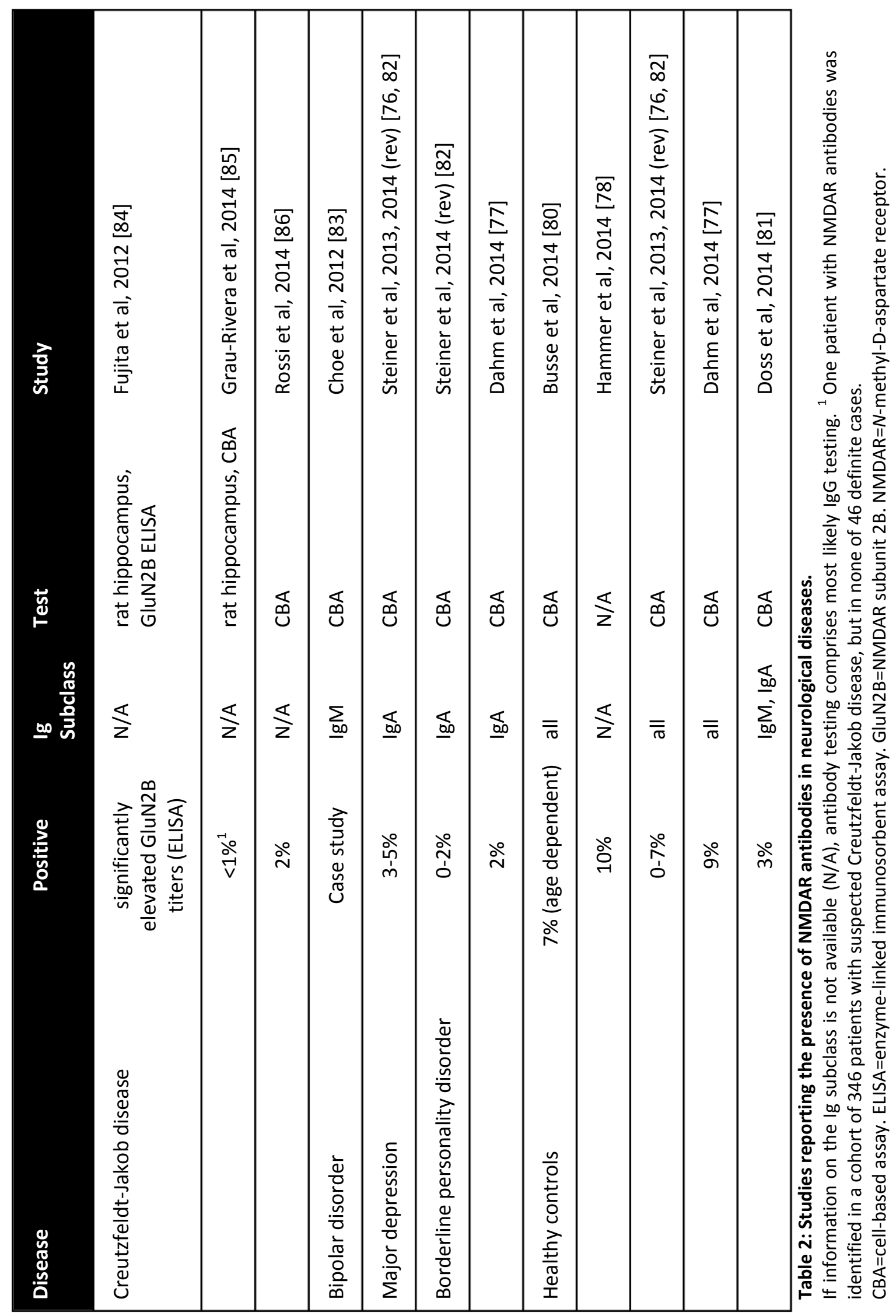

Page 14 


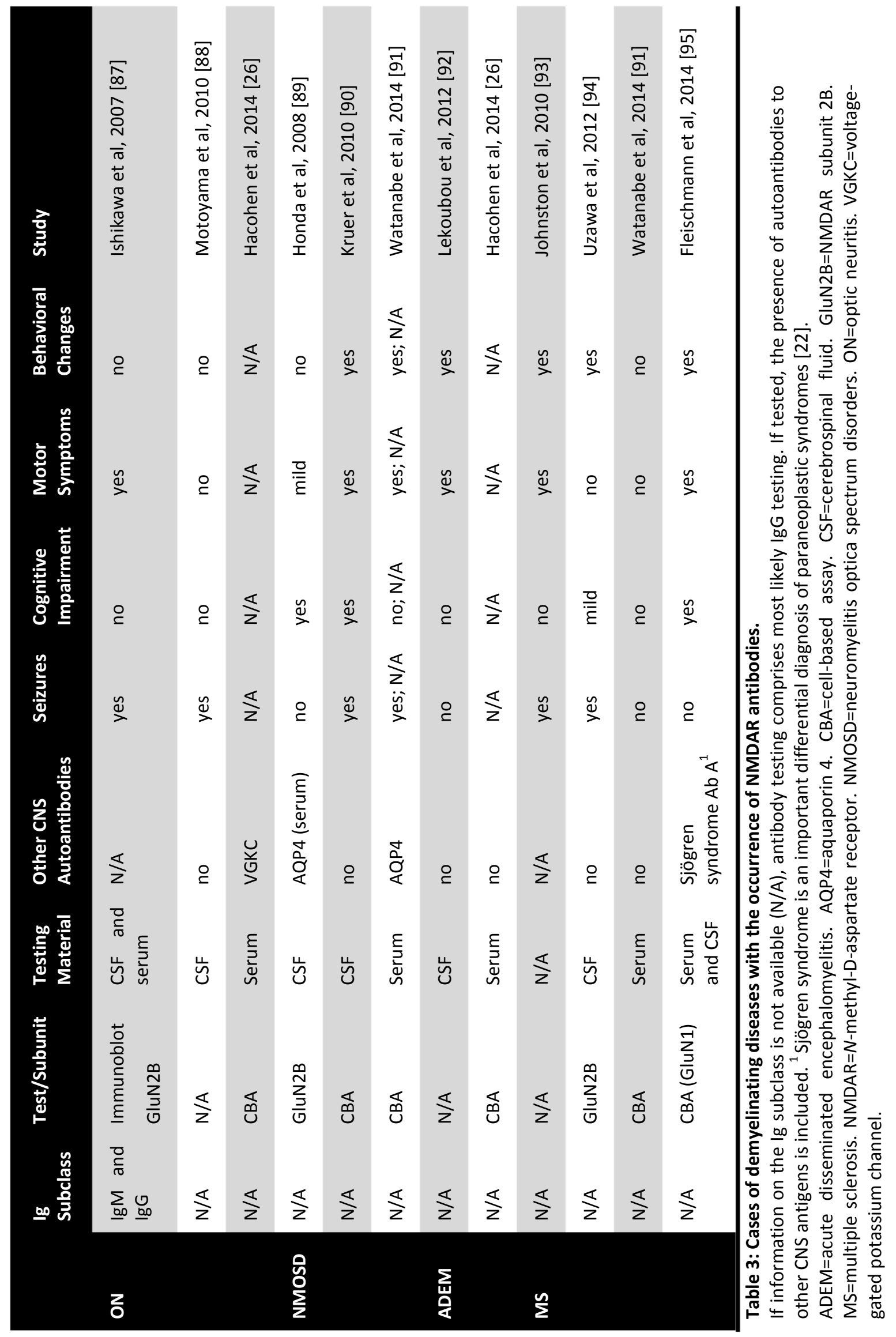




\subsubsection{AQP4 autoantibody-associated diseases and NMOSD}

With the discovery of autoantibodies against AQP4, a water channel expressed on astrocytic foot processes at the BBB, NMO (also known as Devic's disease) was no longer regarded as a variant of MS $[96,97]$. Rather, NMO is now known to be a separate disease entity, which is characterized by inflammation and demyelination of the optic nerve and spinal cord (ON and longitudinally extensive transverse myelitis, LETM, respectively). With a female:male ratio of 9:1 and a median disease onset of 39 years, NMO is considered a rare disease and occurs with a relapsing course in the majority of patients $[98,99]$. In addition, the term NMOSD describes patients that do not completely fulfill the diagnostic criteria [99], including a minority that are seronegative for the otherwise highly specific antibodies against AQP4 [100]. Among different assays to detect AQP4 antibodies, CBA showed highest sensitivity [101-103], particularly when using the AQP4-M23 isoform [100, 104], which is known to form orthogonal arrays of particles in the plasma membrane [105, 106]. AQP4 antibodies have been demonstrated to be cytotoxic in vitro, resulting in activation of the classical complement cascade and subsequent necrosis of cells [107, 108]. Furthermore, the pathogenic effect of AQP4 antibodies in vivo was shown by transfer of purified antibodies, resulting in NMO-like lesions in animals with experimental autoimmune encephalomyelitis (EAE) [109-111] or after intra-cerebral injection of the antibodies [112]. Thus, AQP4 antibodies are pathogenic, but only when the BBB is disrupted or circumvented. Detection of AQP4 antibodies in serum is usually sufficient, since most studies report CSF AQP4 antibodies only in patients with high titer serum antibodies [113-115]. Only few cases of seronegative patients were reported to have AQP4 antibodies detectable in their CSF [116, 117].

\subsubsection{MOG autoantibody-associated diseases}

MOG is found on the outer surface of the myelin sheath of oligodendrocytes [118] and is therefore likely to be an antigen involved in the pathogenesis of demyelinating syndromes. Indeed, MOG antibodies were found in some patients with demyelinating diseases such as clinically isolated syndrome (CIS), MS, and ADEM [119-124], but their role as biomarkers in those syndromes is still controversial $[125,126]$. 
Reactivity to MOG highly depends on its correct conformation [119, 122], pointing out the importance to use CBA to detect MOG antibodies. MOG antibodies extracted from seropositive patients were shown to be cytotoxic in vitro $[120,127,128]$. Furthermore, MOG antibodies play a role in the induction of EAE [129], and contribute to damage in myelinated regions in vivo [128], supporting their pathogenic role. However, the use of MOG antibodies extracted from human patients in rodent disease models can be challenging, since most MOG antibodies do not recognize rodent MOG [130]. Only in patients with high levels of serum antibodies MOG antibodies were also detectable in the CSF [121], similar to AQP4 antibodies. So far, no studies report patients with MOG antibodies in the CSF of seronegative patients.

\section{Acute Disseminated Encephalomyelitis}

ADEM is a rare monophasic demyelinating disorder presenting with meningoencephalitic symptoms, encephalopathy, CSF pleocytosis usually without OCB, but with lesions of the deep gray and white matter. Its exact relation to MS is unknown and well defined diagnostic criteria are still missing [131-133]. Since ADEM is a rare disease, it is difficult to determine exact epidemiologic data, but most studies report that children are mainly affected and that there is a minor male preponderance. Frequently ADEM develops after vaccination or viral infection [134]. Although ADEM predominantly presents with a monophasic disease course, multiphasic forms were described with increasing frequency, making a distinction to MS particularly difficult [135]. High MOG antibody levels were found in up to $30-40 \%$ of children with ADEM [119-124]. Frequent clinical features of ADEM are encephalopathy, ataxia, hypotonia, seizures, thalamic syndrome or hemiparesis [134]. Recently, cognitive impairment was described in a subgroup of patients [136]. Therefore, similar antibodymediated mechanisms as described for NMDAR encephalitis might be of relevance in some patients with ADEM. Since ADEM is usually a self-limiting disease [137], and MS targeted treatment can lead to amelioration of ADEM, further biomarkers for the discrimination of demyelinating syndromes are urgently needed.

\section{Multiple Sclerosis}

Among inflammatory demyelinating diseases of the CNS, MS is the most common pathology affecting people of all ages, with a higher incidence in the female population. The pathological hallmark is the occurrence of lesions in myelinated regions of the CNS. 
Symptoms include deficits in motor, sensory, visual, and autonomic functions, leading to substantial disabilities. The disease often starts with an acute inflammatory event, known as CIS. Subsequent relapsing-remitting MS (RR-MS) is the most common form of MS, during which further demyelinating relapses occur. Although remission following relapses may be complete, most patients develop secondary progressive MS (SP-MS) and disabilities persist. A minority of patients develop the primary progressive form (PP-MS) from onset at approximately 40 years of age [138]. The exact causes for developing MS are unknown, but multifocal inflammatory infiltrates of various immune cells in the CNS along with degradation of myelin, astrogliosis and activation of microglia, the resident macrophages in the brain, strongly suggest an autoimmune etiology $[139,140]$. Environmental risk factors, such as viral infections, vitamin D deficiency, and smoking have been attributed to favor the development of MS. Furthermore, alleles of the major histocompatibility complex (MHC) have been found to be associated with the occurrence of MS [138].

Whereas the exact contribution of T cells in the pathogenesis is still disputed in the field, the concept of MS being a mainly T cell driven disease became manifested over the last decades. $\mathrm{EAE}$, the animal model resembling human MS, which is widely used to study MS, is mainly CD4+ T cell driven, and can be induced by adoptive transfer of encephalitogenic CD4+ T cells [141]. Accumulating evidence further points to an involvement of autoimmunity-driving CD4+ Th17 cells [142] and a possible dysregulation of CD4+ CD25+ FoxP3+ T regulatory cells, which fail to exert their immunosuppressive function in MS patients [143, 144]. Whereas both, CD4+ and CD8+ T cells, are found in MS lesions [145], the contribution of CD8+ T cells in MS pathogenesis is less clear [146].

Although there is no antigen yet known to be specifically targeted in MS [125, 147], an involvement of B cell and humoral immunology is very likely and has been extensively reviewed in [148] recently. Most importantly, in more than $90 \%$ of MS patients, OCB are present in the CSF, indicating intrathecal synthesis of IgG [149]. Moreover, deposition of antibodies and complement was detected in acute MS lesions [150], as were clonally expanded B cells in the CSF of patients $[151,152]$. Further evidence for an involvement of B cells came from the use of $B$ cell depleting treatment with rituximab which could reduce the occurrence of lesions and relapses in MS patients [153]. A promising candidate antigen was MOG which is expressed on the outer surface of the myelin sheath [118]. Immunization with 
the MOG protein contributes to an MS-like pathology in EAE [129], suggesting a pathogenic role in demyelination. But its relevance as a biomarker in demyelinating diseases is still controversial $[125,126]$ and recent studies could detect significant MOG antibody titers only in a subset of predominantly pediatric CIS, MS, and ADEM patients [119-124].

\section{Neuromyelitis Optica Spectrum Disorders}

Since the identification of MOG antibodies, the spectrum of MOG autoantibody-associated diseases has widened. In the meantime, numerous studies report cases of predominantly AQP4 autoantibody seronegative patients with NMOSD having MOG antibodies. Subgroups of patients with definite and high risk NMO (i.e. recurrent ON and LETM) were found with serum MOG antibodies [127]. It was suggested that NMOSD patients with those antibodies have a more favorable outcome, with a predominance of male and young patients [154156]. Recently, also pediatric cases of NMO [157], ON [26, 158] and transverse myelitis [26] were reported to have serum MOG antibodies. So far, only two NMO cases with the cooccurrence of AQP4 and MOG antibodies are known [127, 159]. IgG purified from MOG antibody positive NMO patients, and microinjected into mouse brains, induced disturbances of myelin and axonal protein expression. However, in contrast to AQP4 IgG, these MOG antibodies did not cause inflammation, axonal loss, neuronal or astrocyte death, and the effects were independent of complement, supporting the observation that MOG antibody positive NMOSD patients have a better outcome compared to AQP4 antibody positive patients [160].

In conclusion, detection of autoantibodies to these surface antigens is crucial for early diagnosis and appropriate treatment strategies (Table 4) [161]. As already mentioned above, NMDAR antibodies were found in single cases of patients with demyelinating diseases, including patients with ON, NMOSD, ADEM or MS, which in part showed symptoms associated with the presence of NMDAR antibodies, such as epileptic seizures or cognitive impairment (see Table 3). Epileptic seizures are frequent in patients with ADEM [134], and were also observed in a small proportion of MS patients [162]. Cognitive impairment is frequently seen in MS [138] and recently also in a subgroup of ADEM patients [136]. Therefore, in line with recent studies connecting NMDAR encephalitis with demyelination $[55,56]$, a putative role for NMDAR antibodies in demyelination can be speculated. 


\begin{tabular}{|c|c|c|c|c|}
\hline Antigen & AQP4 & MOG & $?$ & NMDAR \\
\hline Disease & NMOSD & $\begin{array}{l}\text { ADEM, pediatric MS, } \\
\text { AQP4-IgG negative } \\
\text { NMO, recurrent ON, } \\
\text { recurrent myelitis? }\end{array}$ & MS & $\begin{array}{l}\text { NMDAR } \\
\text { encephalitis }\end{array}$ \\
\hline Prevalence & $1-3 / 100,000$ & 1-3/100,000, ? & $100 / 100,000$ & $\begin{array}{l}4 \% \text { of } \\
2-3 / 100,000^{1}, ?\end{array}$ \\
\hline Female:male & $9: 1$ & $1: 1$ & $3: 1$ & $4: 1$ \\
\hline Disease onset & Adult $>>$ childhood & Childhood>>adult & Adult $>$ childhood & $\begin{array}{l}\text { Young } \\
\text { adult>childhood }\end{array}$ \\
\hline Disease course & $\begin{array}{l}\text { Relapsing- } \\
\text { remitting }\end{array}$ & $\begin{array}{l}\text { Monophasic, } \\
\text { recurrent }\end{array}$ & $\begin{array}{l}\text { Relapsing-remitting, } \\
\text { progressive }\end{array}$ & $\begin{array}{l}\text { Monophasic, } \\
\text { recurrent }\end{array}$ \\
\hline Brain MRI & $\begin{array}{l}\text { Normal or } \\
\text { atypical for MS }\end{array}$ & $\begin{array}{l}\text { Normal or atypical for } \\
\text { MS, multifocal, large } \\
\text { lesions }\end{array}$ & $\begin{array}{l}\text { Multiple white } \\
\text { matter lesions }\end{array}$ & $\begin{array}{l}\text { Normal in } 2 / 3 \text { of } \\
\text { patients }\end{array}$ \\
\hline Spinal MRI & $\begin{array}{l}\text { Long-segment } \\
\text { (>3) lesions }\end{array}$ & $\begin{array}{l}\text { Long-segment (>3) } \\
\text { lesions, confluent }\end{array}$ & $\begin{array}{l}\text { Short-segment }(<3) \\
\text { lesions }\end{array}$ & $\begin{array}{l}\text { Normal in most } \\
\text { patients }\end{array}$ \\
\hline CSF OCB & Rare (<10\%) & Rare (<10\%) & Frequent (>95\%) & $60 \%$ \\
\hline CSF pleocytosis & Frequent & Frequent & Moderate & Moderate \\
\hline HLA association & DRB1*03, $1 * 16$, ? & $?$ & $\begin{array}{l}\text { DRB1*15, DQB1*06, } \\
\text { ? }\end{array}$ & $?$ \\
\hline $\begin{array}{l}\text { (Environmental) } \\
\text { risk factors }\end{array}$ & Not EBV, ? & $\begin{array}{l}\text { Vaccination, viral } \\
\text { infection, not EBV, ? }\end{array}$ & $\begin{array}{l}\text { EBV, vitamin D } \\
\text { deficiency, smoking }\end{array}$ & $\begin{array}{l}\text { Ovarian teratoma, } \\
\text { HSV }\end{array}$ \\
\hline $\begin{array}{l}\text { Relapse } \\
\text { treatment }\end{array}$ & \multicolumn{3}{|c|}{ High-dose methylprednisolone, plasmapheresis } & $\begin{array}{l}\text { First-line: Steroids, } \\
\text { IVIG, } \\
\text { plasmapheresis, } \\
\text { removal of tumor }\end{array}$ \\
\hline $\begin{array}{l}\text { Interval } \\
\text { treatment }\end{array}$ & $\begin{array}{l}\text { Azathioprine and } \\
\text { steroids, Rituximab }\end{array}$ & $\begin{array}{l}\text { Azathioprine and } \\
\text { steroids, } \\
\text { Rituximab, IVIG }\end{array}$ & $\begin{array}{l}\text { IFN- } \beta \text {, } \\
\text { glatirameracetate, } \\
\text { Natalizumab, } \\
\text { Fingolimod }\end{array}$ & $\begin{array}{l}\text { Second-line: } \\
\text { Rituximab, } \\
\text { cyclophosphamide }\end{array}$ \\
\hline
\end{tabular}

Table 4: Characteristic features of demyelinating diseases and NMDAR encephalitis.

${ }^{1}$ Encephalitides of any origin have an estimated incidence of 2-3/100,000 in northern Europe; thereof $4 \%$ are NMDAR antibody mediated [35].

$A D E M=a c u t e$ disseminated encephalomyelitis. AQP4=aquaporin 4. CSF=cerebropsinal fluid. EBV=Epstein-Barr virus. HLA=human leukocyte antigen. HSV=herpes simplex virus. IFN- $\beta=$ interferon $\beta$. IVIG=intravenous immunoglobulin. $M O G=$ myelin oligodendrocyte glycoprotein. $M R I=$ magnetic resonance imaging. $M S=$ multiple sclerosis. $\mathrm{NMDAR}=\mathrm{N}$-methyl-D-aspartate receptor. $\mathrm{NMO}=$ neuromyelitis optica. $\mathrm{OCB}=$ oligoclonal bands. Courtesy of M. Reindl and [31, 35, 37]. 


\subsubsection{MS and glutamate receptors}

Increased levels of glutamate in the CSF were found to correlate with disease activity in MS [163], and glutamate concentrations are elevated in acute lesions and normal appearing white matter of MS patients [164-166]. In post mortem hippocampi of MS patients with cognitive impairment demyelination was associated with a decrease in synaptic density [167]. White matter oligodendrocytes, which are responsible for myelin production, and which are mainly affected in MS, express all types of glutamate receptors $[168,169]$. It is therefore highly probable that elevated glutamate levels contribute to excitotoxicity mediated by iGluR and glial injury during MS. Selective blockers of AMPA/kainate receptors $[170,171]$ and antagonists of NMDAR [172-176] were able to alleviate symptoms in rodents with EAE. Conversely, ablation of oligodendroglial NMDAR expression did not change the susceptibility to EAE [177]. In addition, remyelination was shown to be dependent on oligodendrocyte NMDAR [178], complicating a potential use of iGluR antagonists as treatment strategies in MS.

Taken together, glutamate and its receptors expressed in the CNS and periphery modulate immune functions in health and disease and are therefore likely to play a role in the pathogenesis of neuroinflammatory diseases such as MS. 


\section{HYPOTHESIS AND AIMS OF THESIS}

We hypothesized that NMDAR antibodies play a role in the pathogenesis in subgroups of patients with demyelinating syndromes, in particular patients lacking specific antibodies.

In order to investigate a possible role of NMDAR in demyelinating diseases, we aimed to screen large groups of patients with neuroinflammatory and demyelinating diseases, such as MS, ADEM and NMO, for the presence of NMDAR antibodies. We thereby focused on patients with symptoms resembling NMDAR encephalitis, such as psychiatric abnormalities, epileptic seizures or cognitive impairment. Furthermore, we included serological analysis of antibodies against the glial surface antigens MOG and AQP4 which are found in demyelinating diseases.

To achieve this goal, the first main focus of this PhD thesis was to establish a highly specific live cell-based assay for the detection of antibodies against NMDAR in our laboratory. Based on this assay we further aimed to develop a flow cytometry based detection method, since the evaluation of cell surface staining by fluorescence microscopy is strongly dependent on the experience of the investigators. Furthermore, a flow cytometry based analysis for the detection of antibodies to surface antigens would enable quantification of antibody levels over time and also to precisely calculate intrathecal synthesis of the antibodies in those diseases. We therefore compared diagnostic accuracy of both antibody detection methods. 


\section{MATERIALS AND METHODS}

\subsection{Patients}

\subsubsection{Ethical approval}

The present study was approved by the Ethical Committee of the Medical University of Innsbruck (study numbers AM3041A and AM4059). All patients and controls gave written informed consent to the study protocol. All samples from the Hospital Clínic Barcelona were deposited in the collection of biological samples named "neuroimmunologia" registered in the biobank of IDIBAPS, Barcelona, Spain. Samples were handled in an anonymized way, thus the Comité Ético de Investigación Clínica of Hospital Clínic de Barcelona accepted to waive the specific written informed consent from the patients or next of kin.

\subsubsection{Patients and controls for assay validation}

Serum samples from patients and controls were collected in the Clinical Department of Neurology Innsbruck and the Hospital Clínic Barcelona between 2010 and 2013, and stored at $-80^{\circ} \mathrm{C}$ until use.

The discovery group (76 individuals from Innsbruck) consisted of:

- Seven patients with NMDAR encephalitis (five females and two males; median age 20 years, range 5-34).

- 37 neurological controls (21 females and 16 males; median age 40 years, range 2369; 33 patients with MS, three patients with $\mathrm{CIS}$, and one patient with viral encephalitis).

- 32 healthy controls (27 females and five males; median age 43 years, range 27-68).

The validation group (32 patients from Barcelona) consisted of:

- 16 patients with NMDAR encephalitis (11 females and five males; median age 16 years, range 3-42).

- 16 neurological controls (nine females and seven males; median age 28 years, range 4-70; four patients with NMO, one patient with MS, and 11 patients with suspected autoimmune encephalitis, including limbic encephalitis, non-focal encephalitis, encephalomyelitis, cerebellar dysfunction, and hypophysitis). 
The demographic data of both groups are shown in the results section (Table 6). Significant differences of gender and age between the groups result from disease specific gender and age distributions.

Diagnosis of NMDAR encephalitis was based on clinical assessment (new onset of neuropsychiatric symptoms) and demonstration of antibodies in serum or CSF with at least two assays (CBA with fixed cells and tissue immunohistochemistry) as recommended recently [44]. In the discovery group the clinical diagnosis of NMDAR encephalitis diagnosis was confirmed by the presence of NMDAR antibodies in the serum and CSF of patients. One sample was tested in a diagnostic laboratory (Oxford Neuroimmunology Testing Service, Oxford, UK), two samples were tested in our laboratory using a commercially available certified test kit (Euroimmun AG, Lübeck, Germany), and four samples were tested in both laboratories.

In the blinded validation group from Barcelona diagnosis was confirmed by the research center of neuroimmunology (IDIBAPS, Hospital Clínic, University of Barcelona, Spain) using an in-house CBA and tissue immunohistochemistry in CSF and serum samples. Antibody negativity was proven for all control samples of the validation group. All samples of the validation group were blinded by Romana Höftberger and Josep Dalmau.

MS and CIS were diagnosed according to the 2010 revisions to the McDonald criteria [179], NMO was diagnosed according to the 2006 revised diagnostic criteria [98].

\subsubsection{Patients screened for NMDAR antibodies}

Serum and CSF samples from patients were collected in the Clinical Department of Neurology Innsbruck between 2009 and 2014, and the Hospital Clínic Barcelona between 2010 and 2013 , and stored at $-80^{\circ} \mathrm{C}$ until use.

All patients described above (3.1.2) were included in this part of the study. In addition the following patients were included:

- Two patients with NMDAR encephalitis (one female and one male; both aged 16 years). 
- 47 patients with NMO and related disorders (37 females and 10 males; median age 48 years, range $3-81 ; 26$ patients with definite NMO, 14 patients with LETM, seven patients with $\mathrm{ON})$.

- 55 patients with ADEM (29 females and 26 males; median age seven years, range 2$52)$.

- 26 patients with CIS (20 females and six males; median age 16 years, range 4-51).

- 63 patients with MS (38 females and 25 males; median age 42 years, range 6-71).

- 25 patients with SLE (22 females and three males; median age 40 years, range 22-69; none of those patients had neuropsychiatric symptoms).

- 91 neurological controls (32 females and 59 males; median age 15 years, range 1-89; thereof 38 patients with inflammatory and 53 patients with non-inflammatory diseases).

- 15 healthy controls (12 females and three males; median age 43 years, range 21-62).

The demographic data of all patients included is summarized in the results section (Table 8). Significant differences of gender and age between the groups result from disease specific gender and age distributions.

Pairs of serum and CSF were available for three patients with NMDAR encephalitis, seven patients with MS, and five patients with ADEM.

The inclusion criteria for NMDAR encephalitis, NMO, CIS, and MS are described above (3.1.2). ADEM patients were diagnosed according to the 2013 revisions of the International Pediatric Multiple Sclerosis Study Group [133].

\subsection{Transient expression of human NMDAR and CD2 in HEK293A cells}

To express fully functional human NMDAR in the mammalian cell line HEK293A (human embryonic kidney cells), vectors containing complementary (c)DNA of three subunits of NMDAR were used for transfection: GluN1 (human (h)GRIN1), GluN2A (hGRIN2A), and GluN2B (hGRIN2B). Proteins encoding GluN1 and GluN2B were fused to a green fluorescent protein (GFP). For expression of the control surface protein human CD2, which is an adhesion molecule normally found on $\mathrm{T}$ and natural killer cells, an expression vector containing cDNA of hCD2 fused to a GFP was used. 


\subsubsection{Vector constructs}

The insert sequence (hGRIN1) from a cloned vector construct used in the experiments was verified by dsDNA sequencing (Microsynth, Balgach, Switzerland) and cloned as described below. Vector constructs containing hGRIN2A and hGRIN2B-GFP cDNA were purchased from Source BioScience (Nottingham, UK) and Origene (Rockville, MD), respectively. All final vectors used in the experiments can be seen in Figure 4 (human NMDAR) and Figure 5 (human CD2).

\subsubsection{Human GRIN1 expression vector}

Complementary DNA of hGRIN1 (NM_000832.5) was amplified from an expression vector (pCMV6-XL5) containing hGRIN1 purchased from Origene (Art. No. SC308819), and cloned into the mammalian expression vector Vivid Colors ${ }^{\mathrm{TM}}$ pcDNA $^{\mathrm{TM}} 6.2 \mathrm{C}$-EmGFP-GW/TOPO ${ }^{\circledR}$ (Life Technologies, Carlsbad, CA, Art. No. K359-20), resulting in hGRIN1 C-terminally fused to emerald green fluorescent protein (EmGFP). The cloning procedure is described in detail in 3.2.2 and the resulting expression vector (pcDNA 6.2 C-EmGFP TOPO hGRIN1) is shown in Figure 4.

\subsubsection{Human GRIN2A expression vector}

The expression vector pDEST26 containing hGRIN2A cDNA (NM_000833.3) was purchased from Source BioScience (Art. No. IOH36573-pDEST26) and used without further cloning in subsequent experiments (Figure 4).

\subsubsection{Human GRIN2B expression vector}

Human GRIN2B cDNA (NM_000834.2) C-terminally fused to GFP (expression vector pCMV6AC-GFP) was purchased from Origene (Art. No. RG223623) and used without further cloning (Figure 4). 

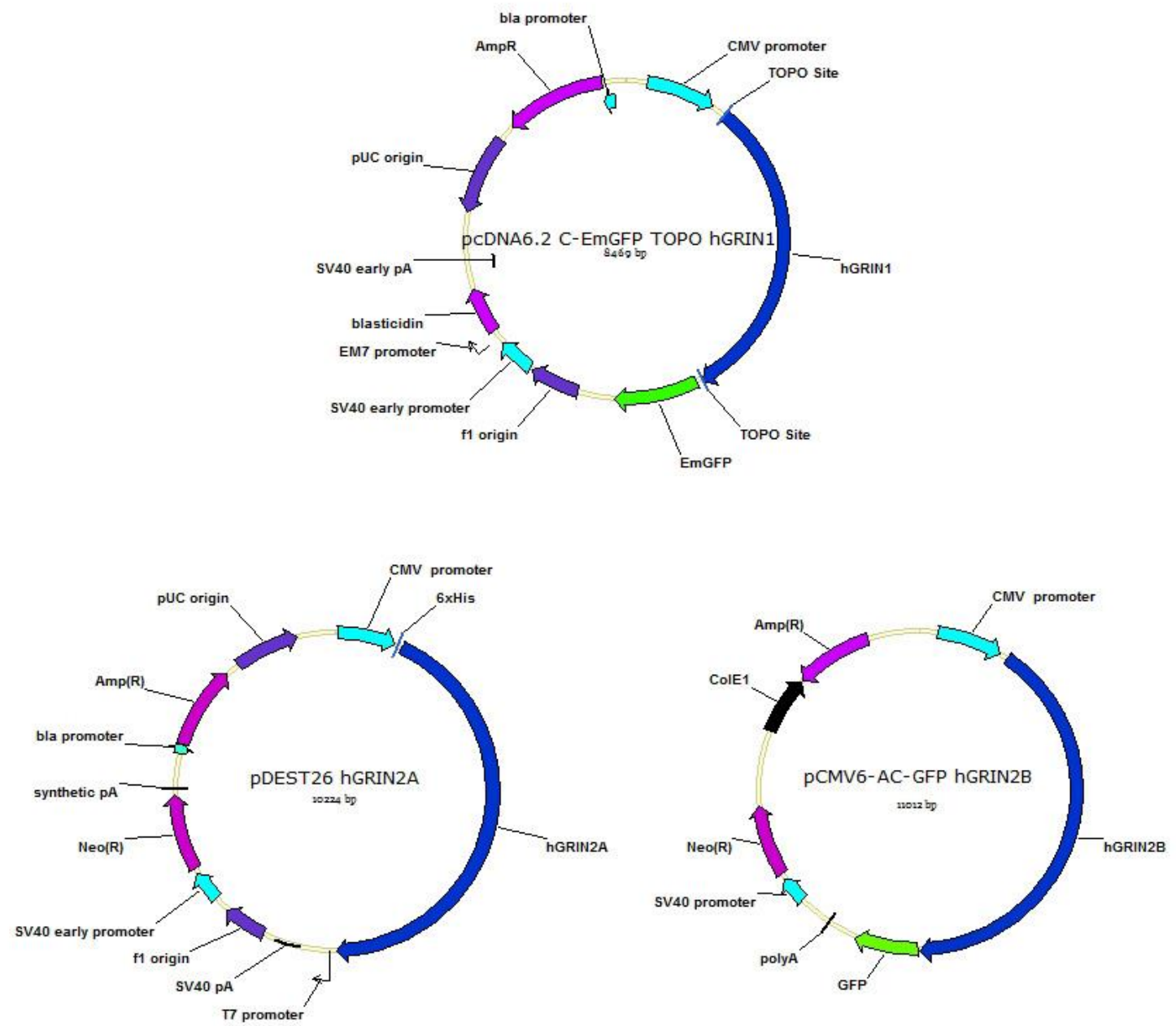

Figure 4: Vectors used for expression of functional human NMDAR.

$A m p(R)=a m p i c i l l i n$ resistance. $\quad C M V=c y t o m e g a l o v i r u s . \quad(E m) G F P=(e m e r a l d)$ green fluorescent protein. hGRIN=human glutamate receptor, ionotropic, NMDA (gene). Neo(R)=neomycin resistance. NMDAR=N-methylD-aspartate receptor.

\subsubsection{Human CD2 expression vector}

Human CD2 originally amplified from human peripheral blood mononuclear cells, cloned into

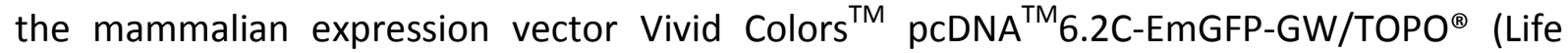
Technologies), resulting in hCD2-EmGFP fusion protein, was kindly provided by S. Mader [121] (Figure 5). 


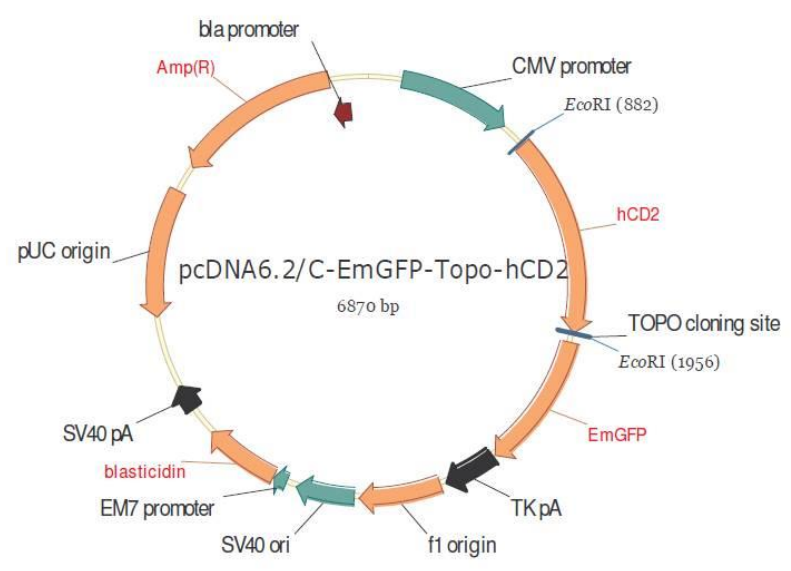

Figure 5: Vector used for the expression of hCD2-EmGFP fusion protein.

Courtesy of S. Mader.

$\mathrm{Amp}(\mathrm{R})=$ ampicillin resistance. $\mathrm{CMV}=$ cytomegalovirus. EmGFP=emerald green fluorescent protein. $\mathrm{hCD} 2=\mathrm{human}$ cluster of differentiation 2.

\subsubsection{Cloning}

\subsubsection{Designing the construct for hGRIN1-EmGFP}

The vector construct for hGRIN1-EmGFP fusion protein was designed using the vector NTI Advance 11.5.2 software (Life Technologies). The nucleotide sequence of GRIN1 (NM_000832.5) was obtained from the NCBI database (http://www.ncbi.nlm.nih.gov/) and the plasmid map of the expression vector Vivid Colors $^{\mathrm{TM}}$ pcDNA $^{\mathrm{TM}} 6.2 \mathrm{C}-\mathrm{EmGFP} \mathrm{GW} / \mathrm{TOPO}^{\circledR}$ was available from the providing company (Life Technologies). The sense primer was designed as recommended by the providing company's manual, by including a guanin at position -3 relative to the start codon (ATG) according to the Kozak consensus sequence (G/A)NNATGG [180]. Primers for cloning were made by custom oligonucleotide synthesis from Microsynth.

Sense primer: 5'-GCCATGAGCACCATGCG-3' (17bp)

Antisense primer: 5'-CACCACGGTGCTGACCG-3' (17bp)

\subsubsection{Linearization of hGRIN1}

To ensure full accessibility of the cDNA sequence of hGRIN1 for subsequent polymerase chain reaction $(\mathrm{PCR})$, the expression vector containing the sequence of interest was 
linearized. Therefor $2 \mu \mathrm{g}$ of plasmid DNA were digested with ten units Notl (New England Biolabs, Ipswich, MA, Art. No. R0189S) which cut the plasmid at one restriction site for four hours at $37^{\circ} \mathrm{C}$.

\subsubsection{PCR}

Human full length GRIN1 cDNA was amplified from the linearized expression vector (pCMV6XL5) containing hGRIN1 purchased from Origene by PCR as follows:

\section{PCR reagents}

$1.0 \mu$ l Linearized plasmid DNA (5 ng/ $\mu \mathrm{l})$

$1.0 \mu \mathrm{l}$ dNTP (100 nM stock; Takara, Kyoto, Japan, Art. No. 4715-1)

$5.0 \mu$ I TITANIUM Taq buffer (10 x) (Takara, Art. No. 8434-1)

$1.0 \mu \mathrm{l}$ Sense Primer $(100 \mu \mathrm{M})$

$1.0 \mu$ l Antisense Primer $(100 \mu \mathrm{M})$

$1.0 \mu$ I TITANIUM Taq polymerase (Takara, Art. No. 8434-1)

Ad $50 \mu \mathrm{ld} \mathrm{H}_{2} \mathrm{O}$

In order to dissociate the two DNA strands, initial denaturation was performed as a single step heating period for one minute at $94^{\circ} \mathrm{C}$. Twenty two-step cycles of denaturation with subsequent annealing and elongation were performed (30 seconds at $94^{\circ} \mathrm{C}$ followed by two minutes at $68^{\circ} \mathrm{C}$ ). A final elongation step at $68^{\circ} \mathrm{C}$ was performed for 20 minutes. The resulting PCR product had a size of approximately $2.7 \mathrm{~kb}$.

\subsubsection{Agarose gel electrophoresis}

Reagents

$5 \times$ Tris-borate-ethylenediaminetetraacetic acid (EDTA) (TBE) buffer

108 g Tris (TRIS-(hydroxymethyl)-aminomethane; Scharlau Chemie, Sentmenat, Spain, Art. No. Tr0423)

55 g Boric acid (Scharlau Chemie, Art. No. A4418)

9.3 g EDTA (Roth, Karlsruhe, Germany, Art. No. 8040.3)

Ad 2 liters $\mathrm{dH}_{2} \mathrm{O}$ 
The amplified PCR product was separated on a $0.8 \%$ agarose gel. Therefor $0.8 \mathrm{~g}$ of agarose (Biozym Scientific GmbH, Vienna, Austria, Art. No. 840004) were added to $100 \mathrm{ml} 1 \times \mathrm{TBE}$ buffer and heated in a microwave oven to dissolve the agarose. To visualize DNA, $1 \times$ GelRed (Biotium Inc, Hayward, CA, Art. No. 41003) was added to the agarose solution which was then poured into a medium gel chamber, inserting a comb at one end of the gel. After solidifying the gel at room temperature (RT) the comb was removed carefully and the gel was inserted into a tank containing 1 x TBE buffer. The slots were situated at the side of the cathode. Before loading, the solution containing the PCR product was supplemented with $1 \times$ DNA loading buffer (Biozym). To determine the size of the PCR product, a DNA ladder (Quantitas Quick, Biozym) ranging from 0.5-5 kb or 1-10 kb was used. The gel was run at 80 Volts for two hours and the separated PCR product was visualized under UV light. Since UV light damages DNA, the time of exposure was kept as little as possible.

\subsubsection{Isolation of PCR product by gel extraction}

The PCR product was isolated from the $0.8 \%$ agarose gel using the QIAEX II Gel Extraction Kit (QIAGEN GmbH, Hilden, Germany, Art. No. 20021) according to the manufacturer's instructions. Briefly, the DNA fragment was excised from the agarose gel using a sharp scalpel and transferred into a $1.5 \mathrm{ml}$ microcentrifuge tube. After solubilizing the agarose fragment, the DNA was selectively bound to QIAEX II silica-gel particles in the presence of chaotropic salt. Following a few washing steps, the DNA was eluted using $20 \mu \mathrm{l} \mathrm{dH}_{2} \mathrm{O}$. The DNA concentration was determined via a NanoDrop ND-1000 UV/Vis-spectralphotometer (Peqlab GmbH, Erlangen, Germany).

\subsubsection{TOPO ${ }^{\circledR}$ cloning reaction and transformation}

The isolated PCR product was cloned into the Vivid Colors ${ }^{\mathrm{TM}}$ pCDNA $^{\mathrm{TM}} 6.2 \mathrm{C}-\mathrm{EmGFP}$ GW/TOPO ${ }^{\circledR}$ vector according to the manufacturer's instructions (Life Technologies). Briefly, the isolated PCR product was mixed with a salt solution containing the vector and incubated for ten minutes at RT. One vial of One Shot ${ }^{\circledR}$ TOP10 chemically competent Escherichia coli (E. coli) (Life Technologies, Art. No. C4040) was thawed on ice, and then $2 \mu$ l of the Topo cloning reaction were added and incubated for 30 minutes on ice. The $E$. coli were heat shocked at 
$42^{\circ} \mathrm{C}$ for exactly 30 seconds and immediately placed on ice. Subsequently pre-warmed S.O.C. medium (Life Technologies) was added and the bacteria were incubated at $37^{\circ} \mathrm{C}$ for one hour with shaking. Finally, $100 \mu \mathrm{l}$ and $50 \mu \mathrm{l}$ of the transformation mixture were spread with a Drigalski spatula on each one pre-warmed lysogeny broth (LB) agar plate containing $100 \mathrm{\mu g} / \mathrm{ml}$ ampicillin (Sigma-Aldrich, St. Louis, MO, Art. No. A-9518). The plates were incubated over night at $37^{\circ} \mathrm{C}$.

\subsubsection{LB agar plates}

Thirty-two grams of LB agar (Life Technologies, Art. No. 22700-025) were dissolved in one liter of $\mathrm{dH}_{2} \mathrm{O}$ and the solution was autoclaved at $121^{\circ} \mathrm{C}$ for 20 minutes. After cooling to approximately $60^{\circ} \mathrm{C}, 100 \mu \mathrm{g} / \mathrm{ml}$ of ampicillin was added. The warm LB agar was poured into petri dishes and stored at $4^{\circ} \mathrm{C}$ after solidifying.

\subsubsection{Plasmid mini preparation}

Ten colonies were picked from the LB agar plates, transferred into $2.5 \mathrm{ml}$ autoclaved LB Broth Base (20 g/liter; Life Technologies, Art. No. 12780-052) containing ampicillin, and shaken at $37^{\circ} \mathrm{C}$ over night. Afterwards $1.5 \mathrm{ml}$ of the overnight culture were harvested by centrifugation $(8,000 \mathrm{~g}, 5$ minutes, RT). The remaining amount of the overnight culture was stored for preparation of glycerol stocks at $4^{\circ} \mathrm{C}$ for up to one month. After confirming the correct insert sequence the transformed TOP10 E. coli were frozen at $-80^{\circ} \mathrm{C}$ after adding autoclaved glycerol (1:1; Sigma-Aldrich, Art. No. G-7893) to the bacterial suspension.

For subsequent plasmid mini preparation, buffers of the QIAGEN QIAprep Spin Miniprep Kit (Art. No. 27104) were used according to the manufacturer's instructions. The supernatant of the harvested overnight culture was discarded and the pellet was resuspended in $300 \mu \mathrm{l}$ of cold resuspension buffer P1 containing RNAse and then the bacteria were lysed with $300 \mu \mathrm{l}$ lysis buffer P2, inverted and incubated for a maximum of five minutes at RT. Subsequently, $300 \mu \mathrm{l}$ of chilled neutralizing buffer N3 were added and incubated at $4^{\circ} \mathrm{C}$ for 15 minutes. After centrifugation at $12,000 \mathrm{~g}$ for 15 minutes, $800 \mu$ of the supernatant were mixed with $700 \mu \mathrm{l}$ isopropanol (Gatt-Koller, Absam, Austria, Art. No. 402150172) and incubated at RT for 15 minutes. After centrifugation at $12,000 \mathrm{~g}$ for five minutes, the supernatant was discarded 
and the pellet washed twice with $500 \mu \mathrm{l} 70 \%$ ethanol (Gatt-Koller, Art. No. 402043372). The air dried pellet was dissolved in $30 \mu \mathrm{ld} \mathrm{H}_{2} \mathrm{O}$.

\subsubsection{Restriction enzyme digestion}

The orientation of the inserted PCR product in the vector was analyzed by restriction enzyme digestion using a restriction enzyme that generated two DNA fragments. Approximately $2 \mu \mathrm{g}$ of DNA were digested with ten units Stul (New England Biolabs, Art. No. R0187S) for one hour at $37^{\circ} \mathrm{C}$. The digested fragments were analyzed on a $0.8 \%$ agarose gel. The correctly inserted PCR product into the Topo ${ }^{\circledR}$ vector yielded two fragments of $2.3 \mathrm{~kb}$ and $6.2 \mathrm{~kb}$ of size, respectively. The plasmid with the correctly inserted PCR product was verified by dsDNA sequencing (Microsynth).

\subsubsection{Plasmid maxi preparation}

For the preparation of large amounts of the plasmid, QIA filter Plasmid Maxi Kit (QIAGEN, Art. No. 12262) was used according to the manufacturer's instructions. Briefly, $250 \mathrm{ml}$ of an overnight culture (LB with ampicillin) was harvested at 6,000 g for 30 minutes at $4^{\circ} \mathrm{C}$. The pellet was resuspended with $10 \mathrm{ml}$ cold resuspension buffer P1 containing RNAse, mixed with $10 \mathrm{ml}$ pre-warmed lysis buffer P2 and incubated for five minutes at RT. Subsequently, $10 \mathrm{ml}$ of chilled neutralization buffer P3 were added and the lysate was poured into a QIAfilter cartridge. During incubation for ten minutes at RT, high speed maxi tips were equilibrated with $10 \mathrm{ml} \mathrm{QBT}$ buffer. The lysate was cleared by filtration through the QIAfilter cartridge and added to the high speed maxi tip. The bound DNA was washed with $60 \mathrm{ml} \mathrm{QC}$ buffer and eluted with $15 \mathrm{ml}$ QF buffer. The DNA was precipitated by adding $10.5 \mathrm{ml}$ isopropanol and incubation at RT for five minutes. The mixture was attached onto a QIAprecipitator maxi module, washed twice with $2 \mathrm{ml} 70 \%$ ethanol, air dried, and eluted with $1 \mathrm{ml}$ TE buffer. DNA concentration was measured as described above (3.2.2.5).

\subsubsection{Cell culture}

\subsubsection{Culturing HEK293A cells}

HEK293A cells (ATCC, LGC Standards GmbH, Wesel, Germany) were grown in Dulbecco's modified Eagle's medium supplemented with $2 \mathrm{mM}$ L-glutamine (Art. No. 41965-039), 
1 x MEM NEAA (Art. No. 11140-050), and 10\% fetal calf serum (FCS; Art. No. 10270-106; all Life Technologies). The cells were maintained in $75 \mathrm{~cm}^{2}$ cell culture flasks (BD, Franklin Lakes, $\mathrm{NJ}$ ) and grown in a cell incubator at $37^{\circ} \mathrm{C}$ in a humidified atmosphere containing $5 \% \mathrm{CO}_{2}$. Cells were split twice a week when the cells had reached approximately $90 \%$ confluence: medium was removed and cells were washed with $1 \times$ phosphate buffered saline (PBS; Sigma-Aldrich, Art. No. P-3813). Cells were detached using $3 \mathrm{ml}$ 0.05\% trypsin-EDTA (Life Technologies, Art. No. $25300-054)$ for three minutes at $37^{\circ} \mathrm{C}$. Trypsin was neutralized by adding $10 \mathrm{ml}$ growth medium and the suspension was centrifuged at $500 \mathrm{~g}$ for five minutes at RT. The cell pellet was resuspended in $10 \mathrm{ml}$ fresh medium and $1 \times 10^{6}$ cells were transferred to a new flask or a flask rinsed with $1 \times$ PBS. For cell counting a Neubauer improved counting chamber (Glaswarenfabrik Karl Hecht, Sondheim, Germany) was used: a suspension containing $50 \mu \mathrm{l}$ trypan blue (Sigma-Aldrich, Art. No. T-8154), $30 \mu \mathrm{l} 1$ x PBS and $20 \mu \mathrm{l}$ cell suspension was mixed and transferred into the space between the cell counting chamber and an attached cover slip. Viable cells (no blue staining) were counted in four $4 \times 4$ squares of the chamber.

Cell number per $m l=$ Mean of cells per square $\times 5$ (dilution factor $) \times 10,000$

\subsubsection{Freezing and thawing of HEK293A cells}

Early passages of HEK293A cells were frozen in liquid nitrogen. Therefor the cell pellet was dissolved in $1 \mathrm{ml}$ cell freezing medium containing 90\% FCS and 10\% dimethyl sulfoxide (Sigma-Aldrich, Art. No. D5879) and transferred into cryo vials. The cells were frozen in a Styrofoam box at $-80^{\circ} \mathrm{C}$ and transferred into liquid nitrogen after 24 hours.

After approximately 40 passages vials from earlier passages of HEK293A cells were thawed: the vial was thawed quickly in a $37^{\circ} \mathrm{C}$ water bath and transferred into flasks containing warm growth medium. The medium was changed after 48 hours and then cells were grown until being confluent.

\subsubsection{Transfection of HEK293A cells}

For the live CBA, HEK293A cells were seeded in tissue culture test plates 96F (TPP, Trasadingen, Switzerland, Art. No. 92096) at a density of $2 \times 10^{4}$ cells per $100 \mu \mathrm{l}$ per well. After 24 hours cells were transfected with plasmids containing each one of three NMDAR 
subunits hGRIN1-EmGFP, hGRIN2A and hGRIN2B-GFP at a molar ratio of 3:1:1 using FuGENE ${ }^{\circledR}$ HD transfection reagent (Promega, Madison, WI, Art. No. E2312) at a reagent:DNA ratio (v/w) of 3.5:1 (100 ng total DNA per well) and protected with $30 \mu \mathrm{M}(+)-\mathrm{MK}-801$ (Sigma-Aldrich, Art. No. M107) to prevent excitotoxicity. After 48 hours transfected cells were used for subsequent experiments.

Transfection rates of NMDAR subunits were determined by antibody staining: cells were fixed with ice cold methanol for ten minutes, blocked at RT with $40 \mu \mathrm{g} / \mathrm{ml}$ goat IgG (SigmaAldrich, Art. No. 15256) for 15 minutes in phosphate buffered saline/10\% heat-inactivated FCS (Sigma-Aldrich, Art. No. F0804; washing buffer, in which all subsequent dilutions were made) and incubated with anti-GluN1 (1:500; Millipore, Temecula, CA, Art. No. MAB363), anti-GluN2A (1:500; Millipore, Art. No. MAB5216) or anti-GluN2B (1:300; Novus Biologicals, Cambridge, UK, Art. No. NB100-74475) antibodies with orbital shaking (200 rpm) at $4^{\circ} \mathrm{C}$ for one hour. After three washing steps cells were incubated with Alexa Fluor ${ }^{\circledR} 546$ goat antimouse IgG antibody (1:1,000; Life Technologies, Art. No. A-11030) for 30 minutes at RT without agitation. Microscopic examination was done using a DMI 4000B inverse microscope (Leica, Wetzlar, Germany).

For the flow cytometry based assay, HEK293A cells were seeded in tissue culture test plates 6 (TPP, Art. No. 92006) at a density of $3 \times 10^{5}$ cells per $3 \mathrm{ml}$ per well and transfected with human NMDAR as described above ( $3 \mu \mathrm{g}$ total DNA per well). Unspecific binding of serum antibodies was determined by using HEK293A cells transiently transfected with hCD2-EmGFP fusion protein [121]. Likewise NMDAR, 24 hours after plating CD2-EmGFP cDNA was used to transfect HEK293A cells with FuGENE ${ }^{\circledR}$ HD transfection reagent at a reagent:DNA ratio (v/w) of 3.5:1.

For assessment of overall transfection efficiency, cells were detached with trypsin without EDTA (0.25\% in PBS; PAA, GE Healthcare, Chalfont St Giles, UK, Art. No. L11-002). Cells were incubated with $200 \mu \mathrm{l}$ trypsin for five minutes at RT, resuspended in washing buffer containing $20 \mu \mathrm{M}(+)-\mathrm{MK}-801$ (Sigma-Aldrich), and centrifuged at $500 \mathrm{~g}$ for five minutes. Washed cells were resuspended in 1 x PBS containing $20 \mu \mathrm{M}(+)-\mathrm{MK}-801$ (Sigma-Aldrich) and analyzed on a BD Accuri ${ }^{\mathrm{TM}} \mathrm{C} 6$ flow cytometer. 


\subsection{Live cell-based immunofluorescence assay}

A graphic overview of antibody staining can be seen in Figure 6. For live cell staining, all dilutions were made in washing buffer containing $20 \mu \mathrm{M}$ (+)-MK-801 (Sigma-Aldrich). Fortyeight hours post transfection live cells were blocked with $40 \mu \mathrm{g} / \mathrm{ml}$ goat IgG (Sigma-Aldrich) for 15 minutes at RT, incubated with serum samples at serial dilutions of 1:20, 1:40 and 1:80 for one hour without agitation at $4^{\circ} \mathrm{C}$, washed three times and bound antibodies were visualized by incubation with $C y 3^{T m}$-conjugated goat anti-human $\lg G(H+L)$ antibody $(1: 300$; Jackson ImmunoResearch Laboratory, West Grove, PA, Art. No. 109-166-088) for 30 minutes at RT without agitation. For nuclear staining 4',6-diamidino-2-phenylindole (DAPI; SigmaAldrich, Art. No. D8417) was used to exclude dead cells. For this purpose, $0.1 \mu \mathrm{g} / \mathrm{ml}$ DAPI were added after three washing steps. Microscopic examination was done by two independent investigators blinded for any clinical data (myself, Kathrin Schanda or Markus Reindl) using a DMI 4000B inverse microscope (Leica, Wetzlar, Germany). Excitation and emission wave lengths to visualize fluorophores were as follows: EmGFP/GFP: 490/15 and 535/35 nm; Cy3: 570/25 and 630/60 nm; DAPI: 400/15 and 460/25 nm. Samples positive for NMDAR antibodies were further serially diluted to assess endpoint antibody titers (1:20, 1:40, 1:80 etc.). Likewise, CSF samples were applied at serial dilutions starting with undiluted CSF, if available, supplemented with $20 \mu \mathrm{M}(+)-\mathrm{MK}-801$ (followed by dilutions of 1:2, 1:4, 1:8 etc.).

In order to visualize the colocalization of NMDAR and serum antibodies, cells were grown on angiogenesis $\mu$-slides (ibidi, Martinsried, Germany, Art. No. 81506), transfected with the three NMDAR subunits hGRIN1-EmGFP, hGRIN2A and hGRIN2B-GFP, and incubated with human serum samples as described above with the exception of DAPI staining, which was omitted. Images were obtained with a TCS SP5 confocal laser scanning microscope (Leica). 


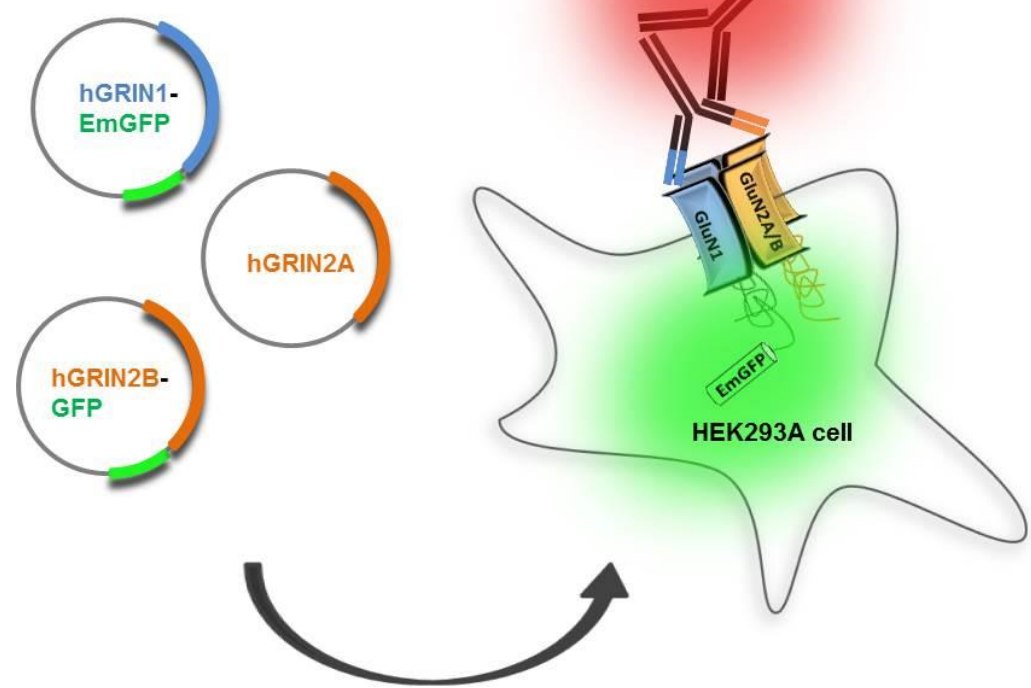

Figure 6: Principle of the live cell-based immunofluorescence assay.

HEK293A cells are transfected with NMDAR subunits (hGRIN1-EmGFP/2A/2B-GFP). Upon binding of patients' antibodies to the cell surface, a secondary antibody conjugated with Cy3 recognizes bound antibodies.

(Em)GFP=(emerald) green fluorescent protein. HEK293A cell=human embryonic kidney cell 293A. hGRIN=human glutamate receptor, ionotropic, NMDA (gene). NMDAR=Nmethyl-D-aspartate receptor.

\subsubsection{Absorption of patient's sera with HEK293A cells expressing NMDAR}

To prove the specificity of antibody binding, sera of selected patients were pre-incubated with HEK293A cells expressing NMDAR, or non-transfected HEK293A cells. The presence of antibodies specific for NMDAR would result in an abolishment of the signal, if sera were incubated with NMDAR expressing cells, but not if incubated with non-transfected cells. To achieve this, cells were seeded and transfected in 6-well tissue culture test plates as described above for the flow cytometry based assay (3.2.3.3). Forty-eight hours post transfection cells were detached using trypsin without EDTA $(0.25 \%$ in PBS; PAA, GE Healthcare) and incubated with serum dilutions.

Detached cells, either transfected with NMDAR or non-transfected, originating from each one well (approximately $1 \times 10^{6}$ cells) were incubated with $300 \mu$ of a 1:20 dilution (in washing buffer) of selected sera at RT under rotation (Dynal ${ }^{\circledR}$ Sample Mixer) for one hour. The cells were collected at $500 \mathrm{~g}$ at RT for five minutes and the supernatant was again 
incubated with freshly harvested cells as described above. In total, serum dilutions were incubated with the cells three times before they were used for the live CBA.

\subsection{Flow cytometry based assay}

Forty-eight hours post transfection cells were detached using trypsin without EDTA $(0.25 \%$ in PBS; PAA, GE Healthcare). Cells were incubated with $200 \mu$ ltypsin for five minutes at RT, resuspended in washing buffer containing $20 \mu \mathrm{M}$ (+)-MK-801 (Sigma-Aldrich), centrifuged at $500 \mathrm{~g}$ for five minutes, and stained as described above with the following modifications: all incubation steps were performed at RT with orbital shaking at $200 \mathrm{rpm}$. Washing steps were performed by repeated centrifugation $(3 \mathrm{x})$ at $500 \mathrm{~g}$ for five minutes and resuspension of the pellets. Duplicates of serum samples at a dilution of 1:100 were used at a cell density of $2 \times 10^{5}$ cells per $200 \mu \mathrm{l}$. Bound serum antibodies were detected by allophycocyanin (APC)conjugated AffiniPure goat anti-human IgG antibody (1:100; Jackson ImmunoResearch Laboratory, Art. No. 109-136-088). Cells were incubated with $100 \mu \mathrm{l}$ washing buffer containing 7-amino-actinomycin D (7-AAD; 1:30; Becton Dickinson, Art. No. 559925) to exclude dead cells for ten minutes at RT and analyzed on a BD Accuri ${ }^{\mathrm{TM}} \mathrm{C} 6$ flow cytometer.

In this manner, a maximum of 22 samples were analyzed in parallel (average 14 samples per analysis). Therefore, not all samples, neither of the discovery nor of the validation group, could be analyzed with the same batch of transfected and trypsinized cells. Consequently, considering the inter-assay variation, when interpreting data from different analysis batches, is of importance. For reanalysis of samples to compare serum dilutions of 1:100 and 1:20 it was taken care that different dilutions of the same sample were analyzed in the very same experiment.

NMDAR and CD2 expressing cells were detected in the green FL-1 channel, dead cells in the red FL-3 channel and antibody binding was measured in the red FL-4 channel (gating strategy for the fluorescence activated cell sorting (FACS) see Figure 7). Ten thousand (Em)GFP pos $7-$ $A A D^{\text {neg }}$ cells were acquired for each sample. Antibody bound to cell surface resulted in a shift to the right on the $\mathrm{x}$-axis in FL-4. Median fluorescence intensity (MFI) from CD2 transfected cells was subtracted from $M F I$ of NMDAR expressing cells $(\triangle M F I)$. Healthy controls and patients with other neurological diseases were used to calculate the cut-off $\Delta \mathrm{MFI}$. 

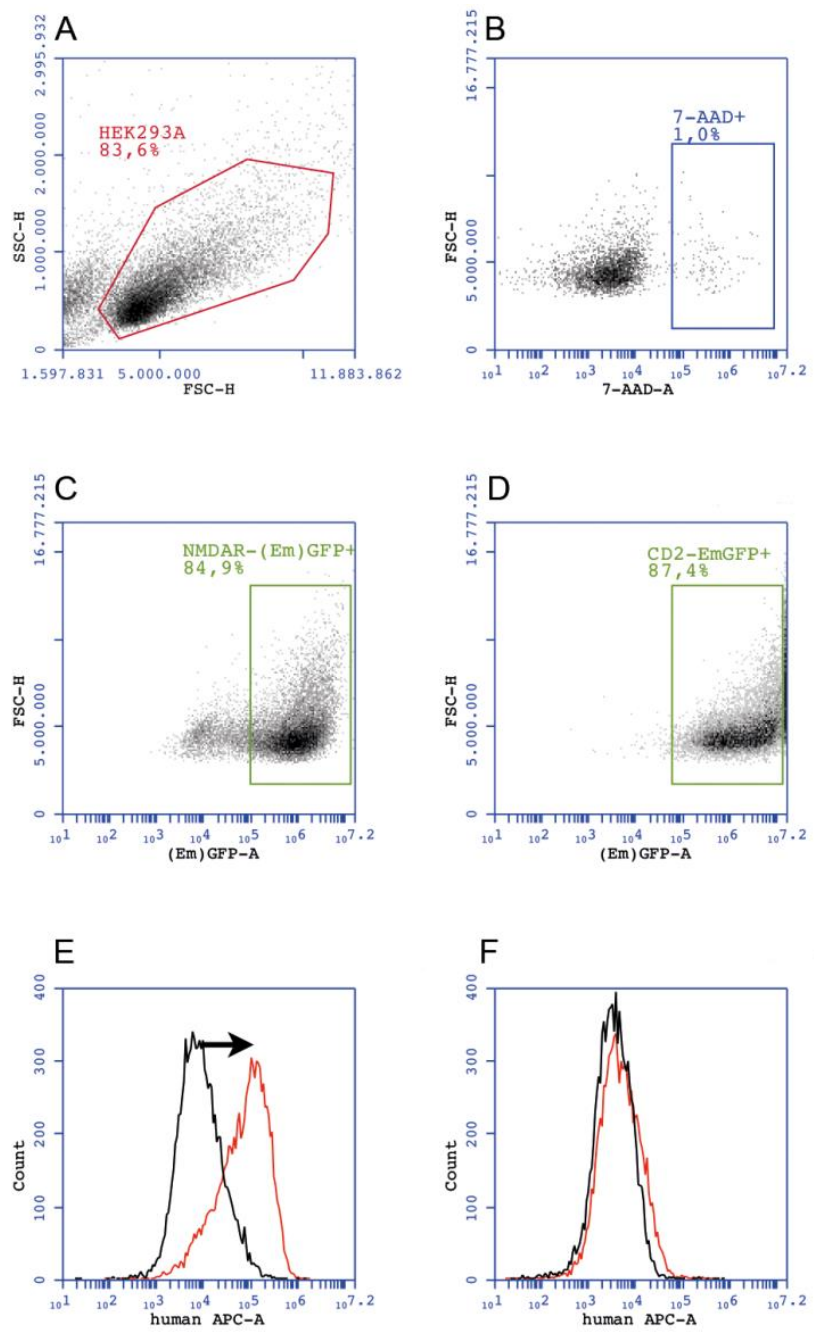

Figure 7: Gating strategy for FACS based analysis.

(A) Gating of the HEK293A main cell population. (B) Exclusion of 7-AAD pos cells. (C)+(D) Gating of $(E m) G F P^{\text {pos }} 7-A A D^{\text {neg }}$ NMDAR and CD2 expressing cells, respectively. The green (“(Em)GFP-A") channel detects both, EmGFP and GFP-tagged proteins. Binding of patient's antibodies to NMDAR results in a difference (arrow) of the APC signal obtained with NMDAR-transfected cells (red line) when compared to the APC signal of CD2transfected cells (black line), which results in $\triangle M F I(E)$. This difference is absent in the serum of a healthy control (F).

7-AAD-A=7-amino-actinomycin D (area). APC-A=allophycocyanin (area). (Em)GFP-A=(emerald) green fluorescent protein (area). $\triangle \mathrm{MFI}=$ delta median fluorescence intensity. $\mathrm{FACS}=$ fluorescence activated cell sorting. $\mathrm{FSC}-\mathrm{H}=$ forward scatter (height). NMDAR=N-methyl-D-aspartate receptor. SSC-H=side scatter (height).

\subsection{Statistics}

Statistical analyses were done using IBM SPSS software (release 22.0, IBM, Armonk, NY) or GraphPad Prism 6 (GraphPad, San Diego, CA).

Analysis of demographic data of patients and NMDAR antibody titers was done using Kruskal-Wallis test, Dunn's multiple comparison post-hoc test, Mann-Whitney $U$ test, 
Fisher's exact test, and Chi-square test. Correlation of parameters was analyzed with Spearman's non-parametric correlation. Receiver operating characteristic (ROC) curve analysis was used to determine cut-off $\triangle \mathrm{MFI}$ for detection of NMDAR antibodies by flow cytometry. Kappa statistics was used to assess the concordance between CBA and FACS.

Statistical significance was defined as two-sided $p$-value $<0.05$ and Bonferroni corrections were applied for multiple comparisons when appropriate. 


\section{$4 \quad$ RESULTS}

\subsection{Expression of functional NMDAR in HEK293A cells}

Expression of NMDAR subunits hGluN1-EmGFP, hGluN2A and hGluN2B-GFP was verified by staining of permeabilized cells with antibodies specific for the respective subunit (see Figure 8). We found an optimal distribution of each subunit by using a molar ratio of hGluN1EmGFP:2A:2B-GFP of 3:1:1 (see Table 5). The overall transfection efficiencies as detected by flow cytometry were $84 \pm 7 \%$ and $93 \pm 6 \%$ for NMDAR-(Em)GFP and CD2-EmGFP, respectively. Survival and transfection rate of NMDAR-(Em)GFP overexpressing cells increased in a dosedependent manner in the presence of the non-competitive NMDAR antagonist (+)-MK-801, indicating the presence of functional NMDAR (Figure 9).

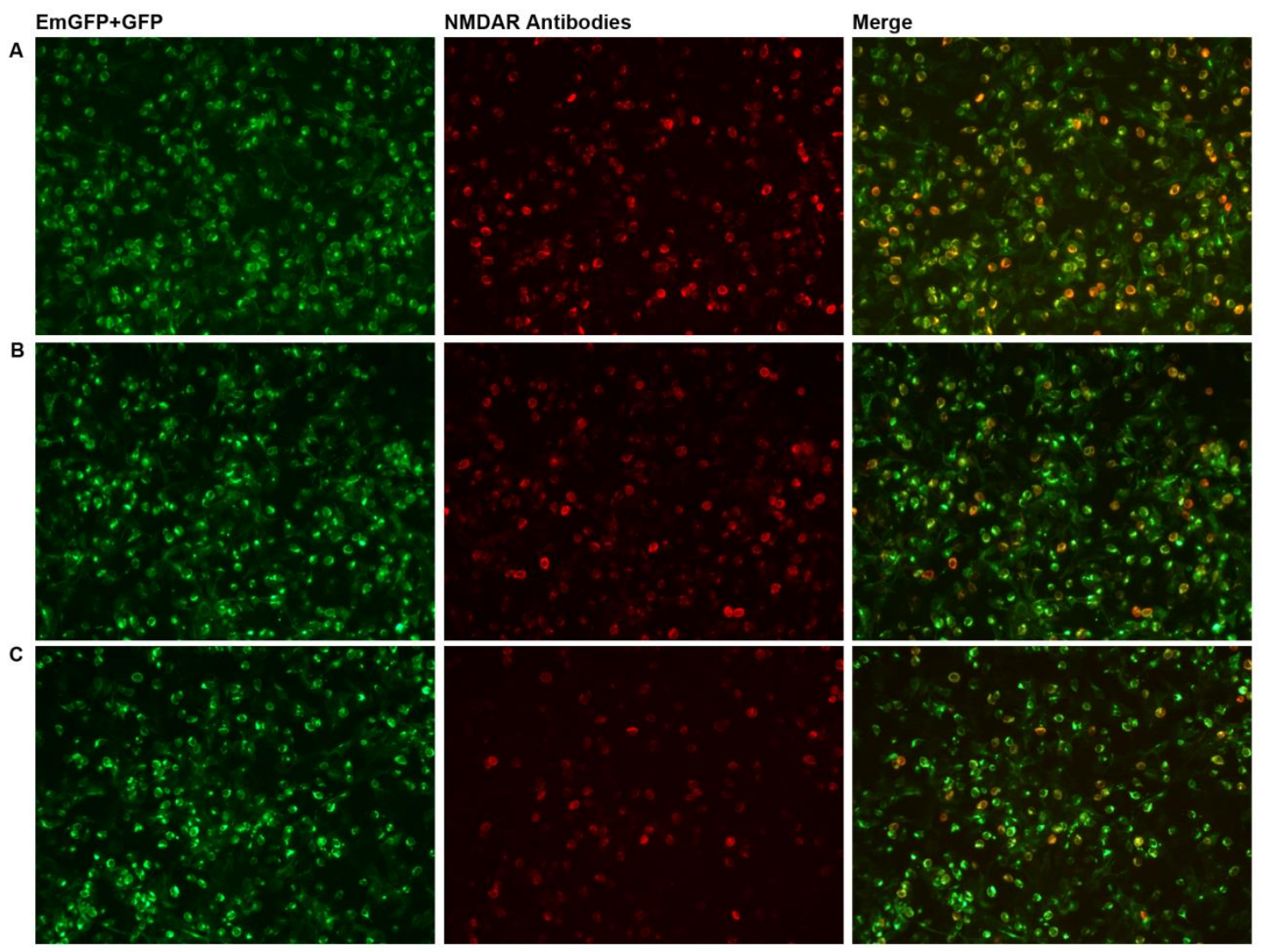

Figure 8: NMDAR-(Em)GFP expressing HEK293A cells.

Antibody staining against hGluN1 (A), hGluN2A (B) and hGluN2B (C) is shown, respectively.

$(E m) G F P=($ emerald) green fluorescent protein. NMDAR $=N$-methyl-D-aspartate receptor. 


\begin{tabular}{|l|l|l|l|l|l|l|l|l|}
\hline \multirow{2}{*}{} & \multicolumn{7}{|l|}{ Ratio GRIN1-EmGFP:2A:2B-GFP } \\
\cline { 2 - 10 } & \multicolumn{2}{|l|}{$3: 1: 1$} & \multicolumn{2}{l|}{ 2:1:1 } & \multicolumn{2}{l|}{$1: 1: 1$} & \multicolumn{2}{l|}{$1: 2: 2$} \\
\hline Antibody & $g$ & $r$ & $g$ & $r$ & $g$ & $r$ & $g$ & $r$ \\
\hline GluN1 & ++ & ++ & ++ & ++ & ++ & ++ & + & - \\
\hline GluN2A & ++ & +++ & ++ & + & ++ & ++ & + & - \\
\hline GluN2B & ++ & + & ++ & - & ++ & - & + & --- \\
\hline
\end{tabular}

Table 5: NMDAR subunit distribution in transfected HEK293A cells.

Different molar ratios of subunit plasmids were used. Intensities of green (g) fluorescence indicating overall transfection efficiency and red ( $r$ ) fluorescence staining indicating expression rate of single subunits were scored from --- (absent) to +++ (very strong).

g=green. GluN=NMDAR subunit. NMDAR=N-methyl-D-aspartate receptor. $r=$ red.

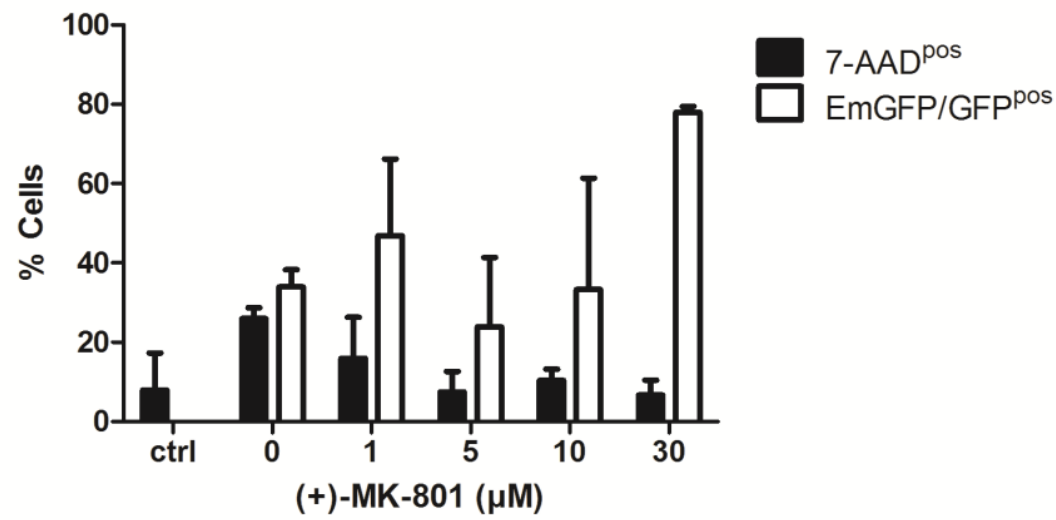

Figure 9: NMDAR survival and transfection rates.

HEK293A cells expressing NMDAR $48 \mathrm{~h}$ post transfection. Dead cells are 7-AAD ${ }^{\text {pos }}$, NMDAR expressing cells EmGFP/GFP ${ }^{\text {pos }}$. Means of two experiments are shown, bars indicate standard deviation.

7-AAD=7-amino-actinomycin D. (Em)GFP=(emerald) green fluorescent protein. NMDAR $=N$-methyl-D-aspartate receptor.

\subsection{Live cell-based immunofluorescence assay}

Sensitivity and specificity of the CBA were determined by applying a discovery group of patients with known NMDAR encephalitis $(n=7)$ as well as neurological $(n=37)$ and healthy controls $(n=32)$ to the test. Validation of the test was performed by testing 32 blinded samples with the CBA. Figure 10 shows the typical antigen distribution of HEK293A cells overexpressing NMDAR tagged with green fluorescent proteins and the staining pattern with serum IgG of an NMDAR encephalitis patient at low magnification and higher magnification 
using a confocal microscope. It clearly shows the colocalization of membrane-associated NMDAR with serum antibodies of the patient but no colocalization with intracellular NMDAR probably residing within the endoplasmic reticulum (Figure 10B). Internalization of NMDAR in response to antibody binding observed in some but not all cells in the live CBA is shown in Figure 10C.

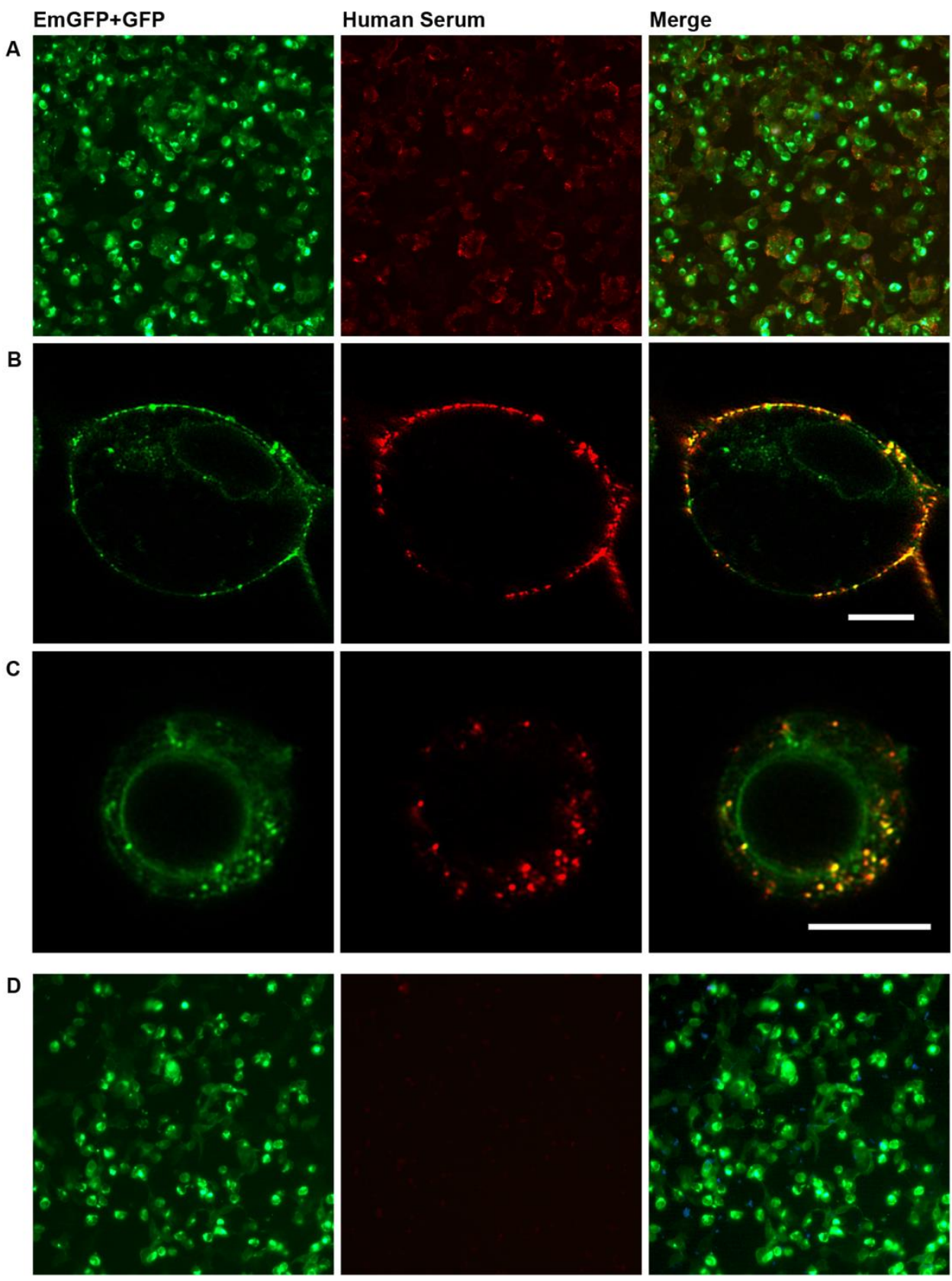

Figure 10: Immunofluorescence CBA for detection of NMDAR antibodies.

HEK293A cells transiently overexpressing functional NMDAR tagged with green fluorescent proteins are shown. Staining pattern of NMDAR antibody positive (A-C) and negative (D) serum. HEK293A cells were transiently transfected to overexpress EmGFP-tagged GluN1, GluN2A and GFP-tagged GluN2B, incubated with diluted human serum and NMDAR antibodies were visualized by a Cy3-conjugated secondary antibody and counterstained with DAPI to detect dead cells (left column: green fluorescence/EmGFP+GFP; middle column: red 
fluorescence/Cy3; right column: overlay of EmGFP/GFP, Cy3 and DAPI (A+D)). (B)+(C) Images show colocalization of NMDAR and serum NMDAR antibodies at high magnification (scale bars: $10 \mu \mathrm{m}$ ). (B) NMDAR antibodies bound to surface of cells. (C) Bound NMDAR antibodies internalized by the cells.

$\mathrm{CBA}=$ cell-based assay. $\mathrm{DAPI}=4^{\prime}, 6$-diamidino-2-phenylindole. (Em)GFP=(emerald) green fluorescent protein. NMDAR=N-methyl-D-aspartate receptor.

\subsection{Flow cytometry based assay}

In a first step different normalization strategies were analyzed to elucidate optimal specificity and reproducibility of the assay. Once the normalization strategy was established, sensitivity and specificity of the flow cytometry based analysis was evaluated by using the same discovery and validation groups as used for validation of the CBA. Both antibody detection methods were finally compared and diagnostic accuracy was assessed.

\subsubsection{Assessment of strategies for analysis of data}

To avoid false positive samples we defined the specificities to be $100 \%$ and assessed the sensitivities for each analysis strategy by ROC curves. Using the $\triangle$ MFI of NMDAR-(Em)GFP and empty EmGFP vector transfected cells resulted in a sensitivity of $85 \%$ (95\% confidence interval (Cl) 54.6-98.1) (Figure 11A), but a very high intra-assay variation of up to $40 \%$. Normalization with CD2-EmGFP transfected cells resulted in a somewhat higher sensitivity of 91\% (95\% Cl 72.0-98.9) (Figure 11B), and a reliable intra-assay variation of 6\%. Therefore, for subsequent measurements CD2-EmGFP transfected cells were used to correct for background reactivity. 
A
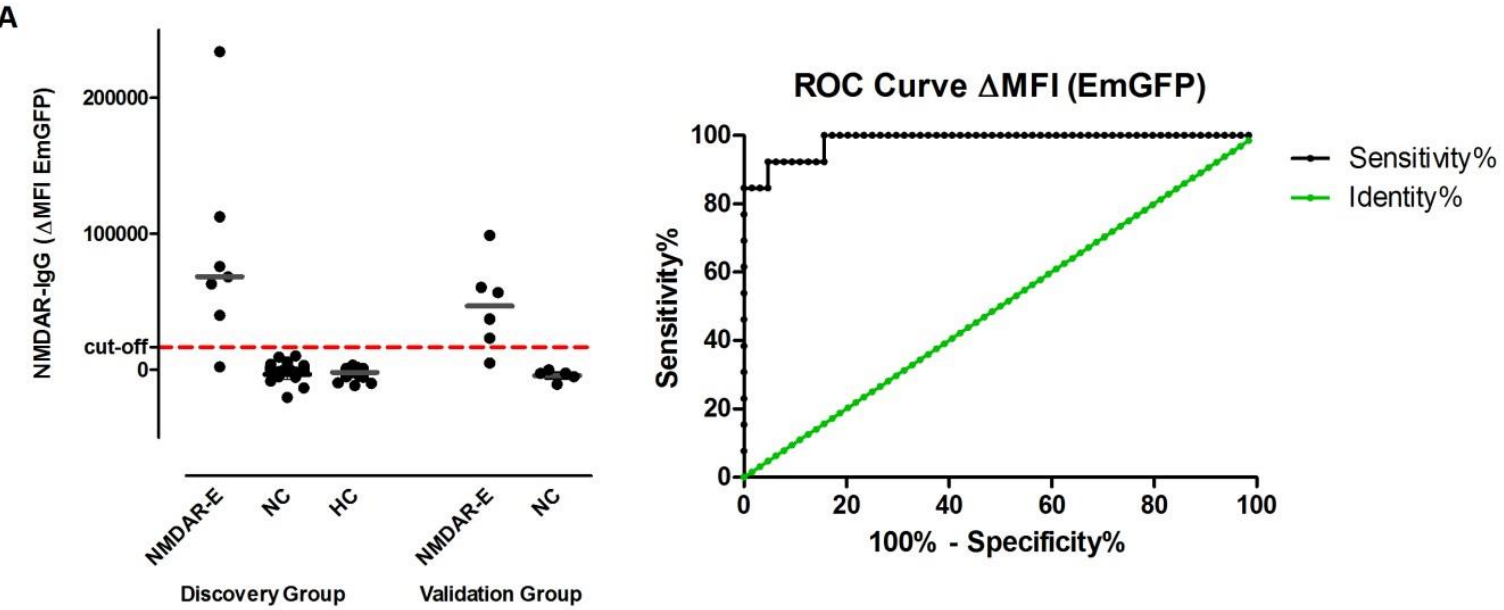

B
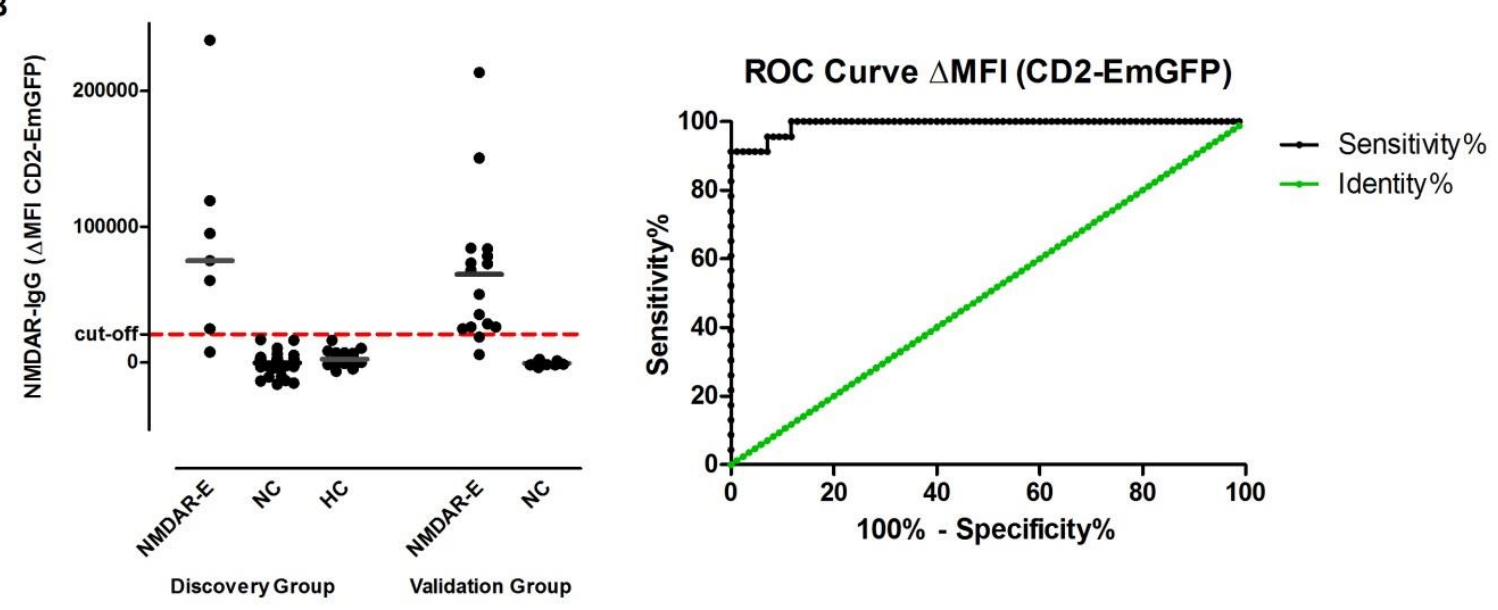

Figure 11: Normalization to EmGFP and CD2-EmGFP expressing cells.

Scatter dot plots and ROC curves of different strategies to normalize data for the FACS assay are shown. (A) Normalization to cells expressing empty EmGFP. (B) Normalization to cells expressing CD2-EmGFP. Respective cut-off values are indicated by red dashed lines.

EmGFP=emerald green fluorescent protein. $\triangle \mathrm{MFI}=$ delta median fluorescence intensity. FACS=fluorescence activated cell sorting. $\mathrm{HC}=$ healthy control. $\mathrm{NC}=$ neurological control. NMDAR-E=N-methyl-D-aspartate receptor encephalitis. ROC=receiver operating characteristic.

Furthermore, we tested whether assessment of background reactivity is necessary at all. However, MFI from NMDAR-(Em)GFP transfected cells only, without any correction for background reactivity, resulted in a sensitivity of $22 \%$ (95\% Cl 7.5-43.7) (Figure 12A). Another possibility would have been to use non-transfected cells as controls. But subtraction of the background MFI that resulted from the signal of non-transfected cells resulted in a sensitivity of $17 \%(95 \% \mathrm{Cl} 5.0-38.8)$ (Figure 12B). Furthermore, since the majority of cells were transfected with NMDAR $(84 \pm 7 \%)$, only few non-transfected cells were available for comparison. Consequently, we found subtraction of the background reactivity resulting from CD2-EmGFP transfected cells to be the most accurate normalization method. When we used 
the mean instead of median fluorescence intensity, sensitivity was $57 \%$ (95\% Cl $34.5-76.8$ )

(Figure 12C).

A
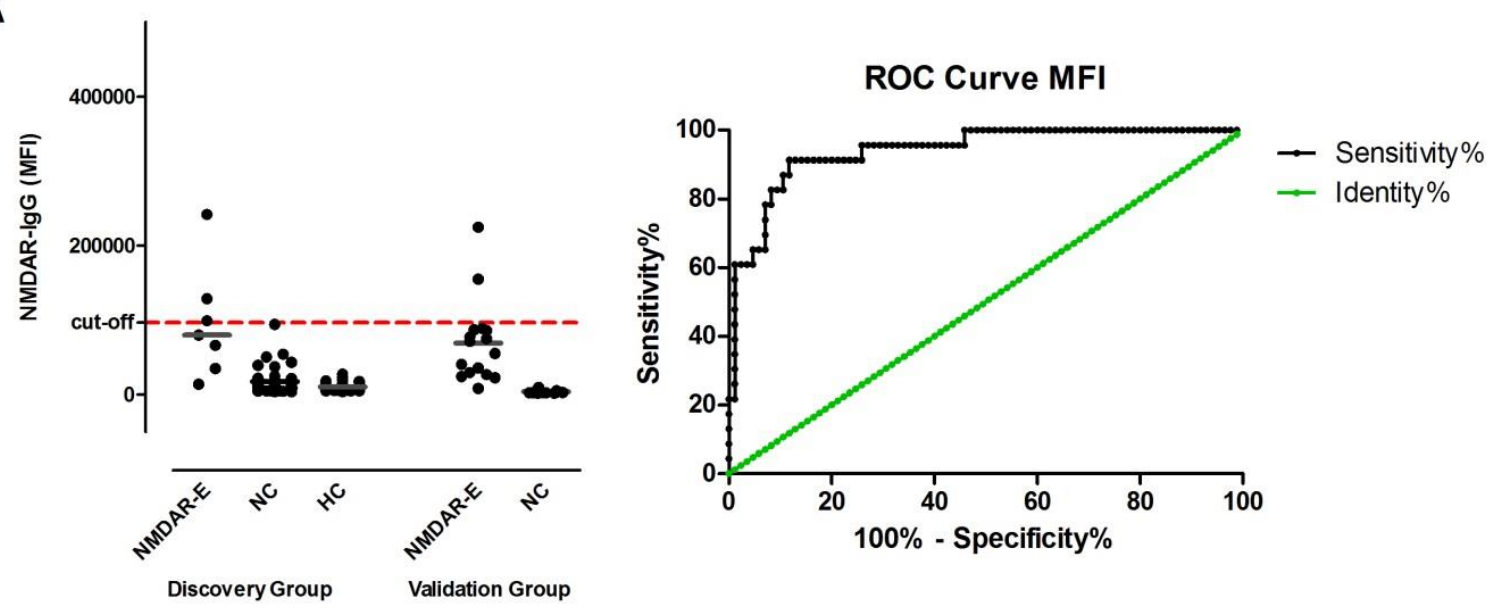

B
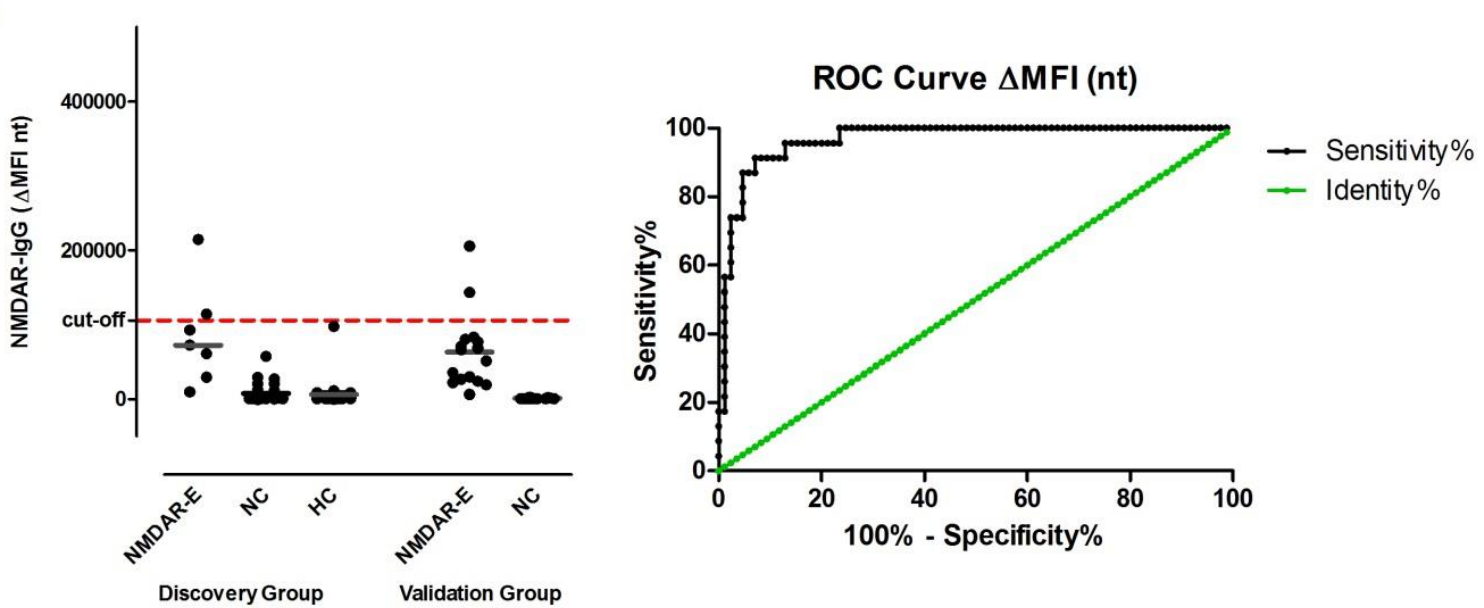

C
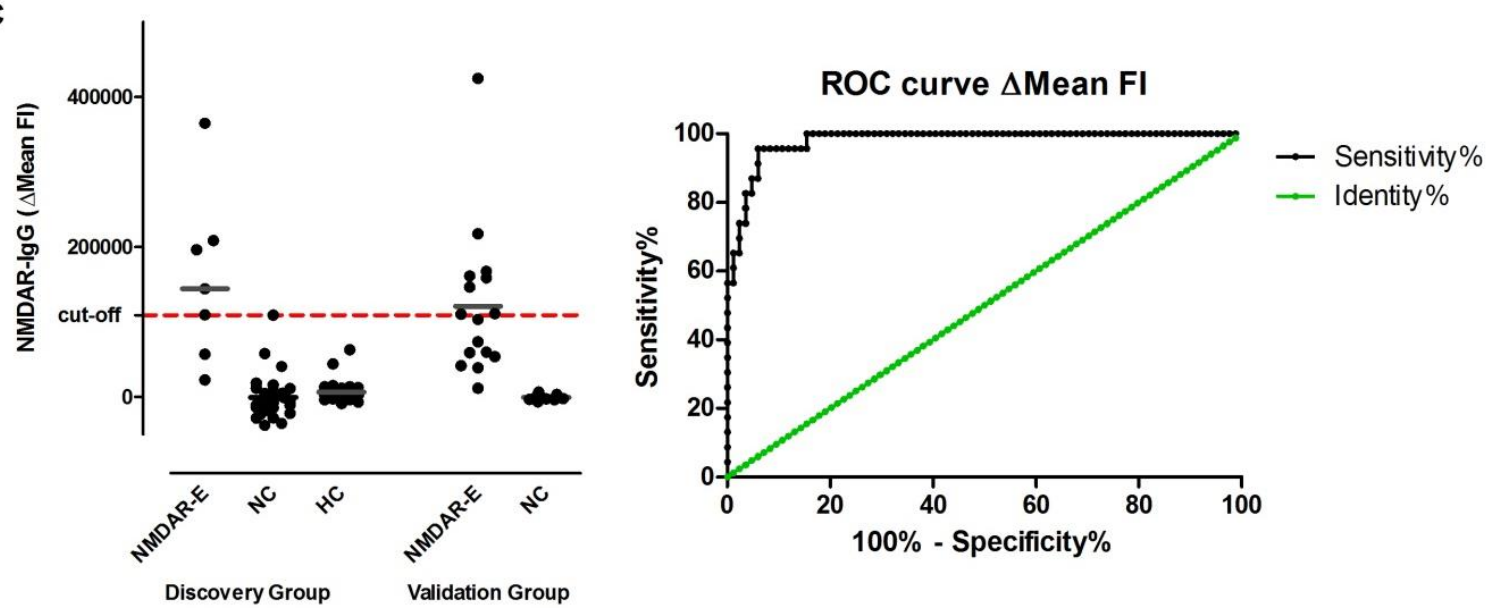

Figure 12: Further normalization strategies for the FACS assay.

Scatter dot plots and ROC curves of different strategies to normalize data for FACS analysis are shown. (A) MFI of specific binding to NMDAR-(Em)GFP overexpressing cells only (no normalization). (B) Normalization to nontransfected (nt) cells. (C) Normalization to cells expressing CD2-EmGFP by using mean fluorescence intensity. Respective cut-off values are indicated by red dashed lines. 
$(\Delta) \mathrm{MFI}=$ (delta) median fluorescence intensity. EmGFP=emerald green fluorescent protein. FACS=fluorescence activated cell sorting. $\mathrm{Fl}=$ fluorescence intensity. $\mathrm{HC}=$ healthy control. $\mathrm{NC}=$ neurological control. NMDAR-E=Nmethyl-D-aspartate receptor encephalitis. $\mathrm{nt}=$ non-transfected. $\mathrm{ROC}=$ receiver operating characteristic.

\subsection{Detection of NMDAR antibodies in the discovery group}

With the CBA, in the discovery group NMDAR antibodies were detected in $7 / 7$ (100\%) patients with NMDAR encephalitis, 0/37 (0\%) neurological controls and 0/32 (0\%) healthy controls (Table 6A). Sensitivity and specificity of the CBA were 100\% (95\% Cl 59.0-100.0 and 94.8-100.0 respectively). Antibody titers in NMDAR encephalitis patients ranged from 1:640 to $1: 20,480$ (median 1:1,280) (Figure 13A).

\begin{tabular}{|c|c|c|c|c|}
\hline \multicolumn{5}{|c|}{ A. Discovery group $(n=76)$} \\
\hline & NMDAR-E & NC & $\mathrm{HC}$ & $p$-value \\
\hline Number & 7 & 37 & 32 & \\
\hline Females & $5(71 \%)$ & $21(57 \%)$ & $27(84 \%)$ & $0.045^{2}$ \\
\hline Age (years) ${ }^{1}$ & $20(5-34)$ & $40(23-69)$ & $43(27-68)$ & $0.001^{3}$ \\
\hline CBA NMDAR IgG & $7(100 \%)$ & $0(0 \%)$ & $0(0 \%)$ & $<0.0001^{2}$ \\
\hline FACS NMDAR IgG & $6(86 \%)$ & $0(0 \%)$ & $0(0 \%)$ & $<0.0001^{2}$ \\
\hline \multicolumn{5}{|c|}{ B. Validation group ( $n=32$ ) } \\
\hline & NMDAR-E & NC & & p-value \\
\hline Number & 16 & 16 & & \\
\hline Females & $11(69 \%)$ & $9(56 \%)$ & & $0.716^{4}$ \\
\hline Age (years) ${ }^{1}$ & $16(3-42)$ & $28(4-70)$ & & $0.001^{5}$ \\
\hline CBA NMDAR IgG & $16(100 \%)$ & $0(0 \%)$ & & $<0.0001^{4}$ \\
\hline FACS NMDAR IgG & $14(87 \%)$ & $0(0 \%)$ & & $<0.0001^{4}$ \\
\hline
\end{tabular}

Table 6: Demographic data of patients and controls.

${ }^{1}$ Data are shown as median (range), $\mathrm{p}$-value: groups were compared using

${ }^{2}$ Chi-Square test and ${ }^{3}$ Kruskal-Wallis test, ${ }^{4}$ Fisher's exact test and ${ }^{5}$ Mann Whitney-U test. Significant differences of gender and age between the groups result from disease specific gender and age distributions.

$\mathrm{CBA}=$ cell-based assay. $\mathrm{FACS}=$ fluorescence activated cell sorting. $\mathrm{HC}=$ healthy control. NC=neurological control. NMDAR-E=N-methyl-D-aspartate receptor encephalitis. 
A

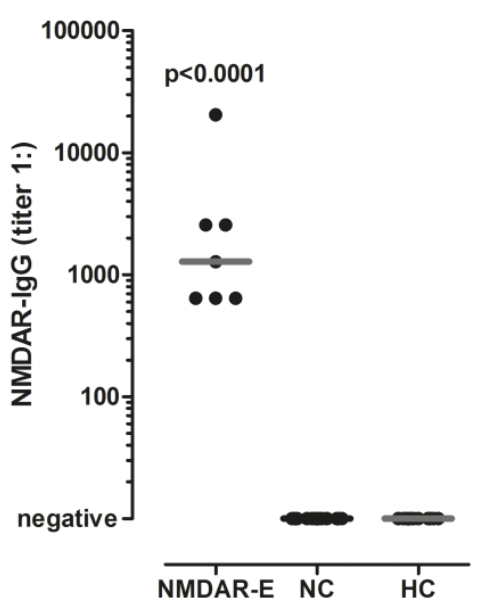

\section{B}

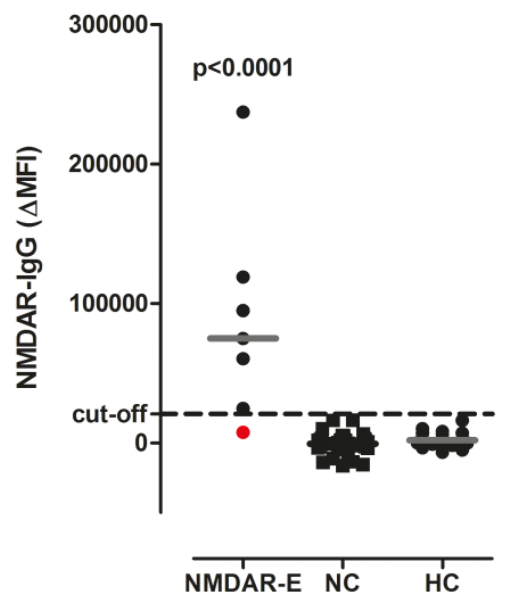

Figure 13: NMDAR IgG antibody titers and $\triangle M F I$ values in the discovery group.

(A) Using the CBA serum NMDAR IgG antibodies were exclusively detected in serum samples of patients with NMDAR encephalitis, but not in neurological and healthy controls. (B) In the FACS assay serum NMDAR IgG $\triangle M F I$ levels were higher in patients with NMDAR encephalitis than in neurological and healthy controls, but one serum positive for NMDAR antibodies was missed with this method (shown in red). The cut-off $\Delta M F I$ value of 20,700 is indicated by a dashed horizontal line. Antibody titers and $\Delta M F I$ values were compared using a nonparametric test (Kruskal Wallis test) and overall $p$-values are shown in the graphs. Medians are indicated by horizontal bars.

$\mathrm{CBA}=$ cell-based assay. $\triangle \mathrm{MFI}=$ delta median fluorescence intensity. $\mathrm{FACS}=$ fluorescence activated cell sorting. $\mathrm{HC}=$ healthy control. $\mathrm{NC}=$ neurological control. NMDAR-E=N-methyl-D-aspartate receptor encephalitis.

Gating and analysis strategy for NMDAR-(Em)GFP and CD2-EmGFP expressing cells of the FACS based assay is shown in Figure 7. In the discovery group the $\triangle \mathrm{MFI}$ was significantly higher in NMDAR patients (median 74,938, range 7,681 to 237,432) compared to neurological controls (median -401 , range $-16,158$ to 16,646 ) and healthy controls (median 1,076 , range $-6,701$ to 16,269 ; Figure $13 B$ ). Using ROC analysis a cut-off $\Delta M F I$ value of 20,700 was determined (area under the curve 0.988, p<0.0001). NMDAR antibodies were detected in 6/7 (86\%) NMDAR encephalitis patients, $0 / 37(0 \%)$ neurological and 0/32 (0\%) healthy controls (Table 6A). Therefore, with a specificity of $100 \%(95 \% \mathrm{Cl} 94.8-100.0)$ the FACS based assay had a sensitivity of $86 \%$ (95\% Cl 42.1-99.6). Intra- and inter-assay variations (coefficient of variation) were $6 \%$ and $22-25 \%$ respectively.

\subsection{Detection of NMDAR antibodies in the validation group}

In a next step the CBA was applied to 32 blinded samples of the validation group from Barcelona. All 16 patients with NMDAR encephalitis were positive for NMDAR antibodies and all 16 neurological controls were seronegative (Table 6B). Antibody titers in NMDAR encephalitis patients ranged from $1: 80$ to $1: 2,560$ (median 1:640) (Figure 14A). Thus, the 
sensitivity and specificity of the CBA of $100 \%$ were confirmed in these blinded samples (95\%

Cl 79.4-100.0).
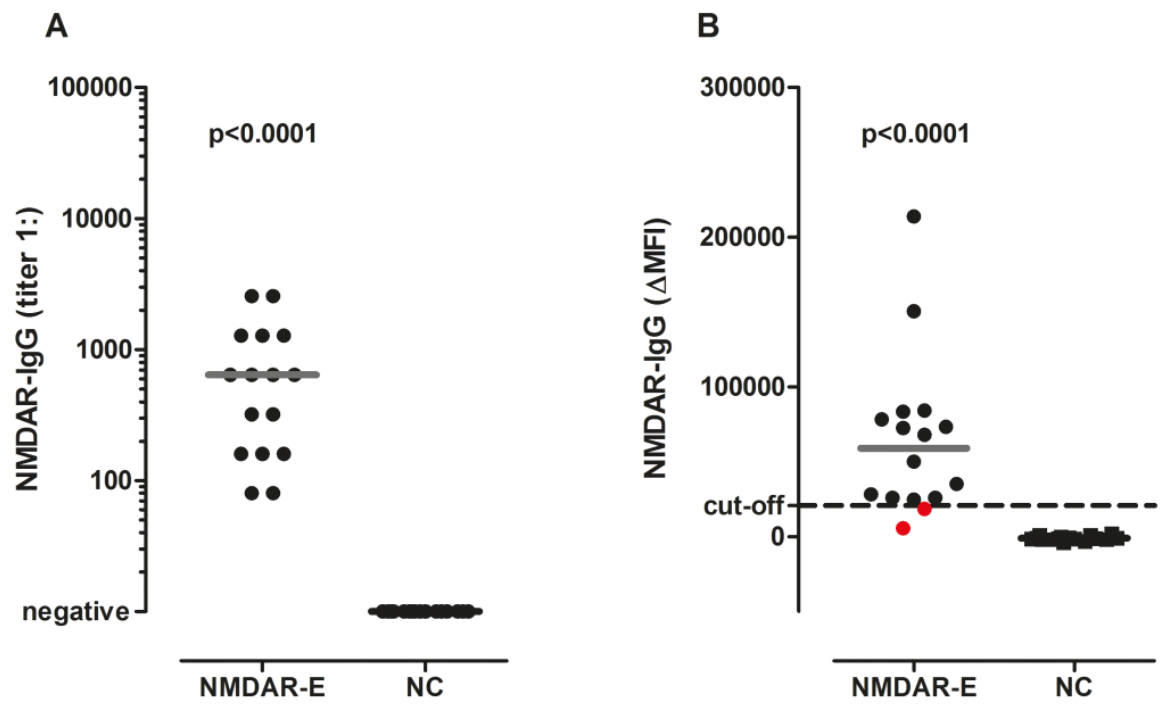

Figure 14: NMDAR IgG antibody titers and $\triangle M F I$ values in the validation group.

(A) With the CBA all sera of NMDAR encephalitis patients were positive for NMDAR IgG antibodies, but none of the neurological controls. (B) Using the FACS assay serum NMDAR IgG $\triangle M F I$ levels were higher in patients with NMDAR encephalitis than in neurological controls, but again two sera positive for NMDAR antibodies were missed with this method (shown in red). The cut-off $\triangle M F I$ value of 20,700 as determined in the discovery group is indicated by a dashed horizontal line. Antibody titers and $\triangle \mathrm{MFI}$ values were compared using a nonparametric test (Mann-Whitney $U$ test) and overall p-values are shown in the graphs. Medians are indicated by horizontal bars.

$\mathrm{CBA}=$ cell-based assay. $\triangle \mathrm{MFI}=$ delta median fluorescence intensity. $F A C S=$ fluorescence activated cell sorting. $\mathrm{NC}=$ neurological control. NMDAR-E=N-methyl-D-aspartate receptor encephalitis.

Likewise, the FACS assay was applied to 32 blinded samples of the validation group from Barcelona. 14/16 patients with NMDAR encephalitis (87\%) were positive for NMDAR antibodies using the cut-off value determined in the discovery group and all 16 neurological controls were seronegative (Table $6 \mathrm{~B}$ ). The $\triangle \mathrm{MFI}$ was significantly higher in NMDAR patients (median 59,085, range 5,784 to 213,910 ) compared to neurological controls (median -1,239, range $-3,751$ to 2,169 , Figure $14 \mathrm{~B}$ ). Thus, the sensitivity and specificity of the FACS assay were equally high in the validation group ( $95 \% \mathrm{Cl} 61.7-98.5$ and $79.4-100.0$ respectively) as in the discovery group.

\subsection{Comparison of CBA and FACS}

Finally, CBA and FACS assays were compared to assess diagnostic accuracy of the tests. Table 7 shows specificities and sensitivities of both testing methods using all samples combined 
from both groups. The concordance kappa value between CBA and FACS was 0.943 $(p<0.0001) .85$ samples were seronegative and 20 samples were seropositive with both methods. Three samples were seropositive in the CBA, but seronegative in the FACS assay. Correlation of antibody titers of the CBA with $\triangle \mathrm{MFI}$ obtained by FACS based analysis was 0.697 (Spearman's $\rho ; p<0.0001 ;$ Figure 15).

\begin{tabular}{|l|l|l|l|l|l|l|}
\hline & $\begin{array}{l}\text { NMDAR-E } \\
(\mathbf{n}=\mathbf{2 3})\end{array}$ & $\begin{array}{l}\text { Controls } \\
(\mathbf{n}=\mathbf{8 5})\end{array}$ & $\begin{array}{l}\text { Sensitivity }^{\mathbf{1}} \\
\mathbf{( 9 5 \%} \mathrm{Cl})\end{array}$ & $\begin{array}{l}\text { Specificity }^{\mathbf{1}} \\
\mathbf{( 9 5 \% ~ C l )}\end{array}$ & $\begin{array}{l}\text { AUC }^{\mathbf{1}} \\
\mathbf{( 9 5 \% ~ C l )}\end{array}$ & p-value $^{\mathbf{1}}$ \\
\hline CBA & 23 & 0 & $\begin{array}{l}100.0 \% \\
(85.1-100.0)\end{array}$ & $\begin{array}{l}100.0 \% \\
(95.7-100.0)\end{array}$ & $\begin{array}{l}1.000 \\
(1.000-1.000)\end{array}$ & $<0.0001$ \\
\hline FACS & 20 & 0 & $\begin{array}{l}87.0 \% \\
(66.4-97.2)\end{array}$ & $\begin{array}{l}100.0 \% \\
(95.7-100.0)\end{array}$ & $\begin{array}{l}0.992 \\
(0.979-1.005)\end{array}$ & $<0.0001$ \\
\hline
\end{tabular}

Table 7: Overall sensitivity and specificity of NMDAR antibody tests.

All samples from the discovery and validation groups are combined in this analysis. ${ }^{1}$ Data were analyzed using ROC analysis.

$A \cup C=$ area under the curve. $C B A=$ cell-based assay. $C l=$ confidence interval. $F A C S=$ fluorescence activated cell sorting. $N M D A R-E=N$-methyl-D-aspartate receptor encephalitis. $R O C=$ receiver operating characteristic.

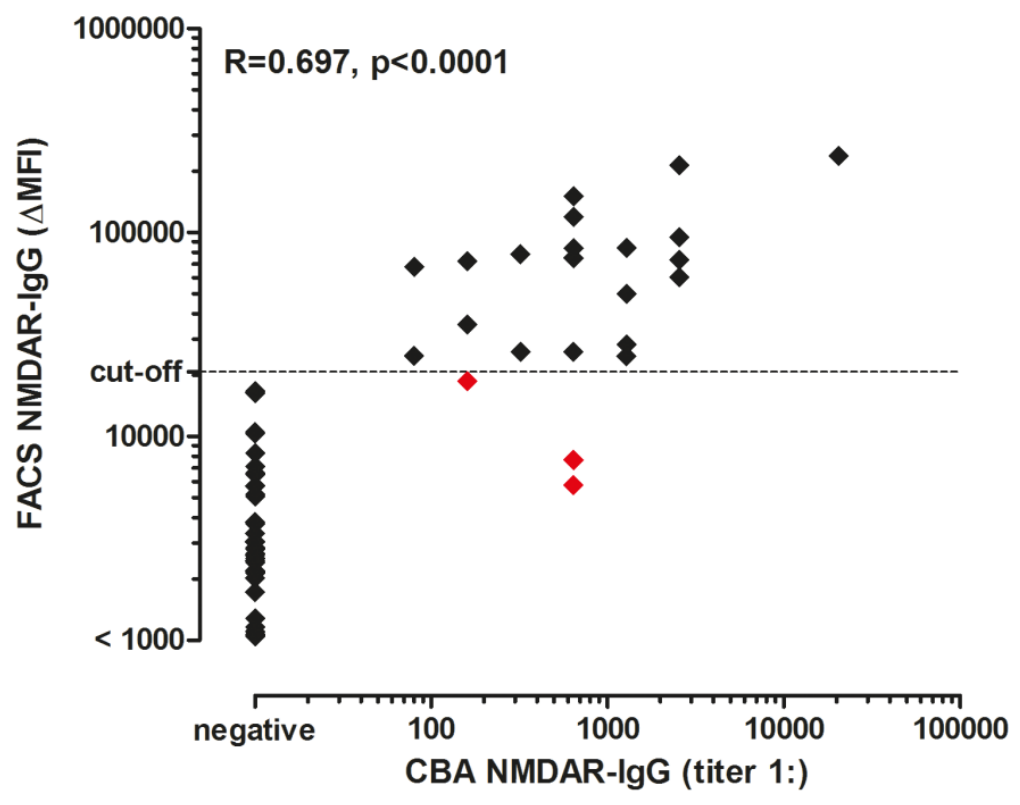

Figure 15: Correlation of NMDAR IgG titers and $\triangle M F I$ values.

IgG titers were determined by CBA, $\triangle \mathrm{MFI}$ values by the FACS assay. The cut-off value $(20,700 \Delta \mathrm{MFI}$, determined by the FACS assay) is indicated by the dashed horizontal line. Correlation of antibody titers and $\Delta \mathrm{MFI}$ values were calculated using non-parametric Spearman correlation. Correlation coefficient $(R)$ and the $p$-value are shown in the graph. False negative samples in the FACS assay are depicted in red. In total, 49 samples had a $\triangle \mathrm{MFI}$ value $<1,000$, which were all negative in the $\mathrm{CBA}$.

$\mathrm{CBA}=$ cell-based assay. $\triangle \mathrm{MFI}=$ delta median fluorescence intensity. FACS=fluorescence activated cell sorting. NMDAR=N-methyl-D-aspartate receptor. $\mathrm{R}=$ correlation coefficient. 
To elucidate why three positive samples could not be detected in the FACS assay, we compared $\triangle \mathrm{MFI}$ and MFI values resulting from IgG binding to NMDAR and CD2 transfected cells alone. Whereas $\triangle \mathrm{MFI}$ and MFI values obtained by binding of IgG to NMDAR transfected cells were significantly $(p<0.01)$ lower in false negative samples, MFI obtained by binding of IgG to CD2 transfected cells did not differ between the groups (Figure 16). Therefore, missing of positive samples cannot be attributed to high background fluorescence intensity, since it was comparable across all samples.

A

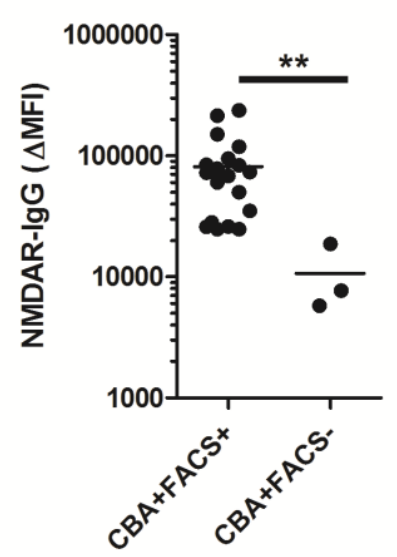

B

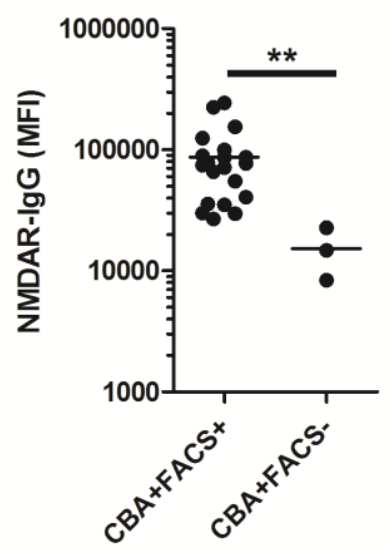

C

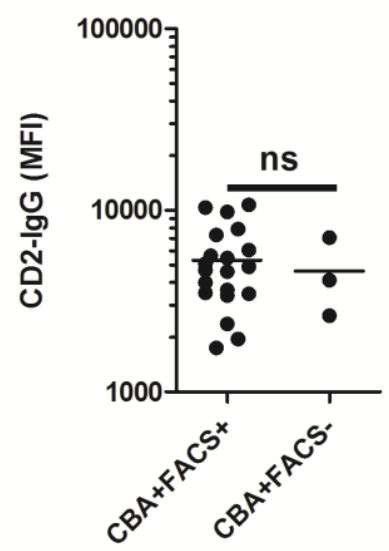

Figure 16: Comparison of $\triangle \mathrm{MFI}$ and MFI obtained by FACS analysis.

For this analysis, NMDAR-IgG positive samples as determined by CBA were used. CBA+FACS+ show samples where NMDAR antibodies were detected with both methods, CBA+FACS- represent samples that were positive in the CBA, but (false) negative in the FACS. (A) $\triangle M F I$ (NMDAR-CD2 IgG). (B) MFI of IgG binding to NMDAR only. (C) MFI IgG binding to CD2 only (note that the scale of the $y$-axis has changed). Medians are indicated by horizontal bars. $\triangle \mathrm{MFI}$ and MFI values were compared using a non-parametric test (Mann-Whitney $U$ test). $* * p<0.01$

$\mathrm{CBA}=$ cell-based assay. $(\Delta) \mathrm{MFI}=($ delta) median fluorescence intensity. FACS=fluorescence activated cell sorting. NMDAR $=N$-methyl-D-aspartate receptor. ns=not significant.

We next analyzed the distribution of NMDAR-(Em)GFP overexpressing HEK293A cell populations resulting from antibody binding of an NMDAR-IgG positive serum. Two distinct (Em)GFP positive cell populations were observed in NMDAR antibody positive samples which differed mainly in their size and APC fluorescence signal (Figure 17). We concluded that those cell populations most likely represent two different cell types: large cells with antibodies bound to the cell surface; and smaller cells with internalized NMDAR in response to antibody binding and/or cells retaining NMDAR in the endoplasmic reticulum, which can also be seen in Figure 10. Comparison of (Em)GFP and APC fluorescence intensities resulting from the FACS based assay of human serum samples with different amounts of NMDAR 
antibodies revealed that the shift to a positive APC signal is not distinct enough in a false negative sample, when using the very same batch of transfected and trypsinized cells (Figure 18).
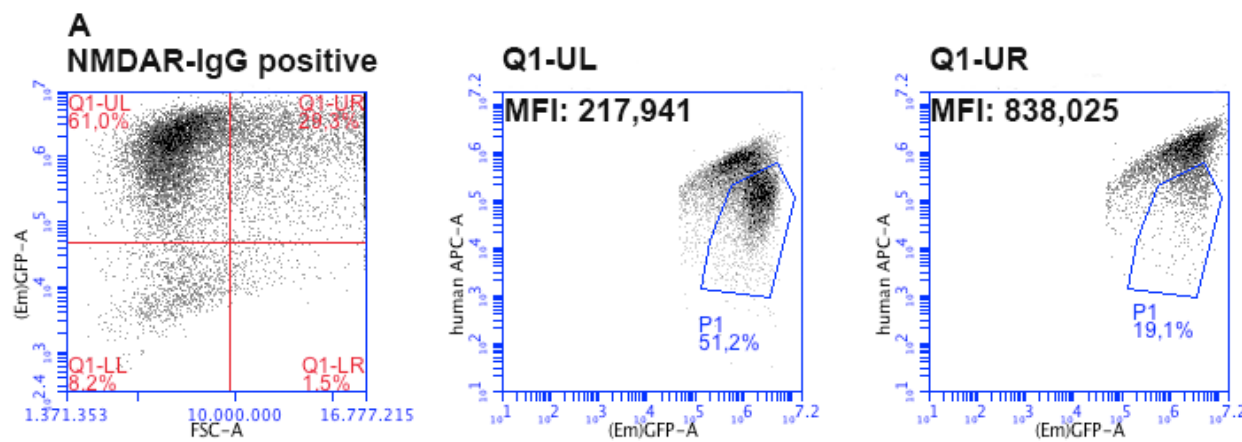

B
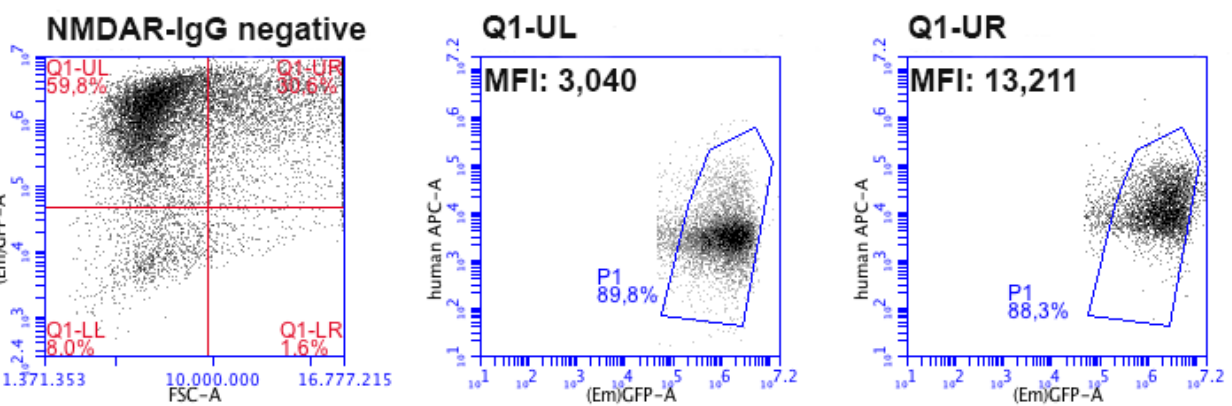

Figure 17: Distribution of APC fluorescence according to cell size.

An NMDAR-IgG positive (A) and negative (B) sample is shown. Left column: gating of (Em)GFP-positive NMDAR expressing HEK293A cells (excluding dead cells) to discriminate small (Q1-UL) and large (Q1-UR) cells. Middle column: relative APC fluorescence signal of small cells (Q1-UL). A second population with lower APC fluorescence signal is highlighted in blue (P1). Right column: relative APC fluorescence signal of large cells (Q1UR). P1 decreased from $51.2 \%$ to $19.1 \%$ in the NMDAR-IgG positive sample. Overall MFI values are shown in the respective graphs.

$A P C-A=a l l o p h y c o c y a n i n$ (area). (Em)GFP-A=(emerald) green fluorescent protein (area). FSC-A=forward scatter (area). MFI=median fluorescence intensity. NMDAR $=N$-methyl-D-aspartate receptor. Q1-UL/UR=upper left/right quadrant. 

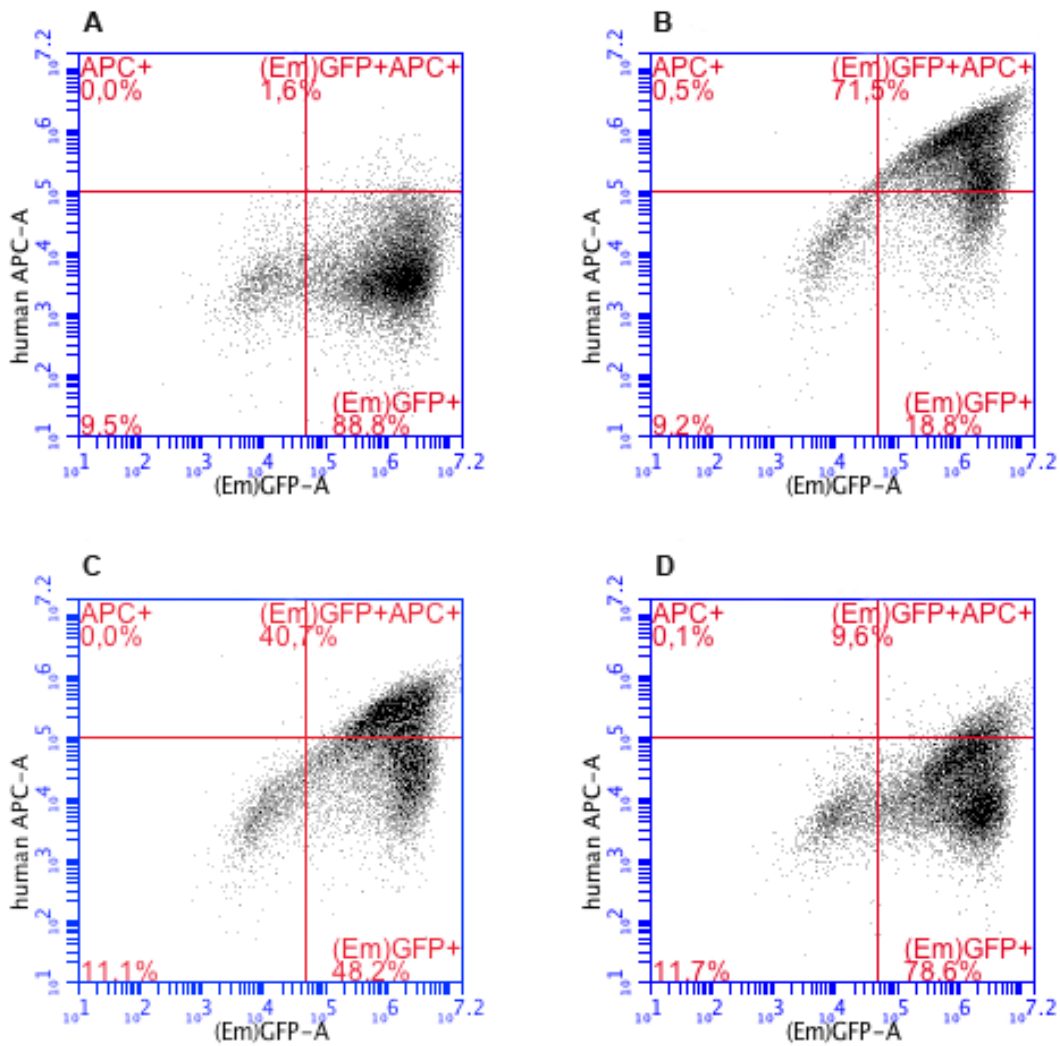

Figure 18: (Em)GFP and APC fluorescence in antibody positive and negative samples.

NMDAR transfected HEK293A cells (EmGFP/GFP positive) were incubated with human serum negative for NMDAR antibodies (A), or human serum high (B; CBA titer 1:20,480) and medium (C; CBA titer 1:640) positive for NMDAR antibodies which were detected by an APC-conjugated secondary antibody. The population within the upper right quadrant ( $\left.(E m) G F P^{\text {pos }} A P C^{\text {pos }}\right)$ represents the cell population expressing NMDAR with bound NMDAR antibodies. (D) shows the cells incubated with a serum negative in the FACS based assay, but positive in the CBA (1:640). Consider that positivity was not determined by the percentage of double positive cells, but the $\triangle$ MFI (A: -1,835; B: 290,060; C: 75,976; D: 8,160).

APC-A=allophycocyanin (area). $\quad \mathrm{CBA}=$ cell-based assay. $\triangle \mathrm{MFI}=$ delta median fluorescence intensity. $($ Em)GFP(-A)=(emerald) green fluorescent protein (area). FACS=fluorescence activated cell sorting. NMDAR=Nmethyl-D-aspartate receptor.

\subsection{Repeat FACS analysis of a subsample using a lower serum dilution}

Aiming to increase the sensitivity by using a lower serum dilution, we reanalyzed 21 samples, including nine positive (six and three from the discovery and validation group, respectively) and 12 negative (each six healthy and neurological controls from the discovery group) for NMDAR antibodies, and compared the previously used 1:100 dilution to a dilution of 1:20. For this comparison, we focused on samples that were false negative or close to the cut-off value during the initial antibody testing with the FACS assay. Using either dilution $8 / 9$ (89\%) NMDAR antibody positive and 0/12 (0\%) antibody negative samples were detected by the FACS assay. Sensitivity and specificity of both dilutions were therefore comparable to 
previously obtained results. Interestingly, the cut-off $\Delta \mathrm{MFI}$ was lower with this set of experiments using the 1:100 dilution compared to previously obtained results (Figure 19), underlining the high inter-assay variation of the FACS based assay. Correlation of $\triangle \mathrm{MFI}$ at both dilutions was 0.9558 (Spearman's $p ; p<0.0001$; Figure 19B). 
A $1: 100$ $1: 20$
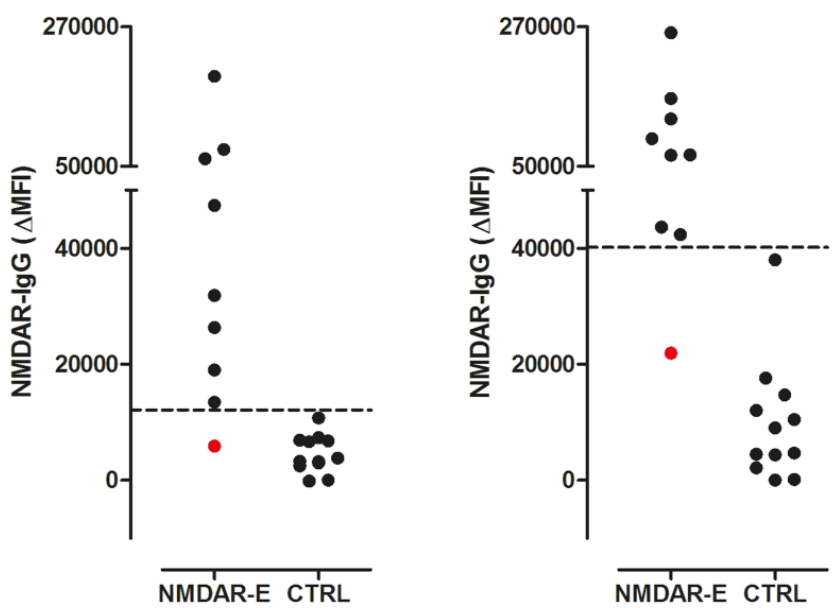

\begin{tabular}{|l|l|l|l|}
\hline \multirow{2}{*}{ Serum Dilution (1:) } & & \multicolumn{2}{|l|}{ NMDAR antibody positive } \\
\cline { 3 - 4 } & Cut-off $\Delta \mathbf{M F I}^{\mathbf{1}}$ & NMDAR-E & CTRL \\
\hline 100 & 12,106 & $8 / 9$ & $0 / 12$ \\
\hline 20 & 40,162 & $8 / 9$ & $0 / 12$ \\
\hline
\end{tabular}

B

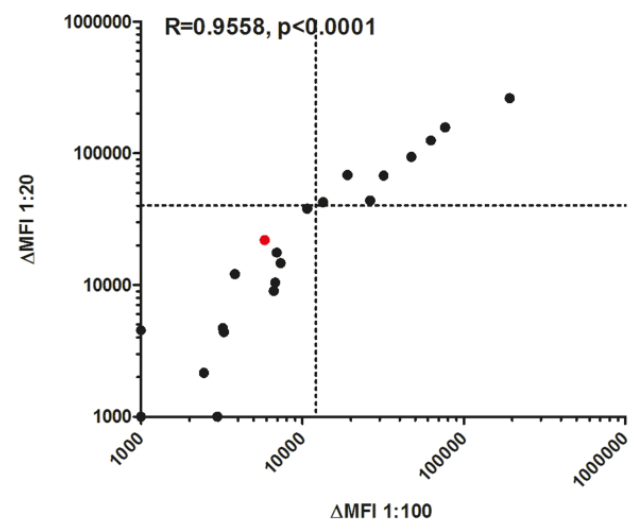

Figure 19: NMDAR antibody $\triangle M F I$ at different serum dilutions.

NMDAR antibody positive $(n=9)$ and negative $(n=12)$ sera as determined by CBA are shown. (A) Serum dilutions of 1:100 and 1:20 are shown. Respective cut-off $\triangle \mathrm{MFI}$ values are indicated by dashed horizontal lines. The table shows cut-off $\triangle \mathrm{MFI}$ and numbers of samples tested positive for NMDAR antibodies by the FACS assay at different serum dilutions. ${ }^{1}$ Data were analyzed using ROC analysis. (B) Correlation of $\triangle M F I$ obtained by using 1:100 and 1:20 dilution in the re-evaluation group of NMDAR positive samples in the CBA. Respective cut-off values are indicated by dashed lines. The one false negative sample at both dilutions is shown in red. For a better graphical presentation, $\Delta \mathrm{MFI}$ values below 1,000 were set to 1,000 . Correlation of all exact $\Delta M F I$ values were calculated using non-parametric Spearman correlation. Correlation coefficient $(R)$ and the $p$-value are shown in the graph. Here, the cut-off at the 1:100 dilution differs from the original cut-off $(20,700)$, since a different batch of cells was used for analysis of this population.

$\mathrm{CBA}=$ cell-based assay. $\mathrm{CTRL}=$ control sample. $\triangle \mathrm{MFI}=$ delta median fluorescence intensity. NMDAR-E=N-methyl-Daspartate receptor encephalitis. $\mathrm{R}=$ correlation coefficient. $\mathrm{ROC}=$ receiver operator characteristic. 
Analysis of the re-evaluation group further demonstrated the high variability of the testing system. The inter-assay variation after including new data from the re-evaluation group increased considerably with coefficients of variation of up to $36 \%$. The variability was not correlated with CBA titers ( $R=0.3024$; Spearman's $\rho$; $p=0.4306$; Figure 20).

A

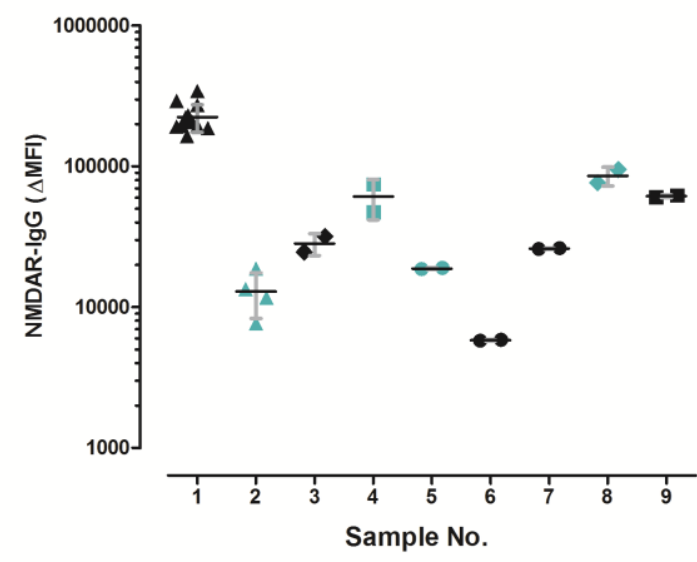

B

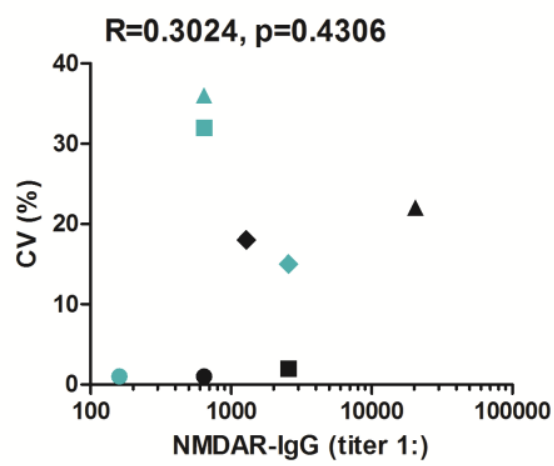

Figure 20: Inter-assay variation of $\triangle \mathrm{MFI}$.

Data were obtained from two independent analysis batches. (A) Individual $\triangle M F I$ variability of the 9 samples positive for NMDAR antibodies in the CBA. Means are shown as horizontal lines, standard deviations are indicated by grey bars. (B) Correlation of individual $\triangle M F I$ variability and respective NMDAR-IgG titers in the CBA. The correlation was calculated using non-parametric Spearman correlation. Correlation coefficient $(R)$ and the p-value are shown in the graph. Symbols represent matching samples in (A) and (B). Sample Nos. 6 and 7 (A) have the same CV and NMDAR-IgG titer (B).

$\mathrm{CBA}=$ cell-based assay. $\mathrm{CV}=$ coefficient of variation. $\triangle \mathrm{MFI}=$ delta median fluorescence intensity. NMDAR- $N$ methyl-D-aspartate receptor. $\mathrm{R}=$ correlation coefficient.

\subsection{NMDAR antibodies in demyelinating diseases}

Demographic data and antibody seroprevalence of all patients and controls are shown in Table 8. Overall, disease relevant autoantibodies against NMDAR, MOG, or AQP4 were found in 101/385 (26\%) patients with NMDAR encephalitis, NMOSD, ADEM, CIS, MS, SLE, or other neurological diseases, and in 0/48 (0\%) healthy controls. 


\begin{tabular}{|l|l|l|l|l|l|l|}
\hline \multicolumn{7}{|l|}{ Patients (n=385) and healthy controls (n=48) } \\
\hline & Number & Females & Age (years) & NMDAR IgG & $\begin{array}{l}\text { MOG IgG } \\
(\geq 1: 160)\end{array}$ & AQP4 IgG \\
\hline NMDAR-E & 25 & $17(68 \%)$ & $17(3-42)$ & $25(100 \%)$ & $0(0 \%)$ & $0(0 \%)$ \\
\hline NMOSD & 51 & $40(78 \%)$ & $47(3-81)$ & $0(0 \%)$ & $4(8 \%)$ & $36(71 \%)$ \\
\hline ADEM & 55 & $29(53 \%)$ & $7(2-52)$ & $0(0 \%)$ & $28(51 \%)$ & $0(0 \%)$ \\
\hline CIS & 29 & $22(76 \%)$ & $16(4-51)$ & $0(0 \%)$ & $2(7 \%)$ & $0(0 \%)$ \\
\hline MS & 97 & $57(59 \%)$ & $40(5-71)$ & $1(1 \%)$ & $1(1 \%)$ & $0(0 \%)$ \\
\hline SLE & 25 & $22(88 \%)$ & $40(22-69)$ & $0(0 \%)$ & $2(8 \%)$ & $0(0 \%)$ \\
\hline OND & 103 & $38(37 \%)$ & $17(1-89)$ & $0(0 \%)$ & $2(2 \%)$ & $0(0 \%)$ \\
\hline HC & 48 & $40(83 \%)$ & $43(21-68)$ & $0(0 \%)$ & $0(0 \%)$ & $0(0 \%)$ \\
\hline p-value & & $<0.0001^{2}$ & $<0.0001^{3}$ & $<0.0001^{2}$ & $<0.0001^{2}$ & $<0.0001^{2}$ \\
\hline Total & 433 & $265(61 \%)$ & $30(1-89)$ & $26(6 \%)$ & $39(9 \%)$ & $36(8 \%)$ \\
\hline
\end{tabular}

Table 8: Demographics and serum antibodies of all patients and controls.

${ }^{1}$ Data are shown as median (range), $p$-value: groups were compared using ${ }^{2}$ Chi-Square test and ${ }^{3}$ KruskalWallis test. Significant differences of gender and age between the groups result from disease specific gender and age distributions.

$A D E M=a c u t e$ disseminated encephalomyelitis. AQP4=aquaporin 4. $\mathrm{CIS}=$ clinically isolated syndrome. $\mathrm{HC}=$ =healthy control. MOG=myelin oligodendrocyte glycoprotein. MS=multiple sclerosis. $\mathrm{NMDAR}(-\mathrm{E})=\mathrm{N}$-methyl-D-aspartate receptor (encephalitis). NMOSD=neuromyelitis optica spectrum disorder. OND=other neurological disease. SLE=systemic lupus erythematosus.

Serum antibodies against NMDAR were present in 25/25 (100\%) patients with NDMAR encephalitis (1:40-1:20,480, median 1:640), and in 1/97 (1\%) patient with MS (0-1:20, median 0). Serum NMDAR antibody titers were significantly higher $(p<0.0001)$ in NMDAR encephalitis patients compared to all other groups (Figure 21A). CSF NMDAR antibodies, only available for $15 \mathrm{CSF} /$ serum pairs, were detected in 3/3 patients with NMDAR encephalitis (1:2-1:64, median 1:16), but in 0/5 ADEM and 0/7 MS patients. CSF from the MS patient with low titer (1:20) serum NMDAR antibodies at disease onset was negative for NMDAR antibodies. The case is described in detail in 4.10.3.

Serum MOG antibodies above the cut-off titer (1:160) were detected in 4/51 (8\%) patients with NMOSD (0-1:2,560, median 0), 28/55 (51\%) with ADEM (0-1:20,480, median 1:160), 2/29 (7\%) with CIS (0-1:2,560, median 0), 1/97 (1\%) with MS (0-1:160, median 0), 2/25 (8\%) with SLE (0-1:320, median 0), and 2/103 (2\%) patients with other neurological diseases (0- 
1:320, median 0). MOG antibodies below the cut-off titer (1:160) were found in 4/25 (16\%) patients with NMDAR encephalitis (0-1:80, median 0), 1/46 (2\%) patient with NMOSD (01:2,560, median 0), 5/29 (17\%) patients with CIS (0-1:2,560, median 0), 17/97 (18\%) with MS (0-1:160, median 0), 4/25 (16\%) with SLE (0-1:320, median 0), 6/103 (6\%) with other neurological diseases (0-1:320, median 0), and 2/48 (4\%) healthy controls (0-1:40, median 0$)$. Serum MOG antibody titers were significantly higher in patients with ADEM compared to patients with NMDAR encephalitis $(p=0.0002)$, NMOSD $(p<0.0001), C I S(p=0.006), M S$ $(p<0.0001)$, SLE $(p=0.009)$, other neurological diseases $(p<0.0001)$, and healthy controls $(p<0.0001$; Figure 21B). One of the patients with NMDAR encephalitis and a MOG antibody titer (1:80) below the cut-off at disease onset developed white matter lesions and MOG antibodies above the cut-off titer 3.5 years after disease onset. The case is described in detail in 4.10.2.

Serum AQP4 antibodies were exclusively found in 36/51 (71\%) NMOSD patients (0-1:20,480, median 1:160), but not in patients with NMDAR encephalitis, other demyelinating diseases, SLE, other neurological diseases or healthy controls. Serum AQP4 antibody titers were significantly higher $(p<0.0001)$ in patients with NMOSD compared to all other groups (Figure 21C). 
A

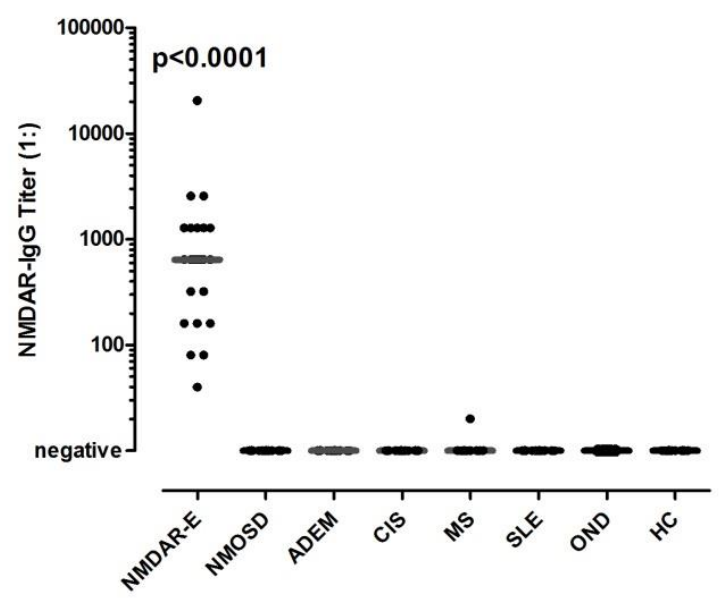

B

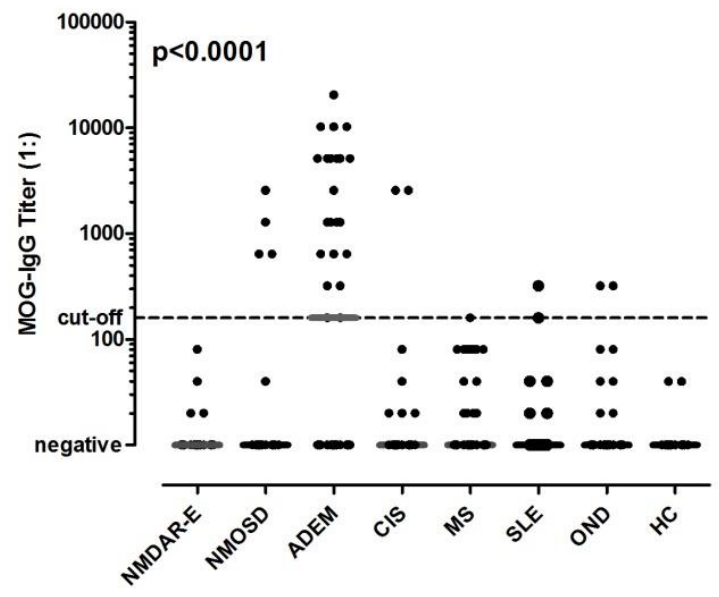

C

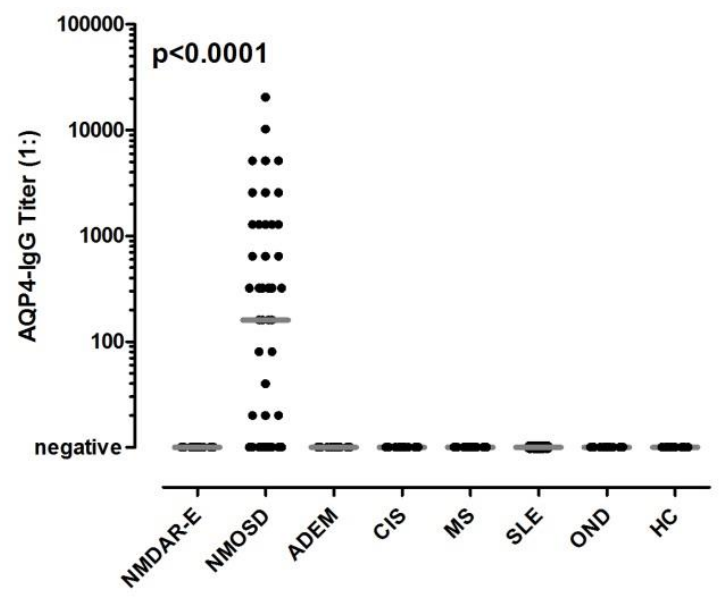

Figure 21: Serum antibody titers in demyelinating diseases, SLE, and control groups.

Antibody titers against NMDAR (A), MOG (B), and AQP4 (C) are shown. (B) The cut-off titer of 1:160 is indicated by a dashed line. (A-C) Medians are indicated by horizontal grey bars. Medians were compared using nonparametric Kruskal-Wallis test. Overall $p$-values are shown in the graphs.

ADEM=acute disseminated encephalomyelitis. AQP4=aquaporin 4. CIS=clinically isolated syndrome. $\mathrm{HC}=$ healthy control. $M O G=$ myelin oligodendrocyte glycoprotein. $M S=$ multiple sclerosis. $\operatorname{NMDAR}(-E)=N$-methyl-D-aspartate receptor (encephalitis). NMOSD=neuromyelitis optica spectrum disorder. OND=other neurological disease. $\mathrm{SLE}=$ systemic lupus erythematosus. 


\subsection{NMDAR antibodies in SLE}

Demographic data and serum antibodies of SLE patients are included in Table 8. Among 25 tested SLE patients, none had antibodies against NMDAR or AQP4, and 2/25 (8\%) had disease relevant antibodies against MOG above the cut-off titer (1:160).

While all of the NMDAR antibody positive samples were clearly identified by both blinded investigators, there was one patient sample that yielded inconsistent results, since the microscopic examiners came to different results. Antibodies of this patient also stained nontransfected cells to some extend and absorption of the serum with neither NMDAR transfected nor non-transfected cells could abolish the signal completely. The staining pattern is shown in Figure 22. FACS analysis revealed high binding of IgG to CD2-EmGFP transfected cells, resulting in a $\Delta \mathrm{MFI}$ of $-20,419$, reflecting high background reactivity to control-transfected cells (Figure 23). Reactivity to frozen rat brain sections to detect neuronal antibodies was negative (data kindly provided by Romana Höftberger). The patient had been diagnosed with NMOSD due to the presence of AQP4 antibodies and recurrent LETM and SLE. In addition, anti-nuclear antibodies were detectable. We therefore concluded that the patients' autoantibodies cross-reacted with epitopes on HEK293A cells. In the end, the patient was considered NMDAR antibody negative.
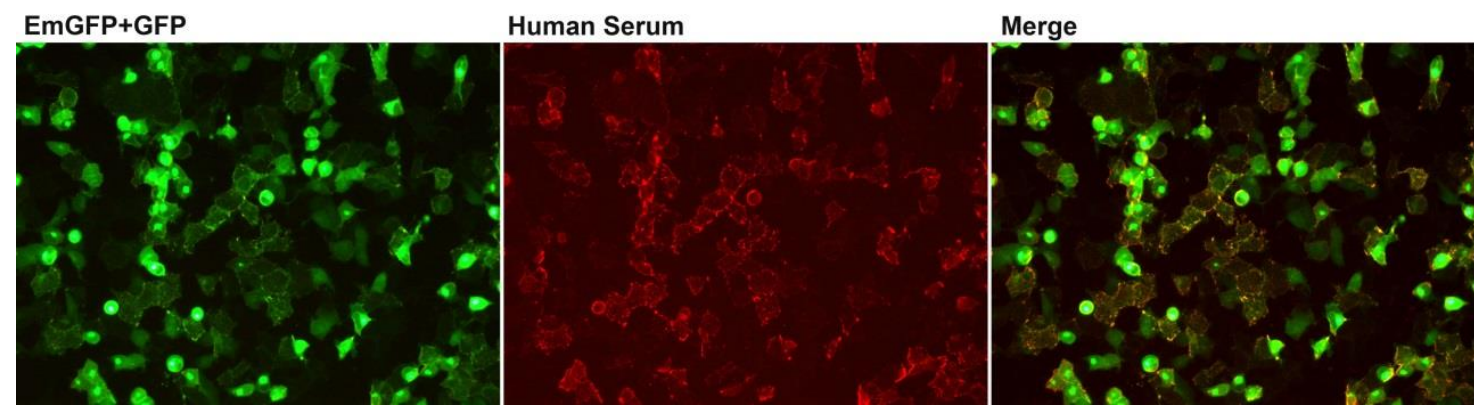

Figure 22: Staining pattern of a patient with recurrent LETM and SLE.

Due to high background reactivity the patient was finally considered as negative for NMDAR antibodies. Left: green fluorescence/EmGFP+GFP; middle: red fluorescence/Cy3; right: overlay of EmGFP/GFP, Cy3 and DAPI. Magnification 400x.

(Em)GFP=(emerald) green fluorescent protein. DAPI=4',6-diamidino-2-phenylindole. LETM=longitudinally extensive transverse myelitis. NMDAR=N-methyl-D-aspartate receptor. SLE=systemic lupus erythematosus. 

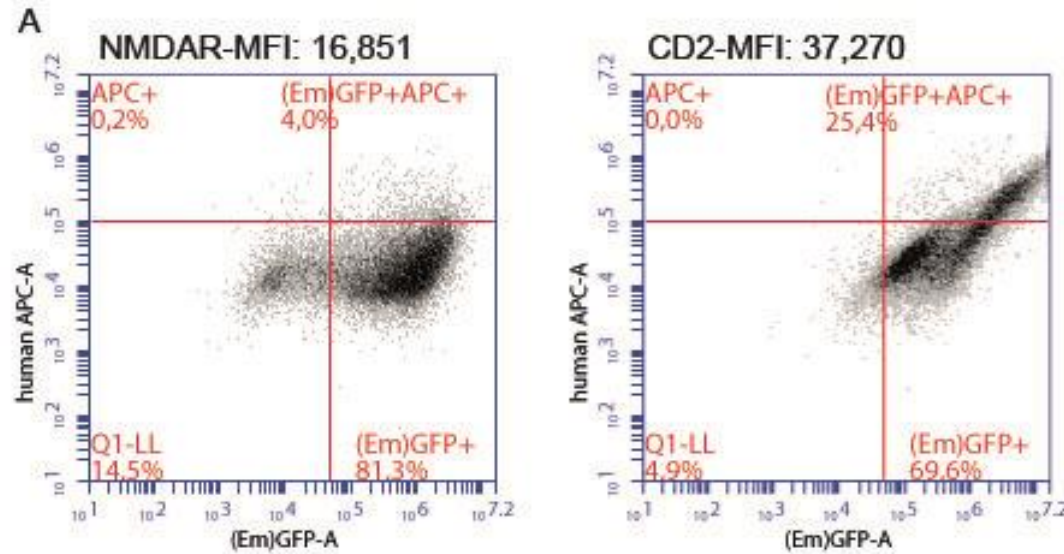

$\Delta \mathrm{MFI}=-20,419$

B
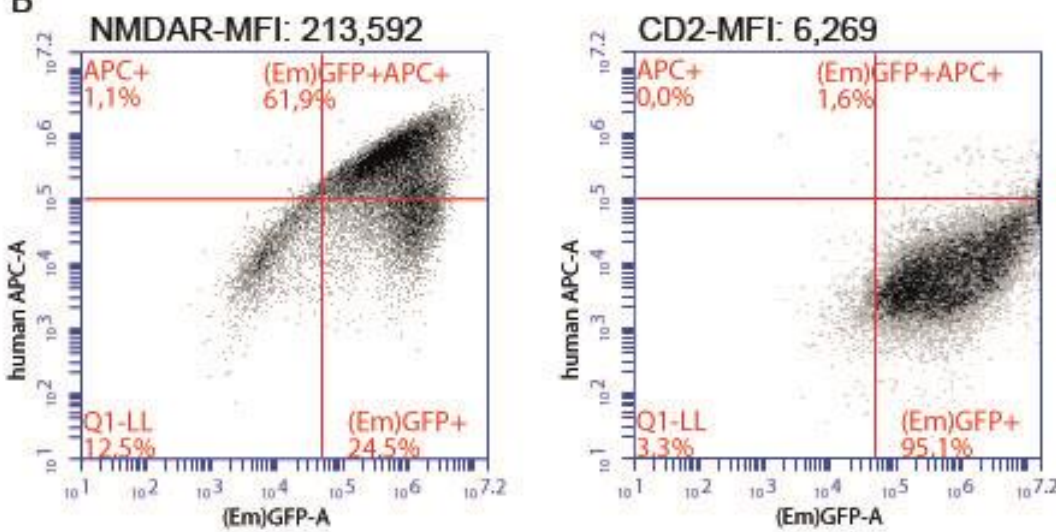

$\triangle M F I=207,323$

Figure 23: (Em)GFP and APC fluorescence of NMDAR-(Em)GFP and CD2-EmGFP transfected cells.

The reported SLE patient (A) and a patient positive for NMDAR antibodies (B) is shown. Left: NMDAR transfected HEK293A cells (EmGFP/GFP positive) incubated with human serum and APC-conjugated secondary antibody. Right: CD2-EmGFP transfected HEK293A cells (EmGFP positive) incubated with human serum and APC-conjugated secondary antibody. The population within the upper right quadrant $\left((E m) G F P^{\text {pos }} A P C^{\text {pos }}\right)$ represents the cell population expressing the respective antigen with bound IgG. Consider that positivity was not determined by the percentage of double positive cells, but the $\Delta \mathrm{MFI}$.

APC-A=allophycocyanin (area). $\triangle \mathrm{MFI}=$ delta median fluorescence intensity. $(\mathrm{Em}) \mathrm{GFP}(-\mathrm{A})=($ emerald) green fluorescent protein (area). FACS=fluorescence activated cell sorting. NMDAR=N-methyl-D-aspartate receptor. $\mathrm{SLE}=$ systemic lupus erythematosus.

\subsection{Case reports}

During the study we could follow two patients with NMDAR encephalitis over an extended time period. Patient \#1 was a "typical" case of NMDAR encephalitis, a young girl with an underlying ovarian teratoma and no relapse within three years of follow-up, whereas patient \#2 was an adult male without tumor experiencing a relapse accompanied by demyelinating events three years after the initial event. In addition, one MS patient who subsequently developed NMDAR antibodies is described (patient \#3). 


\subsubsection{Patient \# 1}

First symptoms occurred at the age of 14 in this female patient. The patient presented with persistent headaches that were followed by an acute psychosis. The initial MRI could not be analyzed due to artefacts caused by excessive movements of the patient. EEG recordings indicated extreme delta brushes. CSF analysis showed an elevated white blood cell count with 58 cells per $\mu$ and the presence of OCB. Bacterial infection was excluded, but the patient was tested positive for HSV DNA. Antibodies against NMDAR were detected in the serum and CSF of the patient. Due to breathing difficulties intubations and finally tracheotomy were necessary. The patient was admitted to the pediatric intensive care unit. Despite plasmapheresis the patient experienced recurrent myoclonic and epileptic seizures, why additionally immune adsorption, antiepileptic therapy and treatment with rituximab were initiated. An ovarian teratoma could only be found after repeated sonographies, which was removed two months after disease onset. Neurological symptoms and overall condition improved slowly during the following months, and serum and CSF were repeatedly analyzed for the presence of NMDAR antibodies. In addition to diagnostic validated antibody testing, respective antibody titers were analyzed by our in-house CBA (Figure 24). Although the symptoms disappeared, there was a reoccurrence of serum NMDAR antibodies within several weeks which could still be detected, albeit at a low titer, two years after disease onset. Titers of two CSF samples during the initial phase of the disease could not be analyzed due to high background reactivity with HEK293A cells. In addition, antibodies against MOG were found in the serum at disease onset, but at a low titer below the cut-off (1:160). Antibodies against AQP4 were absent at any time point. At present the patient is well and has no neurological deficits. 


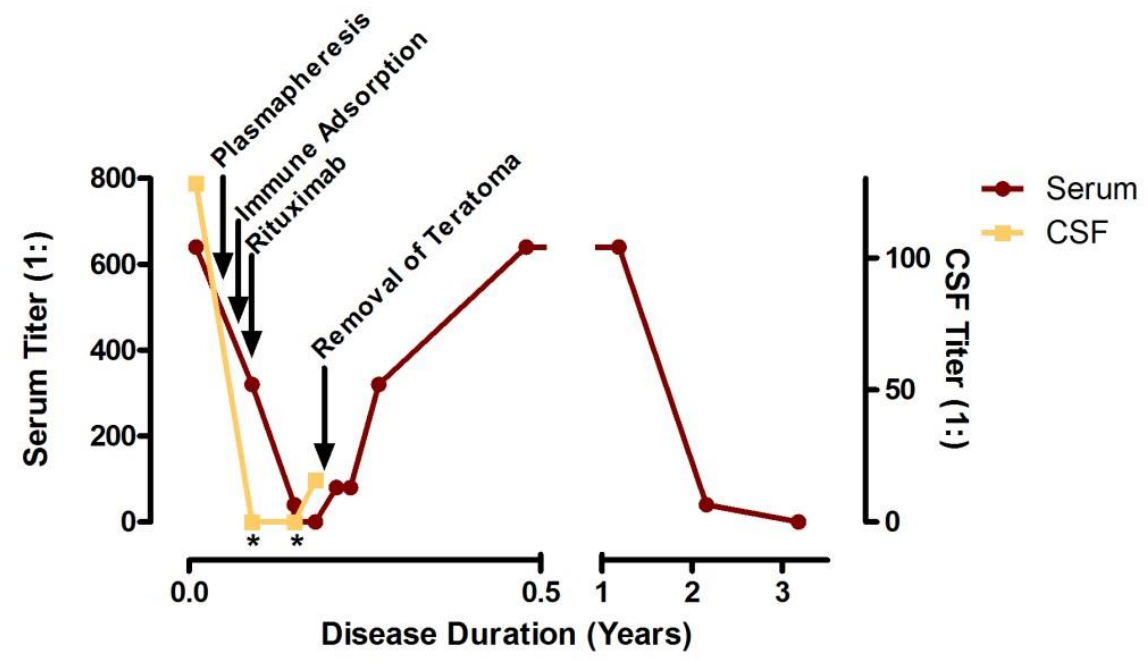

Figure 24: Follow-up of NMDAR antibody titers of patient \#1.

Left and right $y$-axes show serum and CSF titers, respectively. Major therapeutic interventions are indicated by vertical arrows. Asterisks indicate that CSF titers at those time points were not evaluable due to excessive background reactivity.

$\mathrm{CSF}=$ cerebrospinal fluid. NMDAR=N-methyl-D-aspartate receptor.

\subsubsection{Patient \#2}

At disease onset this male patient was 32 years old and presented with psychosis including acoustic hallucinations followed by epileptic seizures. MRI was normal and EEG showed slow baseline activity, but no potentials typical for epilepsy. White blood cell count in the CSF was elevated with 41 cells per $\mu l$ and OCB were present. The patient was tested positive for NMDAR antibodies in serum and CSF, but no tumor was found. The patient finally required intensive care due to respiratory and swallowing difficulties. After treatment with plasmapheresis and steroids the symptoms improved remarkably, with persistent mild short term memory impairment and apathy. NMDAR antibodies persisted, but further MRI were normal. Three years after the first manifestation the condition slowly started to deteriorate again and the patient developed changes in personality, as well as cognitive and speech impairments. At that time MRI was abnormal with active lesions suggestive of demyelination and EEG showed diffuse delta and theta waves. Beside persisting antibodies against NMDAR, also antibodies against VGKC (CASPR2) and MOG above the cut-off titer (1:160) were detected. After the patient was treated with high dose cortison and rituximab, B cell count and antibody titers decreased, and the condition slowly improved. Retrospective analysis 
showed low titer MOG antibodies below the cut-off at disease onset (Figure 25). Unfortunately, CSF was not available for research purposes.

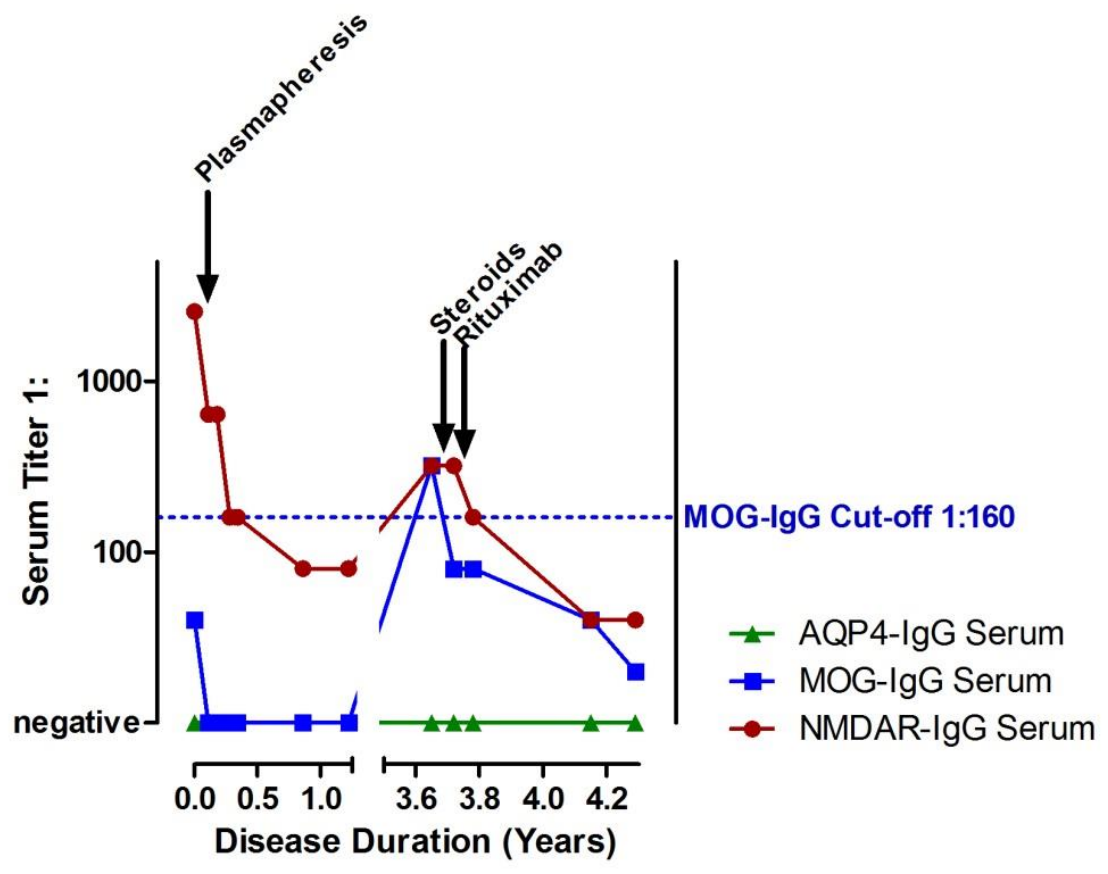

Figure 25: Follow-up of serum NMDAR, MOG and AQP4 antibody titers of patient \#2.

The cut-off titer for MOG antibodies is indicated by a blue dashed line. Major therapeutic interventions are indicated by vertical arrows.

AQP4=aquaporin 4. MOG=myelin oligodendrocyte glycoprotein. NMDAR=N-methyl-D-aspartate receptor.

\subsubsection{Patient \#3}

At the age of 23 this female patient presented with paresthesia of the left hand. MRI showed multiple lesions and investigation of CSF showed the presence of OCB and 15 cells per $\mu$. The patient was diagnosed with MS and after treatment with high-dose methylprednisolone complete remission was observed. Three months later suspected ON coincided with a clear increase of lesions in the MRI and the patient was treated again with methylprednisolone, followed by complete remission. However, three years after disease onset ON occurred again and after treatment the patient had some residual visual deficits. Seven months later the patient gave birth to a healthy child. Three months later, at the age of 26 , the patient presented with psychiatric symptoms and motor deficits. The MRI again showed dramatic progression of lesion load and serum was positive for low-titer anti-nuclear antibodies. Retrospective analysis for NMDAR antibodies revealed low titer NMDAR antibodies in serum, but not CSF, at disease onset, and an increase of serum NMDAR antibodies to the date of 
onset of symptoms suggestive of NMDAR encephalitis (Figure 26). Antibody specificity for NMDAR was proven by absorption of serum with NMDAR transfected and non-transfected cells prior to antibody testing with the CBA. Thereby, absorption with NMDAR transfected cells abolished the signal, while incubation with non-transfected cells did not, proving the specificity of the antibodies against NMDAR. Antibodies against MOG or AQP4 were absent at any time point. Before the patient could be treated for an autoimmune cause of the psychiatric symptoms, the patient was transferred to an external psychiatric unit and no further clinical data were available.

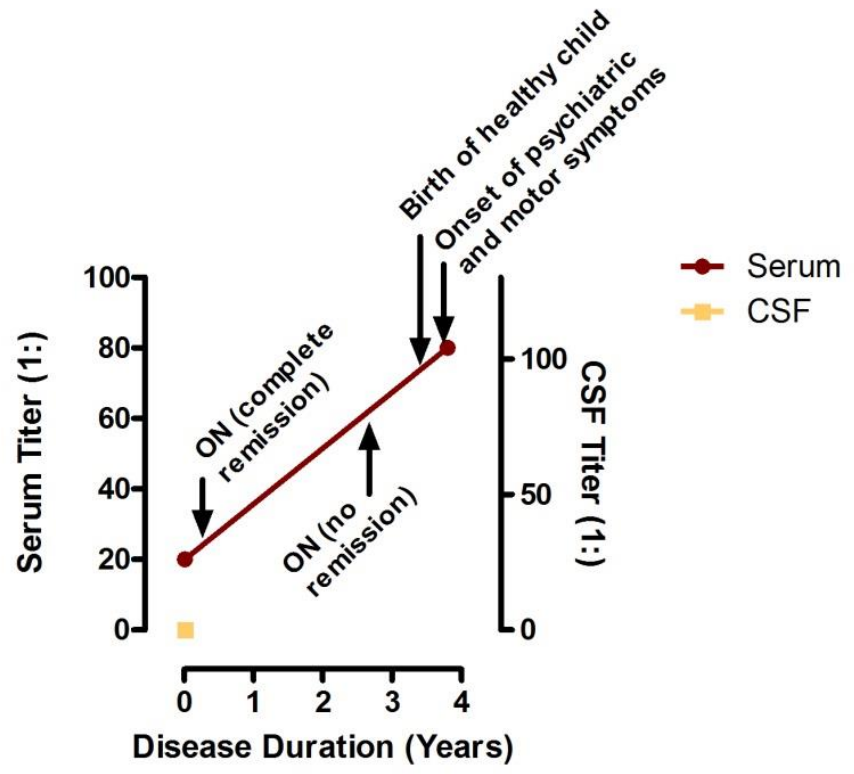

Figure 26: Follow-up of NMDAR antibody titers of patient \#3.

The period from disease onset of MS until the occurrence of symptoms suggestive of NMDAR encephalitis is shown. Left and right y-axes show serum and CSF titers, respectively. CSF was only available at disease onset. Major events during the disease course are indicated.

$\mathrm{CSF}=$ cerebrospinal fluid. $\mathrm{MS}=$ multiple sclerosis. $\mathrm{NMDAR}=\mathrm{N}$-methyl-D-aspartate receptor. $\mathrm{ON}=0$ ptic neuritis. 


\section{DISCUSSION}

Although NMDAR encephalitis is considered a rare disease, there is an increasing number of studies identifying this disorder [34, 49, 50, 52-54]. Although the exact frequency is unknown, several recent studies [31,34-36] suggest this disorder to be more frequent than previously thought. Therefore, this form of encephalitis is likely to be underdiagnosed, and there is an increasing need for the availability of antibody testing. Although several testing methods are used to detect autoantibodies to NMDAR, a discrepancy in testing results exists, which led to controversial data regarding the presence of NMDAR antibodies in various diseases. We therefore aimed to establish a highly specific and sensitive live CBA and FACS based analysis for the detection of NMDAR antibodies, and compared diagnostic accuracy of both testing methods. Secondly, we investigated a cohort of patients with demyelinating diseases with the live CBA, having excellent sensitivity and specificity, for the presence of these autoantibodies.

\subsection{Comparison of live CBA and FACS based analysis}

Currently, CBA are widely used for the detection of NMDAR antibodies. As different protocols are used to perform CBA, outcomes of antibody testing vary. Most protocols use fixation of cells, making it impossible to exclude potential unspecific binding to dead cells. Here, we compared a live CBA with FACS based analysis to detect serum autoantibodies binding to functional NMDAR.

Sensitivities were high in both testing methods, although we found a higher sensitivity in the CBA $(100 \%)$ compared to the FACS based analysis (87\%). Using a lower serum dilution did not increase the sensitivity of the FACS assay and revealed that the cut-off $\triangle M F I$ was variable in a different batch of experiments, further demonstrating a high inter-assay variation. Whereas some samples yielded reproducibly low (and others high) results, even when comparing results from different batches of experiments, others showed a very high interassay variability, suggesting that trypsinization might destroy the epitope recognized by some sera but not others. In general, although the inter-assay variation was already high when using the same batch of cells for analysis, it further increased (25 to 36\%) when including the same samples analyzed with another batch of cells used for transfection. It is therefore recommended to set a new $\Delta M F I$ in every experiment for future attempts to 
improve a FACS based analysis for detection of surface antigens, which can be a logistical challenge. In our analysis this became even more evident, when two sera that were false negative in the original analysis would have been positive in the second. Consequently, by regularly setting new cut-offs, the sensitivity could possibly be improved, but as one sample was still missed, the CBA would still have yielded a better sensitivity.

False negative samples showed already low NMDAR specific signals rather than high background fluorescence. Although overall we observed a high correlation between CBA titers and $\triangle \mathrm{MFI}$, false negative samples did not necessarily have a low titer in the CBA. Therefore it is not likely that the fluorescence signal is too weak to be detected by the flow cytometer. Rather, cells expressing fluorescently labeled NMDAR but partly retaining the receptors intracellularly might accumulate and decrease the relative number of cells expressing NMDAR on their surface, leading to a low signal of surface bound IgG, resulting in the observed lower sensitivity compared to the CBA. As can be seen in visual inspections, the frequency of cells expressing NMDAR on the surface varies, which could also be a source of high inter-assay variation in the FACS based assay. The use of fixed and permeabilized cells would make intracellular epitopes accessible, but then it is not possible to exclude dead cells any more, which could lead to unspecific binding, possibly resulting in a lower specificity.

Both methods are based on the expression of functional NMDAR in HEK293A cells, differing only in the detection of secondary antibody signals. A FACS based analysis would have several advantages. Signal strength correlates with antibody titers and is therefore a quantitative method without the need for analyzing serial dilutions. In contrast to CBA, FACS based analysis does not rely on the experience of the investigators. Furthermore, once a sample has been analyzed, original data can always be reevaluated. However, since the sensitivity of the FACS based analysis was lower (87\%), and the inter-assay variation was high, this method is not reliable for routine antibody testing. Moreover, FACS based analysis has limitations for the study of CSF samples, which in some patients is crucial for antibody detection. Future studies to improve sensitivity and reproducibility of the FACS based analysis should aim to use non-adherent cells to avoid differential destruction of epitopes by trypsinization. A further challenge will be to adjust cut-offs in every new experiment, e.g. by using internal reference samples or by readjusting the cut-off in every experiment using control sera. 
Hippocampal NMDAR form tetramers with two GluN1 and two GluN2 subunits, with an agedependent shift from GluN2B to GluN2A [13]. In contrast to existing testing methods using either transfected cells with only GluN1 $[46,47]$ or in combination with GluN2B $[33,44]$ we used NMDAR containing both GluN2A and GluN2B, aiming to increase the density of functional NMDAR expressed on the surface of HEK293A cells and not to miss any NMDAR antibodies due to age-dependent changes in subunit composition. NMDAR encephalitis is associated with antibodies recognizing a well-defined epitope on the extracellular region of the GluN1 subunit of NMDAR $[29,44,45]$. In contrast, antibodies to the GluN2A or GluN2B subunits react with a linear epitope and their significance is unclear. In our testing methods, we used live cells expressing functional NMDAR without disruption of the native conformation. Since GluN2A and GluN2B cannot be expressed on the cell surface without the presence of GluN1 $[181,182]$, we did not find any antibodies recognizing either GluN2A or GluN2B alone with this setting, neither in NMDAR encephalitis patients nor in controls. Moreover, with our assay we were able to avoid unspecific antibody binding to dead cells. This is not possible in assays where cells are fixed before $[29,43]$ or after $[33,44]$ serum (or CSF) incubation as it is done in other labs. In contrast to others that used NMDAR and EGFP co-transfected cells [33] we used NMDAR subunits directly fused to EmGFP (GluN1) or GFP (GluN2B) for transfection of cells, which enabled us to truly colocalize NMDAR with bound antibodies. Through the combination of using live cells and NMDAR directly linked to a fluorophore we could even visualize the internalization of NMDAR which is known to occur in response to NMDAR antibodies by applying patients' antibodies to cultured neurons [41] or by intraventricular infusion of patients' antibodies into mice [42]. And finally, to our knowledge this is the first live CBA that includes protection of the cells by (+)-MK-801 against excitotoxicity throughout the staining procedure, which we found is crucial for not losing living cells that bind NMDAR antibodies to their surface, particularly in the FACS based assay. This might also explain the discrepancy in sensitivity of our test compared to a lower sensitivity in live CBA found by others [44].

In the present study we focused on the establishment of serologic antibody testing methods since the availability of CSF was limited, the collection of CSF is invasive, and serum testing often produces more background than CSF testing. A study investigating the largest known cohort of NMDAR encephalitis patients [31] found a better correlation of CSF antibody titer 
with disease activity, and CSF was suggested to be more sensitive than serum [37]. Future investigations should aim to optimize the FACS based analysis to provide more reliable results, even when only low CSF volumes are available.

Controversial data exist regarding NMDAR antibody levels in serum and CSF and their clinical relevance [77], further underlined by a recent study using a live CBA with fixation after serum incubation that showed serum positivity in $23 \%$ of patients with an unlikely autoimmune syndrome, as well as CSF negativity in some cases considered with definite NMDAR encephalitis [183]. In contrast to their live CBA, here we used endpoint titration instead of a visual scoring system. Furthermore, we found that protection of the NMDAR overexpressing cells is necessary throughout the assay to assure their survival, which is of particular importance when assessing undiluted CSF. One limitation of our assay is that we used only sera of NMDAR encephalitis patients that had a definite clinical diagnosis partly based on their seropositivity to assess specificity and sensitivity. This limitation is in part caused by the fact that using previously established criteria that confer high specificity and sensitivity [44], some of our collaborators (Romana Höftberger and Josep Dalmau) never encountered patients with NMDAR encephalitis without antibodies in the CSF, or patients with serum NMDAR antibodies and an unlikely autoimmune disorder. It is therefore even more important to launch a multicenter study to compare results of different laboratories that conduct NMDAR antibody testing.

In conclusion, we compared two highly sensitive serologic testing methods to detect autoantibodies to NMDAR. In our experience both methods had a high specificity, whereas the sensitivity of the immunofluorescence CBA was higher than that of the FACS assay. This might be especially important for the analysis of CSF antibodies, since they are crucial for the diagnosis of NMDAR encephalitis, and a particularly high sensitivity is needed due to the low amounts of immunoglobulins that can be present in CSF.

\subsection{Antibody titers and disease course in NMDAR encephalitis}

To illustrate possible disease courses of NMDAR encephalitis we followed two patients with NMDAR encephalitis over an extended time period: patient \#1, a "typical" case of NMDAR encephalitis; and patient \#2, who experienced a relapse accompanied by demyelinating events three years after the initial event. 
Follow-up of patient \#1 over three years from disease onset showed a typical disease course of NMDAR encephalitis. The acute onset of symptoms in female pediatric patients with an underlying ovarian teratoma is a frequent presentation of this condition (compare Figure 2). Like most NMDAR encephalitis patients this patient presented with acute psychosis, followed by seizures and autonomic instabilities [29, 31]. EEG showed extreme delta brushes, a unique pattern associated with NMDAR encephalitis, which was seen in $30 \%$ of adult patients [38], but also occasionally in pediatric patients [39]. The patient had elevated cell numbers in the CSF and OCB, suggesting intrathecal synthesis of antibodies. NMDAR antibody titers were high in both the CSF and serum at disease onset, which decreased in response to immunomodulatory treatments such as plasmapheresis and immune adsorption. However, the epileptic symptoms persisted, most likely due to the presence of an occult ovarian teratoma, which is known to be associated with the production of NMDAR autoantibodies and its removal is crucial in the treatment strategy [17, 30, 31]. Only after removal of the tumor the condition of the patient improved slowly, despite a reoccurrence of the autoantibodies and a substantial rise of antibody titer in the serum. CSF was not available from this period, because lumbar puncture is invasive and symptoms had already been improving.

The rebound of antibody titers could arise from the previous treatment with rituximab (personal observation Kevin Rostásy), which induces B cell depletion and therefore inhibits antibody production, and has been shown to be effective in the treatment of autoimmune diseases, including NMO [184] and MS [153]. Surprisingly, the rise in antibody titer did not correlate with disease activity during this period. It would have been interesting to analyze CSF antibody titers, since it was shown that CSF antibody levels correlate with disease activity more than serum antibody levels do [37]. NMDAR antibodies could not be detected in the serum three years after the disease, consistent with a good overall health condition and no neurological deficits. Antibodies against MOG were detected only at disease onset, but at a titer below the cut-off, which has no pathogenic relevance and is also seen in healthy controls occasionally [121].

In conclusion, this case shows the effectiveness of immunomodulatory treatment on antibody levels and the necessity of the removal of the ovarian teratoma, if present. This outcome is in line with an observational cohort study showing that $81 \%$ of patients had a 
good outcome after treatment. Within two years, the risk of having a relapse was $12 \%$ in this study. Although no admission to the intensive care unit was reported to favor a good outcome [31], our patient had a good outcome despite admission to the intensive care unit.

The second case (patient \#2) described a male adult patient that also had a typical disease course in the beginning. Elevated cell numbers and OCB present in the CSF suggested intrathecal antibody synthesis. NMDAR antibodies were detected in the CSF, but CSF was not available for research purposes and titration. Despite typical presentation of NMDAR encephalitis, no tumor could be identified, and although immunomodulatory therapy could improve the condition of the patient remarkably, persisting NMDAR antibodies could have caused the residual cognitive symptoms. When the condition deteriorated again after three years, MRI showed active lesions suggesting demyelination for the first time, which prompted screening for further autoantibodies. Indeed, autoantibodies against VGKC (CASPR2) and MOG above the cut-off titer could be identified, which have both been linked to demyelinating diseases [26, 27, 119-124]. Retrospective analysis of serum MOG antibodies showed MOG antibodies below the cut-off at disease onset, which has no pathogenic relevance [121]. Treatment with steroids and rituximab resulted in a decrease of all autoantibodies, indicating its effectiveness. Likewise, symptoms started to improve thereafter, but at present NMDAR antibodies are still detectable and the patient is still under clinical surveillance.

In our Neurological Department this is the first described patient with NMDAR encephalitis who developed signs of demyelination during the relapse. The transition from NMDAR encephalitis to a demyelinating disease has been described as a rare event in the condition recently $[55,57]$. If and how NMDAR autoantibodies contribute to demyelination is currently unknown and needs further investigation. Interestingly, the patient developed autoantibodies against MOG and VGKC (CASPR2) not until the demyelinating event, indicating that those antibodies might, independent of NMDAR antibodies, trigger or at least be involved in the process of demyelination.

\subsection{NMDAR autoantibodies in demyelinating diseases}

The aforementioned case demonstrates that NMDAR autoantibodies can be linked with demyelination, which has been shown in a recent study investigating a large cohort of 691 
NMDAR encephalitis patients [55]. In this study, few cases were reported to have demyelinating episodes or NMO and related disorders, with or without the presence of MOG and AQP4 antibodies, with a similar frequency (3.3\%) found in our study (4\%). Interestingly, the majority of patients with this overlapping syndrome did not have an underlying tumor, which was also the case in our patient. The authors further report that these demyelinating episodes are more difficult to treat than NMDAR encephalitis without severe signs of demyelination, which is in line with [56], reporting a higher relapse rate in pediatric patients with NMDAR encephalitis and demyelination. In general, treatment strategy for demyelinating diseases is often different from NMDAR encephalitis, which frequently requires intensive care, why it is of particular importance to distinguish between the disorders at an early time point.

In our retrospective screening for NMDAR antibodies of patients with demyelinating diseases we found one MS patient (patient \#3) who developed these antibodies. In the beginning the disease course was typical for RR-MS with residual visual deficits after the second episode of ON. Since analysis of NMDAR antibodies was done retrospectively, the low titer of serum antibodies during the first episode of demyelination was not known at that time point. CSF was negative for NMDAR antibodies, contrasting studies suggesting CSF to be more sensitive than serum $[31,37]$. Unfortunately, we did not have CSF available from the second time point, when the serum titer was increased. The rise of NMDAR antibodies either preceded or occurred concomitantly with prominent psychiatric and motor symptoms, since serum was available only shortly after the patient developed those symptoms. The exact significance of detected low titer anti-nuclear antibodies remains elusive, since the exact target of the antibodies could not be further specified. A possible cross-reactivity of these antibodies with NMDAR cannot be excluded as was reported for antibodies against dsDNA in SLE $[59,60]$. Still, specificity of the antibodies to NMDAR has been proven by pre-absorption of the serum with NMDAR-transfected cells, which abolished the signal. Most reported cases (18/23) of demyelinating syndromes overlapping with the presence of NMDAR antibodies were also positive for at least one antibody associated with demyelination, namely antibodies against MOG or AQP4 [55]. In our case, no antibodies against MOG or AQP4 were found, suggesting that NMDAR antibodies could be directly involved in demyelination. On the other hand, CSF was negative for NMDAR antibodies and 
serum titer increased very slowly over a period of nearly four years, which indicates that NMDAR antibodies might rather be a bystander mechanism. Of note, NMDAR encephalitis related symptoms occurred three months after the patient gave birth to a healthy child, paralleling a recently described case [95], albeit our case showed a less severe disease course. During MS, the relapse rate is known to be decreased during pregnancy, followed by an increased risk of relapse during the first three months post partum [185], which can be attributed to hormonal changes during and after pregnancy [186].

Overall, we found NMDAR antibodies in one of 232 patients with demyelinating diseases, suggesting that the frequency of those autoantibodies is very low $(<1 \%)$. Given the increasing number of studies claiming the presence of NMDAR antibodies in various neurological diseases, but also in healthy control subjects with frequencies of up to $10 \%$ (for details see Table 2), it is even more important to use antibody testing methods that are highly specific, i.e. that do not detect disease irrelevant antibodies in control groups. Likewise, the presence of NMDAR antibodies in case reports of patients with demyelinating diseases (for details see Table 3 ) cannot be accepted without any restrictions. Our study is the first systematically investigating a cohort of patients with demyelinating diseases for a possible involvement of NMDAR antibodies in such diseases. By using our in-house live CBA, which has proven high specificity, since we did not detect antibodies in any of our control groups, we found a low prevalence of NMDAR antibodies associated with demyelination.

In both cases described here it is not clear if and how NMDAR antibodies have a causative role on the demyelinating event. A pathogenic role of NMDAR antibodies could be speculated due to the following reasons: antibodies in those patients might not only target synaptic NMDAR. Rather, targeted cells in those patients might be oligodendrocytes that are essential for myelination and express GluN3 containing NMDAR [169]. In NMDAR encephalitis, the inhibitory effect of antibodies to NMDAR on hippocampal neurons results from the reversible internalization of the receptors, without affecting other neuronal structures or causing neuronal cell death [41, 42]. Possible effects on other cell types expressing NMDAR are not known. Disruption of oligodendroglial NMDAR might result in temporary demyelination, followed by in an impairment of remyelinating repair mechanisms, which are in part dependent on neuronal activity and the activation of oligodendroglial NMDAR [178]. Once the myelin sheath is disrupted over an extended time 
period, irreversible axonal degeneration occurs [187] which could result in permanent disabilities in patients with NMDAR antibodies and demyelinating events. This hypothesis would be in line with the observation that NMDAR encephalitis with signs of demyelination is more difficult to treat than classical NMDAR encephalitis [55] and that there is a higher relapse rate in children with this overlapping syndrome [56]. If pathogenic mechanisms of the antibodies are really different from classical NMDAR encephalitis, and the time frame of exposure to the antibodies plays a role, an early diagnosis is particularly important.

It is tempting to speculate that NMDAR antibodies in patients with demyelinating events target different epitopes compared to patients suffering from NMDAR encephalitis without demyelination, especially when assuming that brain structures other than synapses could be targeted as well. It has to be considered that primary target epitopes could change over time through cross-reactivity or epitope spreading.

Nevertheless, in the two cases described in this study the occurrence of NMDAR antibodies could be independent of the demyelinating event. In the first case, demyelination developed several years after the first occurrence of NMDAR antibodies, and could have been triggered by other antibodies such as MOG antibodies, which were detected only at relapse, when demyelination initially occurred. The second case described a patient with a demyelinating syndrome that preceded the development of NMDAR antibodies, but without the occurrence of MOG or AQP4 antibodies. It will be challenging to find parameters that predict any possible transition from NMDAR encephalitis to a demyelinating event or vice versa.

\subsection{NMDAR autoantibodies in other neurological diseases}

It has been speculated that subgroups of patients with SLE have autoantibodies against GluN2 of NMDAR, and that these autoantibodies are associated with neuropsychiatric symptoms in those patients [66-71]. Since these studies used ELISA which consider only binding affinity to linear epitopes, it is worthwhile to screen SLE patients for the presence of antibodies against native NMDAR with a CBA. Here, we did not find antibodies specifically targeting NMDAR in any SLE patient. This is in line with another study showing a lack of reactivity of 50 SLE patient's samples, including 29 cases with neuropsychiatric symptoms, to hippocampal and cerebellar rat tissue, and fixed CBA expressing NMDAR [43]. Of note, NMDAR antibodies in SLE have been linked to the presence of neuropsychiatric symptoms 
[66-71], but in our cohort none of our SLE patients had neuropsychiatric symptoms. Another limitation of our investigation was that we did not have CSF samples available, since some studies found those antibodies only in CSF but not in serum $[67,69,70]$. It would therefore be important for future studies to investigate also CSF samples, particularly of SLE patients with neuropsychiatric symptoms.

One patient described in 4.9, who had exorbitantly high background reactivity against CD2 control-transfected HEK293A cells, and had been diagnosed with NMOSD and SLE, underlines the difficulty to detect specific autoantibodies in SLE patients. The high reactivity of the patient's autoantibodies with CD2 transfected cells suggests unspecific binding, possibly due to further autoantibodies present in SLE, such as anti-nuclear antibodies, which might cross-react with a variety of cellular structures. 


\section{CONCLUSION AND OUTLOOK}

We established a live CBA, which has proven high sensitivity and specificity. In comparison, the FACS based assay has a lower sensitivity and high inter-assay variation, and is therefore less reliable for the detection of NMDAR antibodies.

Using the live CBA, which has the advantage of detecting only antibodies that bind to native functional NMDAR, we detected NMDAR antibodies in the serum of one patient with MS. In this patient, the occurrence of those antibodies coincided with the onset of psychiatric symptoms, which are major symptoms in NMDAR encephalitis. Another patient, originally presenting with NMDAR encephalitis, developed demyelinating episodes later on. Therefore, we could show that NMDAR antibodies can be associated with demyelination, although this is a very rare condition, since we found those antibodies in only one patient among 232 patients with demyelinating diseases in total. One major limitation of the study was the restricted availability of CSF, which could possibly be positive for NMDAR antibodies in more cases, also in the cohort of SLE patients investigated.

To date, several testing methods are available to detect autoantibodies to NMDAR and to confirm or reject a diagnosis. It would be important to compare the results of different testing methods conducted in different centers, due to an obvious discrepancy in testing results, which led to controversial data regarding the presence of NMDAR antibodies in various diseases. 


\section{ABBREVIATIONS}

7-AAD 7-amino-actinomycin D

ADCC antibody-dependent cell-mediated cytotoxicity

ADEM acute disseminated encephalomyelitis

$\operatorname{AMPA}(\mathrm{R}) \quad \alpha$-amino-3-hydroxy-5-methyl-4-isoxazolepropionic acid (receptor)

ANNA anti-neuronal nuclear antibody

AQP4 aquaporin 4

AUC area under the curve

BBB blood brain barrier

CA1 cornu ammonis 1

CASPR2 contactin associated protein 2

CBA cell-based assay

CD cluster of differentiation

cDNA complementary DNA

$\mathrm{Cl} \quad$ confidence interval

CIS clinically isolated syndrome

CNS central nervous system

CRMP collapsin response mediator protein

CSF cerebrospinal fluid

$\Delta \mathrm{MFI}$ delta median fluorescence intensity

dsDNA double-stranded DNA

E. coli Escherichia coli

EAE experimental autoimmune encephalomyelitis

EBV Epstein-Barr virus

EDTA ethylenediaminetetraacetic acid 


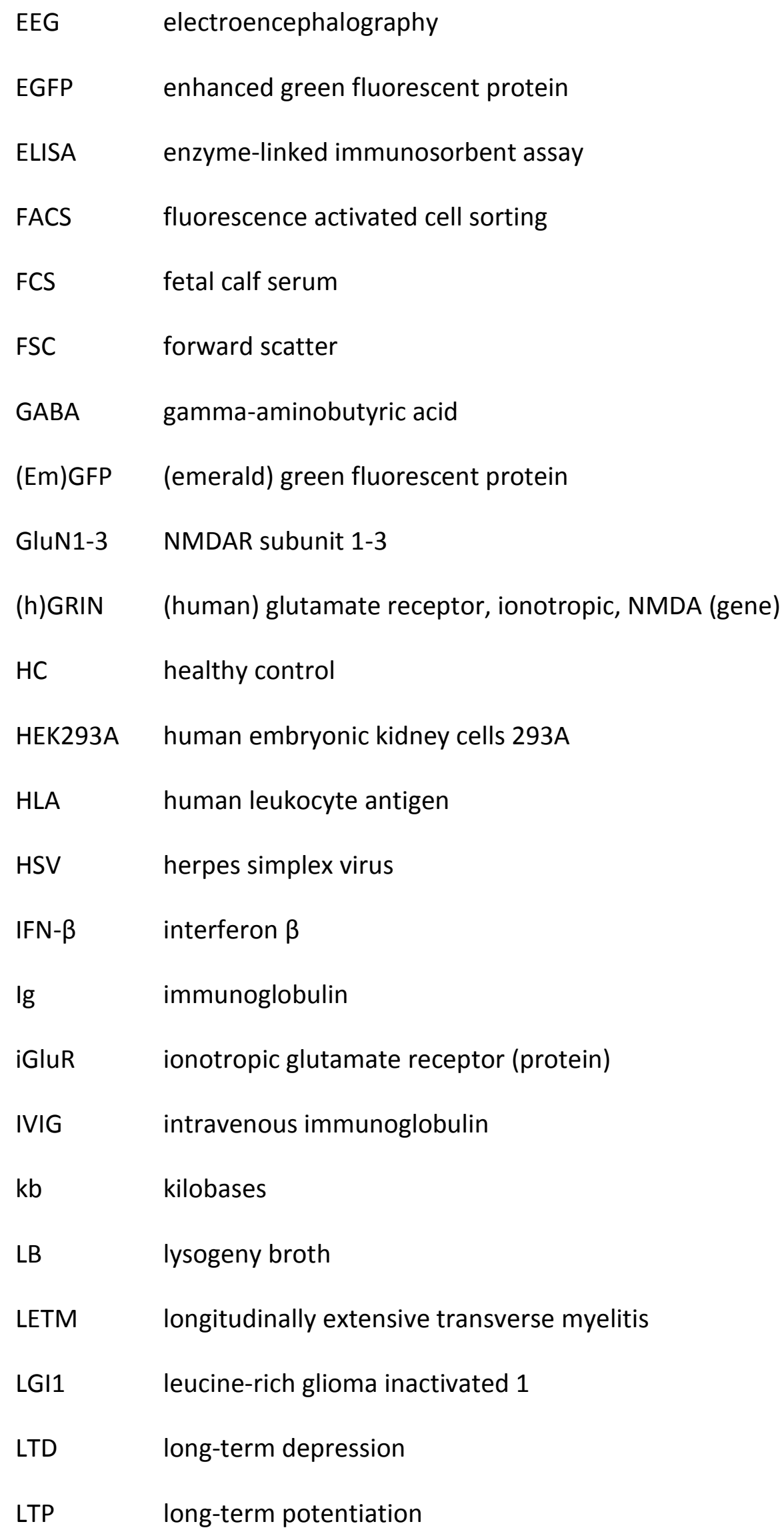




\begin{tabular}{|c|c|}
\hline MFI & median fluorescence intensity \\
\hline mGluR & metabotropic glutamate receptor (protein) \\
\hline MHC & major histocompatibility complex \\
\hline MOG & myelin oligodendrocyte glycoprotein \\
\hline MRI & magnetic resonance imaging \\
\hline MS & multiple sclerosis \\
\hline NC & neurological control \\
\hline $\operatorname{NMDA}(\mathrm{R})$ & $N$-methyl-D-aspartate (receptor) \\
\hline $\mathrm{NMO}(\mathrm{SD})$ & neuromyelitis optica (spectrum disorders) \\
\hline NR1-3 & NMDAR subunit 1-3 \\
\hline ns & not significant \\
\hline $\mathrm{nt}$ & non-transfected \\
\hline OCB & oligoclonal band \\
\hline ON & optic neuritis \\
\hline OND & other neurological diseases \\
\hline PBS & phosphate buffered saline \\
\hline PCP & phencyclidine \\
\hline PCR & polymerase chain reaction \\
\hline PP-MS & primary progressive MS \\
\hline $\mathrm{R}$ & correlation coefficient \\
\hline ROC & receiver operating characteristic \\
\hline RR-MS & relapsing-remitting MS \\
\hline RT & room temperature \\
\hline $\mathrm{SCLC}$ & small-cell lung cancer \\
\hline SLE & systemic lupus erythematosus \\
\hline
\end{tabular}


SP-MS secondary progressive MS

SSC side scatter

TBE Tris-borate-EDTA

VGCC voltage-gated calcium channel

VGKC voltage-gated potassium channel 


\section{REFERENCES}

1. Cooke, S.F. and T.V. Bliss, Plasticity in the human central nervous system. Brain, 2006. 129(Pt 7): p. 1659-73.

2. Massey, P.V. and Z.I. Bashir, Long-term depression: multiple forms and implications for brain function. Trends Neurosci, 2007. 30(4): p. 176-84.

3. Traynelis, S.F., et al., Glutamate receptor ion channels: structure, regulation, and function. Pharmacol Rev, 2010. 62(3): p. 405-96.

4. Niswender, C.M. and P.J. Conn, Metabotropic glutamate receptors: physiology, pharmacology, and disease. Annu Rev Pharmacol Toxicol, 2010. 50: p. 295-322.

5. Pacheco, R., et al., Role of glutamate on T-cell mediated immunity. J Neuroimmunol, 2007. 185(1-2): p. 9-19.

6. Julio-Pieper, M., et al., Exciting times beyond the brain: metabotropic glutamate receptors in peripheral and non-neural tissues. Pharmacol Rev, 2011. 63(1): p. 3558.

7. Murugan, M., E.A. Ling, and C. Kaur, Glutamate receptors in microglia. CNS Neurol Disord Drug Targets, 2013. 12(6): p. 773-84.

8. Dingledine, R., et al., The glutamate receptor ion channels. Pharmacol Rev, 1999. 51(1): p. 7-61.

9. Mehta, A., et al., Excitotoxicity: bridge to various triggers in neurodegenerative disorders. Eur J Pharmacol, 2013. 698(1-3): p. 6-18.

10. Cull-Candy, S., S. Brickley, and M. Farrant, NMDA receptor subunits: diversity, development and disease. Curr Opin Neurobiol, 2001. 11(3): p. 327-35.

11. Gladding, C.M. and L.A. Raymond, Mechanisms underlying NMDA receptor synaptic/extrasynaptic distribution and function. Mol Cell Neurosci, 2011. 48(4): p. 308-20.

12. Malenka, R.C. and M.F. Bear, LTP and LTD: an embarrassment of riches. Neuron, 2004. 44(1): p. 5-21.

13. Cull-Candy, S.G. and D.N. Leszkiewicz, Role of distinct NMDA receptor subtypes at central synapses. Sci STKE, 2004. 2004(255): p. re16.

14. Mader, S., B. Obholzer, and M. Reindl, Relevance of Autoantibodies for the Classification and Pathogenesis of Neurological Diseases, Autoimmune Disorders Current Concepts and Advances from Bedside to Mechanistic Insights, in InTech, D.F.-P. Huang, Editor 2011. p. 163-190.

15. Kovacic, P. and R. Somanathan, Clinical physiology and mechanism of dizocilpine (MK-801): electron transfer, radicals, redox metabolites and bioactivity. Oxid Med Cell Longev, 2010. 3(1): p. 13-22.

16. Nabavi, S., et al., Metabotropic NMDA receptor function is required for NMDA receptor-dependent long-term depression. Proc Natl Acad Sci U S A, 2013. 110(10): p. 4027-32.

17. Dalmau, J., et al., Paraneoplastic anti-N-methyl-D-aspartate receptor encephalitis associated with ovarian teratoma. Ann Neurol, 2007. 61(1): p. 25-36. 
18. Mak, T.W. and M.E. Saunders, Primer to the Immune Response: Academic Cell Update Edition2011: Elsevier Science.

19. Rose, N.R. and C. Bona, Defining criteria for autoimmune diseases (Witebsky's postulates revisited). Immunol Today, 1993. 14(9): p. 426-30.

20. Diamond, B., et al., Brain-reactive antibodies and disease. Annu Rev Immunol, 2013. 31: p. 345-85.

21. Graus, F. and J. Dalmau, Paraneoplastic neurological syndromes. Curr Opin Neurol, 2012. 25(6): p. 795-801.

22. Leypoldt, F. and K.P. Wandinger, Paraneoplastic neurological syndromes. Clin Exp Immunol, 2014. 175(3): p. 336-48.

23. Lai, M., et al., AMPA receptor antibodies in limbic encephalitis alter synaptic receptor location. Ann Neurol, 2009. 65(4): p. 424-34.

24. Lancaster, E., et al., Antibodies to the $G A B A(B)$ receptor in limbic encephalitis with seizures: case series and characterisation of the antigen. Lancet Neurol, 2010. 9(1): p. 67-76.

25. Irani, S.R., et al., Antibodies to Kv1 potassium channel-complex proteins leucinerich, glioma inactivated 1 protein and contactin-associated protein-2 in limbic encephalitis, Morvan's syndrome and acquired neuromyotonia. Brain, 2010. 133(9): p. 2734-48.

26. Hacohen, Y., et al., Autoantibody biomarkers in childhood-acquired demyelinating syndromes: results from a national surveillance cohort. J Neurol Neurosurg Psychiatry, 2014. 85(4): p. 456-61.

27. Kaliakatsos, M., et al., Acute disseminated encephalomyelitis associated with positive voltage gated potassium channel complex antibody. Multiple Sclerosis and Related Disorders, 2013. 2(2): p. 147-150.

28. Derfuss, T. and E. Meinl, Identifying autoantigens in demyelinating diseases: valuable clues to diagnosis and treatment? Curr Opin Neurol, 2012. 25(3): p. 2318.

29. Dalmau, J., et al., Anti-NMDA-receptor encephalitis: case series and analysis of the effects of antibodies. Lancet Neurol, 2008. 7(12): p. 1091-8.

30. Vitaliani, R., et al., Paraneoplastic encephalitis, psychiatric symptoms, and hypoventilation in ovarian teratoma. Ann Neurol, 2005. 58(4): p. 594-604.

31. Titulaer, M.J., et al., Treatment and prognostic factors for long-term outcome in patients with anti-NMDA receptor encephalitis: an observational cohort study. Lancet Neurol, 2013. 12(2): p. 157-65.

32. Florance, N.R., et al., Anti-N-methyl-D-aspartate receptor (NMDAR) encephalitis in children and adolescents. Ann Neurol, 2009. 66(1): p. 11-8.

33. Irani, S.R., et al., $N$-methyl-D-aspartate antibody encephalitis: temporal progression of clinical and paraclinical observations in a predominantly non-paraneoplastic disorder of both sexes. Brain, 2010. 133(Pt 6): p. 1655-67.

34. Viaccoz, A., et al., Clinical specificities of adult male patients with NMDA receptor antibodies encephalitis. Neurology, 2014. 82(7): p. 556-63. 
35. Granerod, J., et al., Causes of encephalitis and differences in their clinical presentations in England: a multicentre, population-based prospective study. Lancet Infect Dis, 2010. 10(12): p. 835-44.

36. Gable, M.S., et al., The frequency of autoimmune N-methyl-D-aspartate receptor encephalitis surpasses that of individual viral etiologies in young individuals enrolled in the California Encephalitis Project. Clin Infect Dis, 2012. 54(7): p. 899904.

37. Dalmau, J., et al., Clinical experience and laboratory investigations in patients with anti-NMDAR encephalitis. Lancet neurology, 2011. 10(1): p. 63-74.

38. Schmitt, S.E., et al., Extreme delta brush: a unique EEG pattern in adults with antiNMDA receptor encephalitis. Neurology, 2012. 79(11): p. 1094-100.

39. Armangue, T., et al., Pediatric anti-N-methyl-D-aspartate receptor encephalitisclinical analysis and novel findings in a series of 20 patients. J Pediatr, 2013. 162(4): p. 850-856 e2.

40. da Silva-Junior, F.P., et al., Serial and prolonged EEG monitoring in anti-N-Methyl$d$-Aspartate receptor encephalitis. Clin Neurophysiol, 2014. 125(8): p. 1541-4.

41. Hughes, E.G., et al., Cellular and synaptic mechanisms of anti-NMDA receptor encephalitis. J Neurosci, 2010. 30(17): p. 5866-75.

42. Planaguma, J., et al., Human $N$-methyl D-aspartate receptor antibodies alter memory and behaviour in mice. Brain, 2014.

43. Wandinger, K.P., et al., Anti-NMDA-receptor encephalitis: a severe, multistage, treatable disorder presenting with psychosis. J Neuroimmunol, 2011. 231(1-2): p. 86-91.

44. Gresa-Arribas, N., et al., Antibody titres at diagnosis and during follow-up of antiNMDA receptor encephalitis: a retrospective study. Lancet Neurol, 2014. 13(2): p. 167-77.

45. Gleichman, A.J., et al., Anti-NMDA receptor encephalitis antibody binding is dependent on amino acid identity of a small region within the GluN1 amino terminal domain. J Neurosci, 2012. 32(32): p. 11082-94.

46. Suh-Lailam, B.B., et al., Anti-NMDA-receptor antibody encephalitis: performance evaluation and laboratory experience with the anti-NMDA-receptor IgG assay. Clin Chim Acta, 2013. 421: p. 1-6.

47. Dale, R.C., et al., Antibodies to surface dopamine-2 receptor in autoimmune movement and psychiatric disorders. Brain, 2012. 135(Pt 11): p. 3453-68.

48. Höftberger, R., S. Mader, and M. Reindl, Chapter 12 Immunohistochemistry, in Cerebrospinal Fluid in Clinical Neurology, T. Deisenhammer, Sellebjerg, Tumani, Editor 2015, Springer in press.

49. Graus, F., et al., Neuronal surface antigen antibodies in limbic encephalitis: clinicalimmunologic associations. Neurology, 2008. 71(12): p. 930-6.

50. Dale, R.C., et al., $N$-methyl-D-aspartate receptor antibodies in pediatric dyskinetic encephalitis lethargica. Ann Neurol, 2009. 66(5): p. 704-9. 
51. Pruss, H., et al., Retrospective analysis of NMDA receptor antibodies in encephalitis of unknown origin. Neurology, 2010. 75(19): p. 1735-9.

52. Suleiman, J., et al., Autoimmune epilepsy in children: case series and proposed guidelines for identification. Epilepsia, 2013. 54(6): p. 1036-45.

53. Suleiman, J., et al., Autoantibodies to neuronal antigens in children with new-onset seizures classified according to the revised ILAE organization of seizures and epilepsies. Epilepsia, 2013. 54(12): p. 2091-100.

54. Hacohen, Y., et al., Paediatric autoimmune encephalopathies: clinical features, laboratory investigations and outcomes in patients with or without antibodies to known central nervous system autoantigens. J Neurol Neurosurg Psychiatry, 2013. 84(7): p. 748-55.

55. Titulaer, M.J., et al., Overlapping demyelinating syndromes and anti-N-methyl-Daspartate receptor encephalitis. Ann Neurol, 2014. 75(3): p. 411-28.

56. Hacohen, Y., et al., NMDA receptor antibodies associated with distinct white matter syndromes. Neurol Neuroimmunol Neuroinflamm, 2014. 1(1): p. e2.

57. Kaneko, K., et al., Anti-N-methyl-D-aspartate receptor encephalitis with multiphasic demyelination. Ann Neurol, 2014. 76(3): p. 462-4.

58. Rahman, A. and D.A. Isenberg, Systemic lupus erythematosus. N Engl J Med, 2008. 358(9): p. 929-39.

59. DeGiorgio, L.A., et al., $A$ subset of lupus anti-DNA antibodies cross-reacts with the NR2 glutamate receptor in systemic lupus erythematosus. Nat Med, 2001. 7(11): p. 1189-93.

60. Kowal, C., et al., Cognition and immunity; antibody impairs memory. Immunity, 2004. 21(2): p. 179-88.

61. Husebye, E.S., et al., Autoantibodies to a NR2A peptide of the glutamate/NMDA receptor in sera of patients with systemic lupus erythematosus. Ann Rheum Dis, 2005. 64(8): p. 1210-3.

62. Hanly, J.G., J. Robichaud, and J.D. Fisk, Anti-NR2 glutamate receptor antibodies and cognitive function in systemic lupus erythematosus. J Rheumatol, 2006. 33(8): p. 1553-8.

63. Harrison, M.J., L.D. Ravdin, and M.D. Lockshin, Relationship between serum NR2a antibodies and cognitive dysfunction in systemic lupus erythematosus. Arthritis Rheum, 2006. 54(8): p. 2515-22.

64. Hanly, J.G., et al., Autoantibodies and neuropsychiatric events at the time of systemic lupus erythematosus diagnosis: results from an international inception cohort study. Arthritis Rheum, 2008. 58(3): p. 843-53.

65. Hanly, J.G., et al., Autoantibodies as biomarkers for the prediction of neuropsychiatric events in systemic lupus erythematosus. Ann Rheum Dis, 2011. 70(10): p. 1726-32.

66. Omdal, R., et al., Neuropsychiatric disturbances in SLE are associated with antibodies against NMDA receptors. Eur J Neurol, 2005. 12(5): p. 392-8. 
67. Yoshio, T., et al., Association of IgG anti-NR2 glutamate receptor antibodies in cerebrospinal fluid with neuropsychiatric systemic lupus erythematosus. Arthritis Rheum, 2006. 54(2): p. 675-8.

68. Lapteva, L., et al., Anti-N-methyl-D-aspartate receptor antibodies, cognitive dysfunction, and depression in systemic lupus erythematosus. Arthritis Rheum, 2006. 54(8): p. 2505-14.

69. Arinuma, Y., T. Yanagida, and S. Hirohata, Association of cerebrospinal fluid antiNR2 glutamate receptor antibodies with diffuse neuropsychiatric systemic lupus erythematosus. Arthritis Rheum, 2008. 58(4): p. 1130-5.

70. Fragoso-Loyo, H., et al., Serum and cerebrospinal fluid autoantibodies in patients with neuropsychiatric lupus erythematosus. Implications for diagnosis and pathogenesis. PLoS One, 2008. 3(10): p. e3347.

71. Gono, T., et al., Anti-NR2A antibody as a predictor for neuropsychiatric systemic lupus erythematosus. Rheumatology (Oxford), 2011. 50(9): p. 1578-85.

72. Hirohata, S., Y. Arinuma, and T. Yanagida, Specificity of enzyme-linked immunosorbent assay for IgG anti-NR2 glutamate receptor antibodies: comment on the concise communication by Yoshio et al. Arthritis Rheum, 2007. 56(1): p. 386-7.

73. Pruss, $\mathrm{H} .$, et al., $N$-methyl-D-aspartate receptor antibodies in herpes simplex encephalitis. Ann Neurol, 2012. 72(6): p. 902-11.

74. Mohammad, S.S., et al., Herpes simplex encephalitis relapse with chorea is associated with autoantibodies to $N$-Methyl-D-aspartate receptor or dopamine-2 receptor. Mov Disord, 2014. 29(1): p. 117-22.

75. Tsutsui, K., et al., Anti-NMDA-receptor antibody detected in encephalitis, schizophrenia, and narcolepsy with psychotic features. BMC Psychiatry, 2012. 12: p. 37.

76. Steiner, J., et al., Increased prevalence of diverse N-methyl-D-aspartate glutamate receptor antibodies in patients with an initial diagnosis of schizophrenia: specific relevance of IgG NR1a antibodies for distinction from $N$-methyl-D-aspartate glutamate receptor encephalitis. JAMA Psychiatry, 2013. 70(3): p. 271-8.

77. Dahm, L., et al., Seroprevalence of autoantibodies against brain antigens in health and disease. Ann Neurol, 2014. 76(1): p. 82-94.

78. Hammer, C., et al., Neuropsychiatric disease relevance of circulating anti-NMDA receptor autoantibodies depends on blood-brain barrier integrity. Mol Psychiatry, 2014. 19(10): p. 1143-9.

79. Pruss, H., et al., IgA NMDA receptor antibodies are markers of synaptic immunity in slow cognitive impairment. Neurology, 2012. 78(22): p. 1743-53.

80. Busse, S., et al., Seroprevalence of $N$-methyl-D-aspartate glutamate receptor (NMDA-R) autoantibodies in aging subjects without neuropsychiatric disorders and in dementia patients. Eur Arch Psychiatry Clin Neurosci, 2014. 264(6): p. 545-50.

81. Doss, S., et al., High prevalence of NMDA receptor IgA/IgM antibodies in different dementia types. Ann Clin Transl Neurol, 2014. 1(10): p. 822-32. 
82. Steiner, J., et al., Prevalence of $N$-methyl-D-aspartate receptor autoantibodies in the peripheral blood: healthy control samples revisited. JAMA Psychiatry, 2014. 71(7): p. 838-9.

83. Choe, C.U., et al., $A$ clinical and neurobiological case of IgM NMDA receptor antibody associated encephalitis mimicking bipolar disorder. Psychiatry Res, 2013. 208(2): p. 194-6.

84. Fujita, K., et al., Antibodies to $N$-methyl-D-aspartate glutamate receptors in Creutzfeldt-Jakob disease patients. J Neuroimmunol, 2012. 251(1-2): p. 90-3.

85. Grau-Rivera, 0., et al., Determination of neuronal antibodies in suspected and definite Creutzfeldt-Jakob disease. JAMA Neurol, 2014. 71(1): p. 74-8.

86. Rossi, M., et al., Neuronal antibodies in patients with suspected or confirmed sporadic Creutzfeldt-Jakob disease. J Neurol Neurosurg Psychiatry, 2014.

87. Ishikawa, N., et al., Detection of autoantibodies against NMDA-type glutamate receptor in a patient with recurrent optic neuritis and transient cerebral lesions. Neuropediatrics, 2007. 38(5): p. 257-60.

88. Motoyama, R., et al., [Anti-NMDA receptor antibody encephalitis with recurrent optic neuritis and epilepsy]. Rinsho Shinkeigaku, 2010. 50(8): p. 585-8.

89. Honda, K. and T. Yuasa, A case of anti-aquaporin-4 and anti-glutamate receptor antibodies positive myelitis presented with modest clinical signs. Magn Reson Med Sci, 2008. 7(1): p. 55-8.

90. Kruer, M.C., et al., NMDA receptor encephalitis mimicking seronegative neuromyelitis optica. Neurology, 2010. 74(18): p. 1473-5.

91. Watanabe, M., et al., Antibodies to neural and non-neural autoantigens in Japanese patients with CNS demyelinating disorders. J Neuroimmunol, 2014. 274(1-2): p. 155-60.

92. Lekoubou, A., et al., Anti-N-methyl-D-aspartate receptor encephalitis with acute disseminated encephalomyelitis-like MRI features. Eur J Neurol, 2012. 19(2): p. e16-7.

93. Johnston, K.A., K.; Pearson, O.R.; Rickards, C.; Vincent, A., POI14 Multiple sclerosis: a potential association with anti-N-methyl-d-aspartate receptor encephalitis. Journal of Neurology, Neurosurgery and Psychiatry, 2010. 81(11): p. e56.

94. Uzawa, A., et al., Anti-N-methyl D-aspartate-type glutamate receptor antibodypositive limbic encephalitis in a patient with multiple sclerosis. Clin Neurol Neurosurg, 2012. 114(4): p. 402-4.

95. Fleischmann, R., et al., Severe Cognitive Impairment Associated With Intrathecal Antibodies to the NR1 Subunit of the N-Methyl-D-Aspartate Receptor in a Patient With Multiple Sclerosis. JAMA Neurol, 2014.

96. Lennon, V.A., et al., A serum autoantibody marker of neuromyelitis optica: distinction from multiple sclerosis. Lancet, 2004. 364(9451): p. 2106-12.

97. Lennon, V.A., et al., IgG marker of optic-spinal multiple sclerosis binds to the aquaporin-4 water channel. J Exp Med, 2005. 202(4): p. 473-7. 
98. Wingerchuk, D.M., et al., Revised diagnostic criteria for neuromyelitis optica. Neurology, 2006. 66(10): p. 1485-9.

99. Wingerchuk, D.M., et al., The spectrum of neuromyelitis optica. Lancet Neurol, 2007. 6(9): p. 805-15.

100. Marignier, R., et al., Aquaporin-4 antibody-negative neuromyelitis optica: distinct assay sensitivity-dependent entity. Neurology, 2013. 80(24): p. 2194-200.

101. Waters, P. and A. Vincent, Detection of anti-aquaporin-4 antibodies in neuromyelitis optica: current status of the assays. Int MS J, 2008. 15(3): p. 99-105.

102. Jarius, S., et al., Standardized method for the detection of antibodies to aquaporin-4 based on a highly sensitive immunofluorescence assay employing recombinant target antigen. J Neurol Sci, 2010. 291(1-2): p. 52-6.

103. Waters, P.J., et al., Serologic diagnosis of NMO: a multicenter comparison of aquaporin-4-IgG assays. Neurology, 2012. 78(9): p. 665-71; discussion 669.

104. Mader, S., et al., Patterns of antibody binding to aquaporin-4 isoforms in neuromyelitis optica. PLoS One, 2010. 5(5): p. e10455.

105. Nicchia, G.P., et al., Aquaporin-4 orthogonal arrays of particles are the target for neuromyelitis optica autoantibodies. Glia, 2009. 57(13): p. 1363-73.

106. Crane, J.M., M. Tajima, and A.S. Verkman, Live-cell imaging of aquaporin-4 diffusion and interactions in orthogonal arrays of particles. Neuroscience, 2010. 168(4): p. 892-902.

107. Kinoshita, M., et al., Astrocytic necrosis is induced by anti-aquaporin-4 antibodypositive serum. Neuroreport, 2009. 20(5): p. 508-12.

108. Sabater, L., et al., Cytotoxic effect of neuromyelitis optica antibody (NMO-IgG) to astrocytes: an in vitro study. J Neuroimmunol, 2009. 215(1-2): p. 31-5.

109. Bradl, M., et al., Neuromyelitis optica: pathogenicity of patient immunoglobulin in vivo. Ann Neurol, 2009. 66(5): p. 630-43.

110. Bennett, J.L., et al., Intrathecal pathogenic anti-aquaporin-4 antibodies in early neuromyelitis optica. Ann Neurol, 2009. 66(5): p. 617-29.

111. Kinoshita, M., et al., Neuromyelitis optica: Passive transfer to rats by human immunoglobulin. Biochem Biophys Res Commun, 2009. 386(4): p. 623-7.

112. Saadoun, S., et al., Intra-cerebral injection of neuromyelitis optica immunoglobulin $G$ and human complement produces neuromyelitis optica lesions in mice. Brain, 2010. 133(Pt 2): p. 349-61.

113. Dujmovic, I., et al., Temporal dynamics of cerebrospinal fluid anti-aquaporin-4 antibodies in patients with neuromyelitis optica spectrum disorders. J Neuroimmunol, 2011. 234(1-2): p. 124-30.

114. Jarius, S., et al., Cerebrospinal fluid antibodies to aquaporin-4 in neuromyelitis optica and related disorders: frequency, origin, and diagnostic relevance. J Neuroinflammation, 2010. 7: p. 52.

115. Takahashi, T., et al., Anti-aquaporin-4 antibody is involved in the pathogenesis of NMO: a study on antibody titre. Brain, 2007. 130(Pt 5): p. 1235-43. 
116. Klawiter, E.C., et al., NMO-IgG detected in CSF in seronegative neuromyelitis optica. Neurology, 2009. 72(12): p. 1101-3.

117. Long, Y., et al., Clinical features of Chinese patients with multiple sclerosis with aquaporin-4 antibodies in cerebrospinal fluid but not serum. J Clin Neurosci, 2013. 20(2): p. 233-7.

118. Clements, C.S., et al., The crystal structure of myelin oligodendrocyte glycoprotein, a key autoantigen in multiple sclerosis. Proc Natl Acad Sci U S A, 2003. 100(19): p. 11059-64.

119. O'Connor, K.C., et al., Self-antigen tetramers discriminate between myelin autoantibodies to native or denatured protein. Nat Med, 2007. 13(2): p. 211-7.

120. Brilot, F., et al., Antibodies to native myelin oligodendrocyte glycoprotein in children with inflammatory demyelinating central nervous system disease. Ann Neurol, 2009. 66(6): p. 833-42.

121. Di Pauli, F., et al., Temporal dynamics of anti-MOG antibodies in CNS demyelinating diseases. Clin Immunol, 2011. 138(3): p. 247-54.

122. Lalive, P.H., et al., Highly reactive anti-myelin oligodendrocyte glycoprotein antibodies differentiate demyelinating diseases from viral encephalitis in children. Mult Scler, 2011. 17(3): p. 297-302.

123. McLaughlin, K.A., et al., Age-dependent B cell autoimmunity to a myelin surface antigen in pediatric multiple sclerosis. J Immunol, 2009. 183(6): p. 4067-76.

124. Probstel, A.K., et al., Antibodies to MOG are transient in childhood acute disseminated encephalomyelitis. Neurology, 2011. 77(6): p. 580-8.

125. Reindl, M., M. Khalil, and T. Berger, Antibodies as biological markers for pathophysiological processes in MS. J Neuroimmunol, 2006. 180(1-2): p. 50-62.

126. Reindl, M., et al., The spectrum of MOG autoantibody-associated demyelinating diseases. Nat Rev Neurol, 2013. 9(8): p. 455-61.

127. Mader, S., et al., Complement activating antibodies to myelin oligodendrocyte glycoprotein in neuromyelitis optica and related disorders. J Neuroinflammation, 2011. 8: p. 184.

128. Zhou, D., et al., Identification of a pathogenic antibody response to native myelin oligodendrocyte glycoprotein in multiple sclerosis. Proc Natl Acad Sci U S A, 2006. 103(50): p. 19057-62.

129. Krishnamoorthy, G. and H. Wekerle, EAE: an immunologist's magic eye. Eur J Immunol, 2009. 39(8): p. 2031-5.

130. Mayer, M.C., et al., Distinction and temporal stability of conformational epitopes on myelin oligodendrocyte glycoprotein recognized by patients with different inflammatory central nervous system diseases. J Immunol, 2013. 191(7): p. 3594604.

131. Wingerchuk, D.M. and C.F. Lucchinetti, Comparative immunopathogenesis of acute disseminated encephalomyelitis, neuromyelitis optica, and multiple sclerosis. Curr Opin Neurol, 2007. 20(3): p. 343-50. 
132. Wender, M., Acute disseminated encephalomyelitis (ADEM). J Neuroimmunol, 2011. 231(1-2): p. 92-9.

133. Krupp, L.B., et al., International Pediatric Multiple Sclerosis Study Group criteria for pediatric multiple sclerosis and immune-mediated central nervous system demyelinating disorders: revisions to the 2007 definitions. Mult Scler, 2013. 19(10): p. 1261-7.

134. Pavone, P., et al., Acute disseminated encephalomyelitis: a long-term prospective study and meta-analysis. Neuropediatrics, 2010. 41(6): p. 246-55.

135. Menge, T., et al., Acute disseminated encephalomyelitis: an acute hit against the brain. Curr Opin Neurol, 2007. 20(3): p. 247-54.

136. Kuni, B.J., B.L. Banwell, and C. Till, Cognitive and behavioral outcomes in individuals with a history of acute disseminated encephalomyelitis (ADEM). Dev Neuropsychol, 2012. 37(8): p. 682-96.

137. Tenembaum, S.N., Acute disseminated encephalomyelitis. Handb Clin Neurol, 2013. 112: p. 1253-62.

138. Compston, A. and A. Coles, Multiple sclerosis. Lancet, 2008. 372(9648): p. 150217.

139. Frohman, E.M., M.K. Racke, and C.S. Raine, Multiple sclerosis--the plaque and its pathogenesis. N Engl J Med, 2006. 354(9): p. 942-55.

140. Lassmann, H., W. Bruck, and C.F. Lucchinetti, The immunopathology of multiple sclerosis: an overview. Brain Pathol, 2007. 17(2): p. 210-8.

141. Sospedra, M. and R. Martin, Immunology of multiple sclerosis. Annu Rev Immunol, 2005. 23: p. 683-747.

142. Steinman, L., A brief history of $T(H) 17$, the first major revision in the $T(H) 1 / T(H) 2$ hypothesis of T cell-mediated tissue damage. Nat Med, 2007. 13(2): p. 139-45.

143. Kleinewietfeld, M. and D.A. Hafler, The plasticity of human Treg and Th17 cells and its role in autoimmunity. Semin Immunol, 2013. 25(4): p. 305-12.

144. Kleinewietfeld, M. and D.A. Hafler, Regulatory $T$ cells in autoimmune neuroinflammation. Immunol Rev, 2014. 259(1): p. 231-44.

145. Chitnis, T., The role of CD4 T cells in the pathogenesis of multiple sclerosis. Int Rev Neurobiol, 2007. 79: p. 43-72.

146. Huseby, E.S., et al., Pathogenic CD8 T cells in multiple sclerosis and its experimental models. Front Immunol, 2012. 3: p. 64.

147. Weber, M.S., B. Hemmer, and S. Cepok, The role of antibodies in multiple sclerosis. Biochim Biophys Acta, 2011. 1812(2): p. 239-45.

148. Krumbholz, M., et al., $B$ cells and antibodies in multiple sclerosis pathogenesis and therapy. Nat Rev Neurol, 2012. 8(11): p. 613-23.

149. Freedman, M.S., et al., Recommended standard of cerebrospinal fluid analysis in the diagnosis of multiple sclerosis: a consensus statement. Arch Neurol, 2005. 62(6): p. 865-70. 
150. Lucchinetti, C., et al., Heterogeneity of multiple sclerosis lesions: implications for the pathogenesis of demyelination. Ann Neurol, 2000. 47(6): p. 707-17.

151. Owens, G.P., et al., Single-cell repertoire analysis demonstrates that clonal expansion is a prominent feature of the $B$ cell response in multiple sclerosis cerebrospinal fluid. J Immunol, 2003. 171(5): p. 2725-33.

152. Colombo, M., et al., Accumulation of clonally related $B$ lymphocytes in the cerebrospinal fluid of multiple sclerosis patients. J Immunol, 2000. 164(5): p. 2782-9.

153. Hauser, S.L., et al., B-cell depletion with rituximab in relapsing-remitting multiple sclerosis. N Engl J Med, 2008. 358(7): p. 676-88.

154. Kitley, J., et al., Neuromyelitis optica spectrum disorders with aquaporin-4 and myelin-oligodendrocyte glycoprotein antibodies: a comparative study. JAMA Neurol, 2014. 71(3): p. 276-83.

155. Kitley, J., et al., Myelin-oligodendrocyte glycoprotein antibodies in adults with a neuromyelitis optica phenotype. Neurology, 2012. 79(12): p. 1273-7.

156. Sato, D.K., et al., Distinction between MOG antibody-positive and AQP4 antibodypositive NMO spectrum disorders. Neurology, 2014. 82(6): p. 474-81.

157. Rostasy, K., et al., Persisting myelin oligodendrocyte glycoprotein antibodies in aquaporin-4 antibody negative pediatric neuromyelitis optica. Mult Scler, 2013. 19(8): p. 1052-9.

158. Rostasy, K., et al., Anti-myelin oligodendrocyte glycoprotein antibodies in pediatric patients with optic neuritis. Arch Neurol, 2012. 69(6): p. 752-6.

159. Woodhall, M., et al., Glycine receptor and myelin oligodendrocyte glycoprotein antibodies in Turkish patients with neuromyelitis optica. J Neurol Sci, 2013. 335(12): p. 221-3.

160. Saadoun, S., et al., Neuromyelitis optica MOG-IgG causes reversible lesions in mouse brain. Acta Neuropathol Commun, 2014. 2: p. 35.

161. Tardieu, M. and K. Deiva, Rare inflammatory diseases of the white matter and mimics of multiple sclerosis and related disorders. Neuropediatrics, 2013. 44(6): p. 302-8.

162. Catenoix, H., et al., Multiple sclerosis and epileptic seizures. Mult Scler, 2011. 17(1): p. 96-102.

163. Sarchielli, P., et al., Excitatory amino acids and multiple sclerosis: evidence from cerebrospinal fluid. Arch Neurol, 2003. 60(8): p. 1082-8.

164. Srinivasan, R., et al., Evidence of elevated glutamate in multiple sclerosis using magnetic resonance spectroscopy at 3 T. Brain, 2005. 128(Pt 5): p. 1016-25.

165. Tisell, A., et al., Increased concentrations of glutamate and glutamine in normalappearing white matter of patients with multiple sclerosis and normal MR imaging brain scans. PLoS One, 2013. 8(4): p. e61817.

166. Azevedo, C.J., et al., In vivo evidence of glutamate toxicity in multiple sclerosis. Ann Neurol, 2014. 76(2): p. 269-78. 
167. Dutta, R., et al., Demyelination causes synaptic alterations in hippocampi from multiple sclerosis patients. Ann Neurol, 2011. 69(3): p. 445-54.

168. Matute, C., M. Domercq, and M.V. Sanchez-Gomez, Glutamate-mediated glial injury: mechanisms and clinical importance. Glia, 2006. 53(2): p. 212-24.

169. Karadottir, R. and D. Attwell, Neurotransmitter receptors in the life and death of oligodendrocytes. Neuroscience, 2007. 145(4): p. 1426-38.

170. Pitt, D., P. Werner, and C.S. Raine, Glutamate excitotoxicity in a model of multiple sclerosis. Nat Med, 2000. 6(1): p. 67-70.

171. Smith, T., et al., Autoimmune encephalomyelitis ameliorated by AMPA antagonists. Nat Med, 2000. 6(1): p. 62-6.

172. Bolton, C. and C. Paul, MK-801 limits neurovascular dysfunction during experimental allergic encephalomyelitis. J Pharmacol Exp Ther, 1997. 282(1): p. 397-402.

173. Sulkowski, G., B. Dabrowska-Bouta, and L. Struzynska, Modulation of neurological deficits and expression of glutamate receptors during experimental autoimmune encephalomyelitis after treatment with selected antagonists of glutamate receptors. Biomed Res Int, 2013. 2013: p. 186068.

174. Sulkowski, G., et al., Effects of antagonists of glutamate receptors on proinflammatory cytokines in the brain cortex of rats subjected to experimental autoimmune encephalomyelitis. J Neuroimmunol, 2013. 261(1-2): p. 67-76.

175. Grasselli, G., et al., Abnormal NMDA receptor function exacerbates experimental autoimmune encephalomyelitis. Br J Pharmacol, 2013. 168(2): p. 502-17.

176. Suhs, K.W., et al., N-methyl-D-aspartate receptor blockade is neuroprotective in experimental autoimmune optic neuritis. J Neuropathol Exp Neurol, 2014. 73(6): p. 507-18.

177. Guo, F., et al., Disruption of NMDA receptors in oligodendroglial lineage cells does not alter their susceptibility to experimental autoimmune encephalomyelitis or their normal development. J Neurosci, 2012. 32(2): p. 639-45.

178. Lundgaard, I., et al., Neuregulin and BDNF induce a switch to NMDA receptordependent myelination by oligodendrocytes. PLoS Biol, 2013. 11(12): p. e1001743.

179. Polman, C.H., et al., Diagnostic criteria for multiple sclerosis: 2010 revisions to the McDonald criteria. Ann Neurol, 2011. 69(2): p. 292-302.

180. Kozak, M., An analysis of vertebrate mRNA sequences: intimations of translational control. J Cell Biol, 1991. 115(4): p. 887-903.

181. Mcllhinney, R.A., et al., Assembly intracellular targeting and cell surface expression of the human $N$-methyl-D-aspartate receptor subunits NR1a and NR2A in transfected cells. Neuropharmacology, 1998. 37(10-11): p. 1355-67.

182. Meddows, E., et al., Identification of molecular determinants that are important in the assembly of $N$-methyl-D-aspartate receptors. J Biol Chem, 2001. 276(22): p. 18795-803.

183. Zandi, M.S., et al., Clinical relevance of serum antibodies to extracellular N-methyld-aspartate receptor epitopes. J Neurol Neurosurg Psychiatry, 2014. 
184. Jacob, A., et al., Treatment of neuromyelitis optica with rituximab: retrospective analysis of 25 patients. Arch Neurol, 2008. 65(11): p. 1443-8.

185. Confavreux, C., et al., Rate of pregnancy-related relapse in multiple sclerosis. Pregnancy in Multiple Sclerosis Group. N Engl J Med, 1998. 339(5): p. 285-91.

186. Robinson, D.P. and S.L. Klein, Pregnancy and pregnancy-associated hormones alter immune responses and disease pathogenesis. Horm Behav, 2012. 62(3): p. 263-71.

187. Trapp, B.D. and K.A. Nave, Multiple sclerosis: an immune or neurodegenerative disorder? Annu Rev Neurosci, 2008. 31: p. 247-69. 


\section{APPENDIX}

\section{Curriculum Vitae}

\section{Personal Data}

Name

Ramberger

Given Name

Melanie

Date of Birth

$29^{\text {th }}$ November, 1985

Place of Birth

Vienna, Austria

Home Address

Pacherstraße 9/15

A-6020 Innsbruck

Phone

+43 (0) 6502911333

Citizenship

Austrian

\section{Professional Address}

Address

Neurological Research Laboratory

Clinical Department of Neurology

Medical University of Innsbruck

Innrain 66/G02

A-6020 Innsbruck

Phone

+43 (0) 51250424365

Fax

+43 (0) 51250424230

E-Mail

melanie.ramberger@i-med.ac.at

\section{Education}

2004

A-levels (Akademisches Gymnasium Vienna, Austria)

2004-2008

Studies of Biotechnology at the University of Applied Life Sciences (FH Campus Wien), field of specialization: Biomedicine (from 2006), graduation to $\mathrm{DI}(\mathrm{FH})$

2008

Diploma Thesis "Verification of Platelet Biomarkers and Low Variable Proteins for Diagnosis of Alzheimer Disease", Surgical Research Laboratories, Department of Surgery, Medical University of Vienna (Rudolf Öhler)

Since 2011

Enrolment in the PhD program SPIN (signal processing in neurons), $\mathrm{PhD}$ Thesis "N-Methyl-D-Aspartate Receptor Antibodies in Neuroinflammatory Diseases", Clinical Department of Neurology, Medical University of Innsbruck (Markus Reindl) 


\section{Oral Presentations}

XII. Neuroscience Wintermeeting, Kitzbühel, Austria, March 2013, "N-Methyl-D-Aspartate Receptor Antibodies in Neuroinflammatory Diseases" (Presenter Award)

Neuroscience Day 2013, Innsbruck, Austria, April 2013, "N-Methyl-D-Aspartate Receptor Antibodies in Neuroinflammatory Diseases"

The Feinstein Institute for Medical Research, New York, USA, July 2013, "N-Methyl-DAspartate Receptor Antibodies in Neuroinflammatory Diseases and $T$ Cell Reactivity in Narcolepsy Patients"

\section{Published Abstracts}

PhD Meeting Innsbruck 2011, Innsbruck, Austria, November 2011, M Ramberger, S Mader, K Schanda, M Reindl: "N-Methyl-D-Aspartate Receptor Antibodies in Neuroinflammatory Diseases"

Neuroscience Day 2012, Innsbruck, Austria, April 2012, M Ramberger, V Gredler, M Reindl: "Activation of mGluR4 reduces maturation of human monocyte-derived dendritic cells"

$39^{\text {th }}$ Annual Meeting of the Society of Neuropediatrics (GNP), Innsbruck, Austria, April 2013, M Ramberger, K Schanda, K Rostásy, S Mader, F Deisenhammer, M Reindl: "N-Methyl-DAspartate Receptor Antibodies in Neuroinflammatory Diseases"

Federation of Clinical Immunology Societies (FOCIS) Annual Meeting, Boston, Massachusetts, USA, June 2013, M Ramberger, K Schanda, K Rostásy, S Mader, F Deisenhammer, M Reindl: "N-Methyl-D-Aspartate Receptor Antibodies in Neuroinflammatory Diseases"

Gordon Research Conference on Fibroblast Growth Factors in Development and Disease, Ventura, California, USA, March 2014, R Irschick, M Ramberger, L Marvaldi, Q Guo, M Youssef, P Claus, L Klimaschewski: "FGFR1 and FGF2 Trafficking in Human Glioma Cells"

Neuroscience Day 2014, Innsbruck, Austria, April 2014, M Ramberger, T Mitterling, B Frauscher, B Högl, M Reindl, A Lutterotti: "Investigating the Orexin/Hypocretin specific T Cell Response in Patients with Narcolepsy with Cataplexy"

$28^{\text {th }}$ Annual Meeting of the Associated Professional Sleep Societies, LLC, Minneapolis, Minnesota, USA, June 2014, M Ramberger, B Högl, T Mitterling, B Frauscher, M Reindl, A Lutterotti: "Investigating the Orexin/Hypocretin specific $T$ Cell Response in Patients with Narcolepsy with Cataplexy"

$12^{\text {th }}$ International Congress of Neuroimmunology, Mainz, Germany, November 2014, M Ramberger, P Peschl, K Schanda, R Irschick, R Höftberger, F Deisenhammer, K Rostásy, T Berger, J Dalmau, M Reindl: "A Highly Senstitive Live Cell Based Assay for Detection of Antibodies Against N-Methyl-D-Aspartate Receptors"

$12^{\text {th }}$ International Congress of Neuroimmunology, Mainz, Germany, November 2014, M Ramberger, B Högl, T Mitterling, A Stefani, B Frauscher, M Reindl, A Lutterotti: "Investigating the Orexin/Hypocretin specific T Cell Response in Patients with Narcolepsy with Cataplexy"

Fusion Conference on Fibroblast Growth Factors in Development and Repair, Cancún, Mexico, February 2015, R Irschick, M Ramberger, J Ecker, F Trivik, L Marvaldi, Q Guo, M Youssef, P Claus, L Klimaschewski: "Modulation of FGFR1/FGF2 trafficking in human glioma cells." 